\title{
البحـث الثالث:
}

\section{دور المشاركة في الأنشطة الطلابية في تعزيز قيم المواطنة هن وجهة

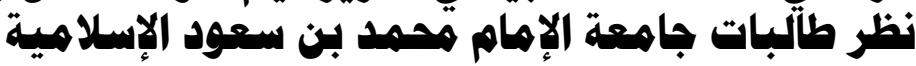

$$
\begin{aligned}
& \text { : إحلاكاث }
\end{aligned}
$$

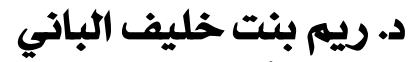

$$
\begin{aligned}
& \text { الأستاذ المساعد بقسم أصول التربيت كليّيت التربيت } \\
& \text { جامعت الإمام محمد بن سعود الإسلاميتية }
\end{aligned}
$$

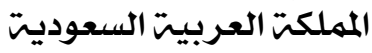





$$
\begin{aligned}
& \text { د. ريه بنت خليف الباني }
\end{aligned}
$$

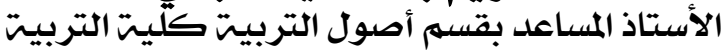

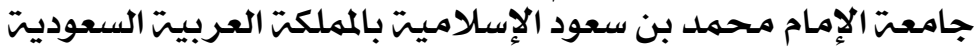

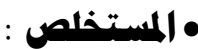

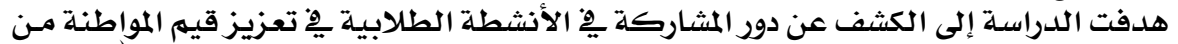

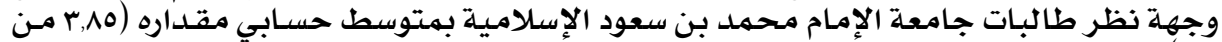

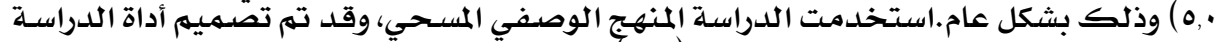

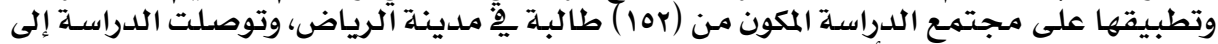

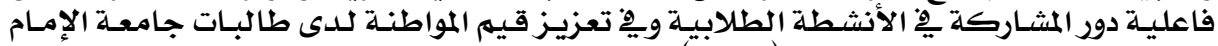

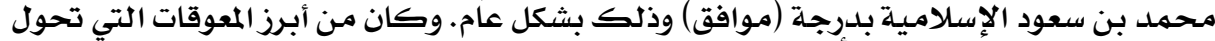

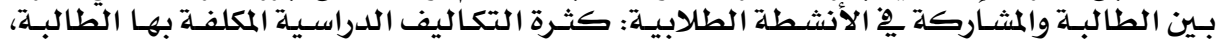

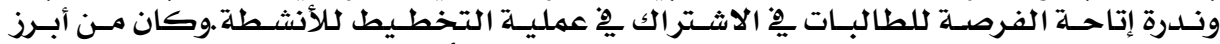

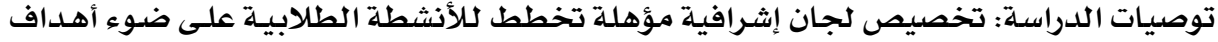

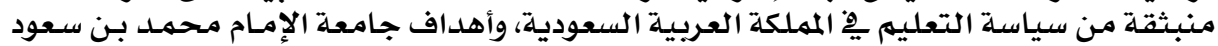

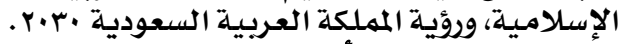
الكلمات المفتاحية:الأنشطة الطلابية - المواطنة - جامعة الإمام محمد بن سعود الإسلامية.

The Role of Students Activities in Strengthening the Value of Citizenship for Female Students of Imam Muhammad Bin Saud Islamic University

Dr. Reem Khulaif Al Bani

$\underline{\text { Abstract }}$

This study aims to reveal the role of student activities in strengthening the value of citizenship as perceived by female students of Imam Muhammad Ibn Saud Islamic University, with arithmetic average (3.85 out of 5.00) in general.The researcher used the survey descriptive methods. The study tool was designed and applied to population totaling (152) female students in Riyadh city. The study reveals the effectiveness of the role of participation of students activities in strengthening the citizenship value for females students in Imam Muhammed Ibn Saud University at Degree of (Agree) in general. There were many impediments precluding the students from participation in activities such as the increment of tuitions, the scarcity of opportunities provided to students to participate in the process of planning for activities. The main recommendations of the study are as follows: determination of qualified supervising committees for planning students activities in light of objectives generated from Saudi Arabia's Education Policy, Imam Muhammad Ibn Saudi University Objectives, Saudi Vision 2030.

Keywords: Students Activities - Citizenship - Imam Muhammad Bin Saud Islamic University. 


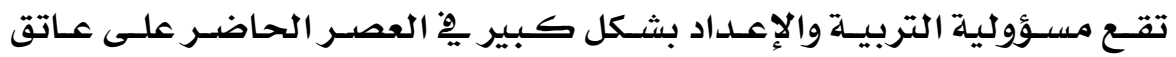

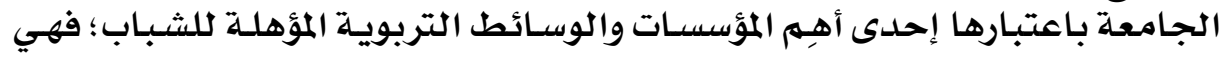

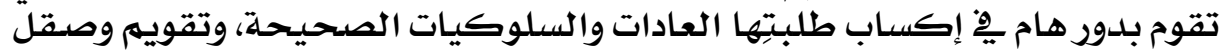

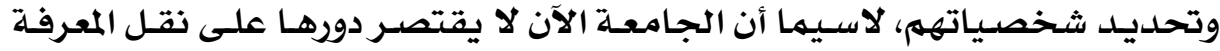

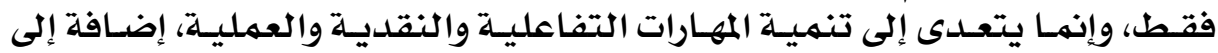

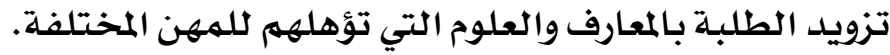

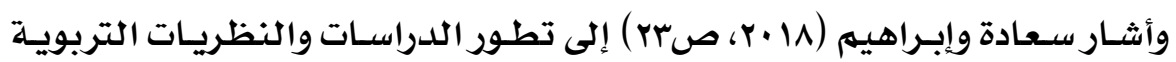

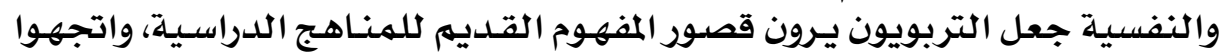

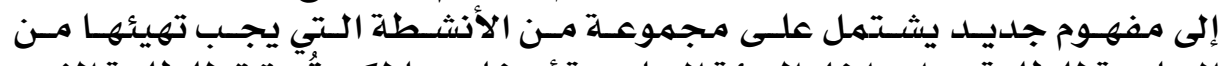

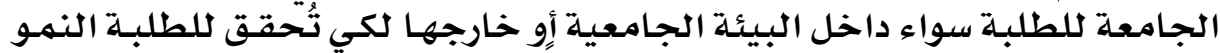

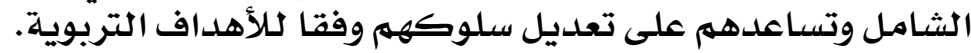

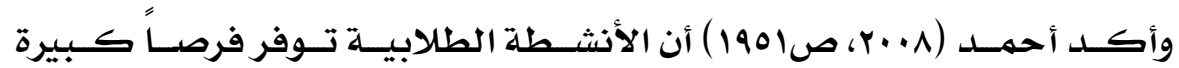

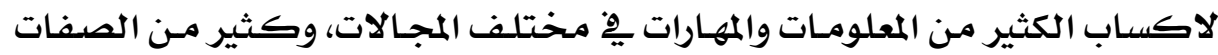

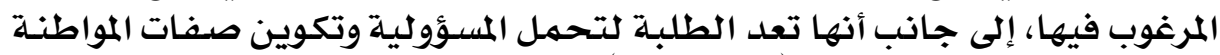

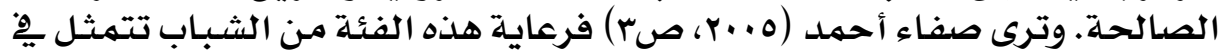

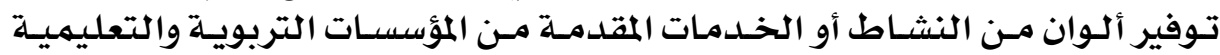

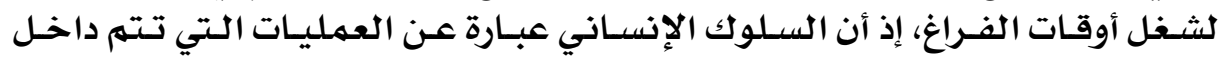

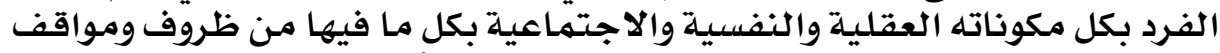

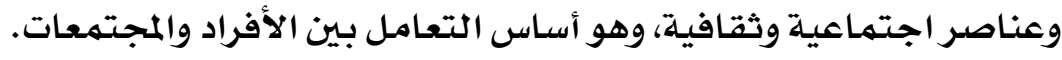

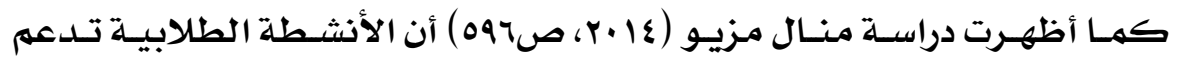

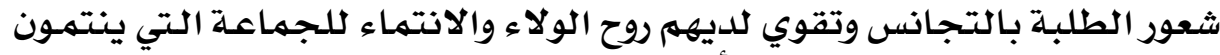

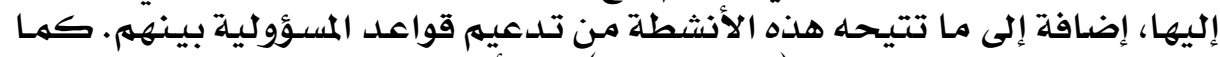

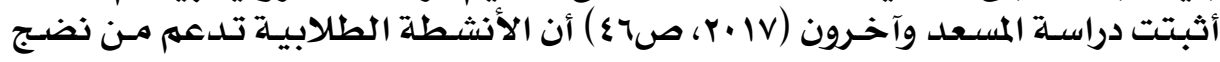

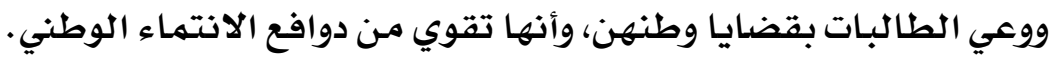

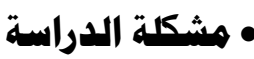

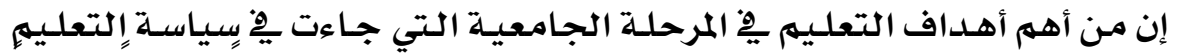

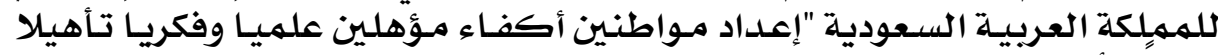

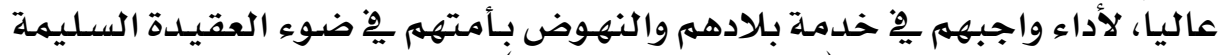

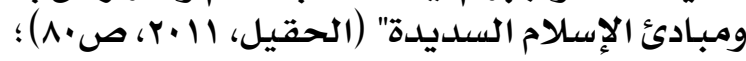

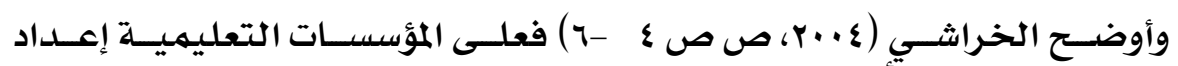

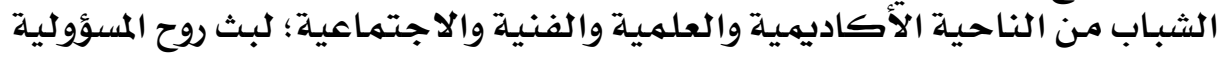

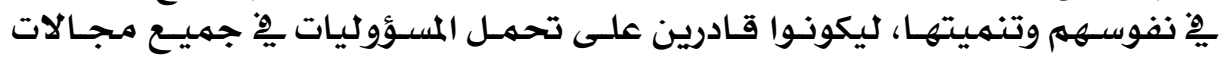

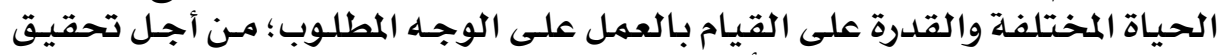

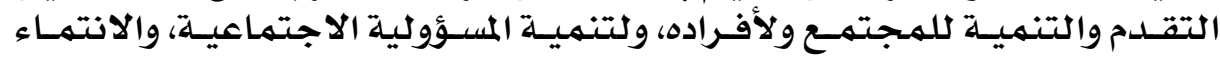

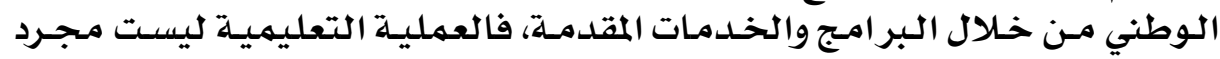




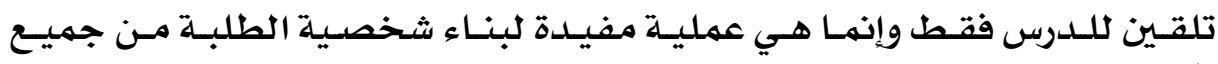
النواحي. تلقين بلدئ.

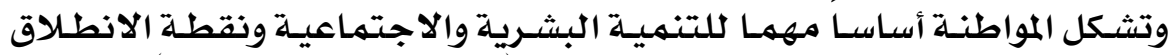

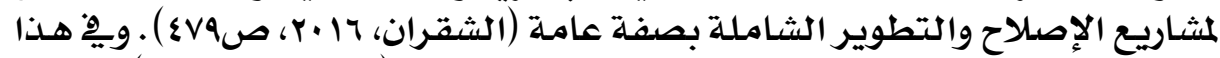

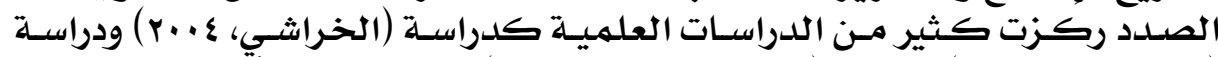

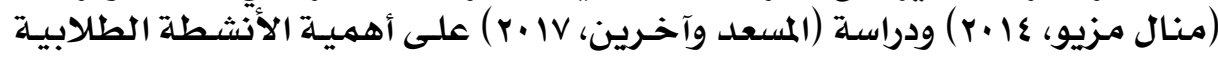

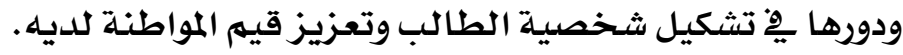

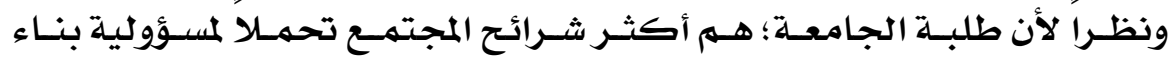

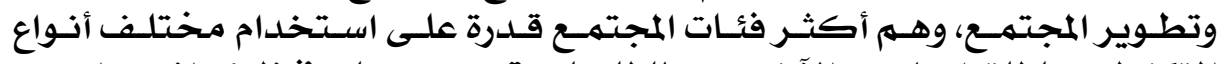

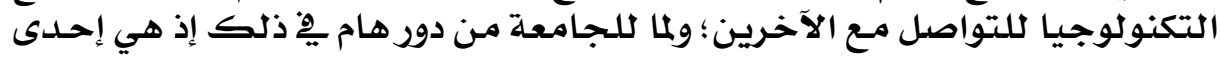

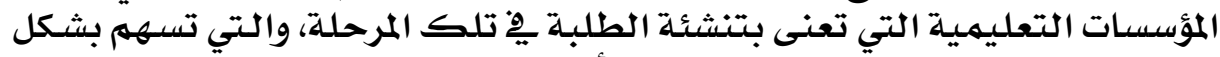

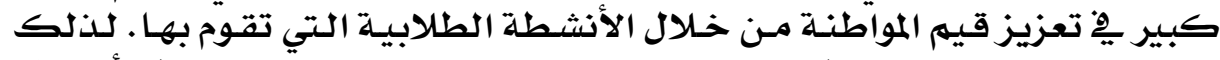

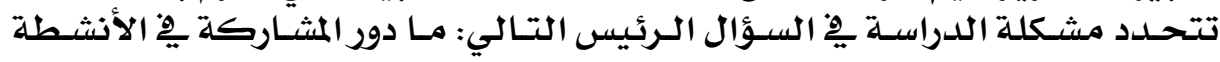

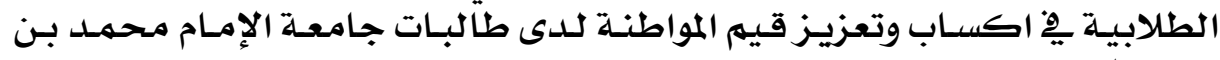

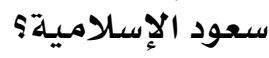
•أسئلة الدراسة الاسمية

يتفرع عن سؤال الدراسة الرئيس الأسئلة الفرعية التالية:

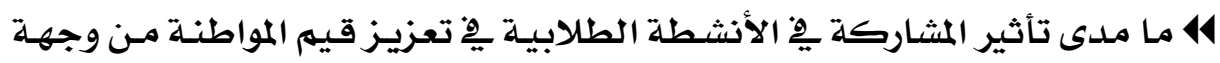

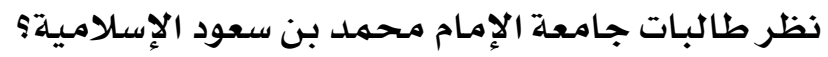

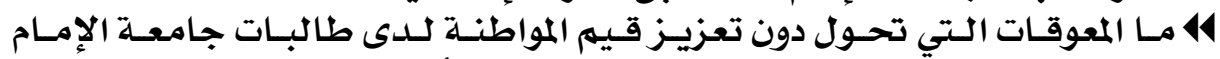

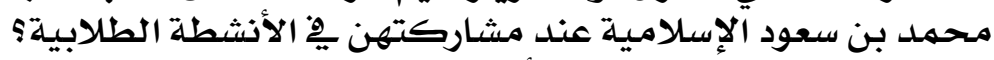

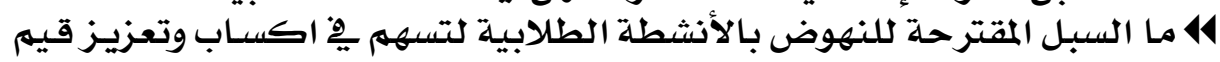

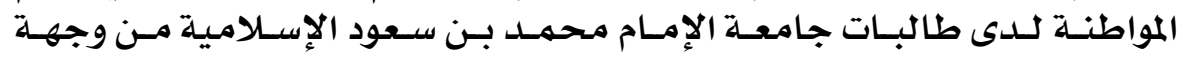

$$
\text { نظرهن؟ }
$$

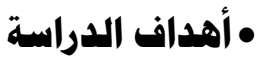

تسعى الباحثة يِّ هذه الدراسـة إلى تحقيق الأهداف التالية:

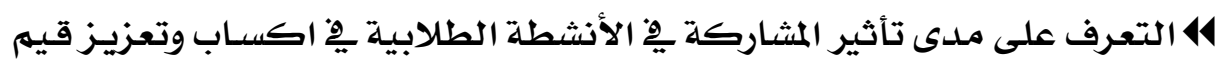

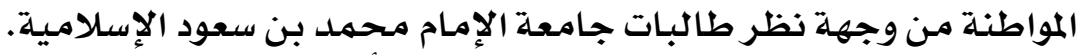

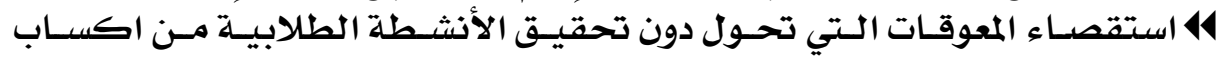

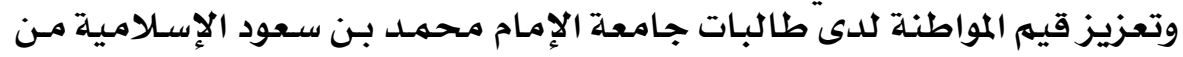

$$
\text { وجهة نظرهن. }
$$

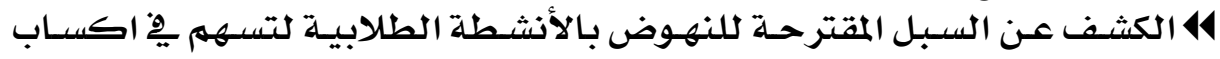

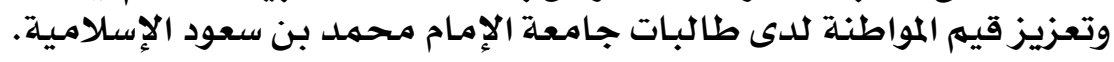

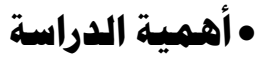
تتمثل أهمية الدراسـة فية: 


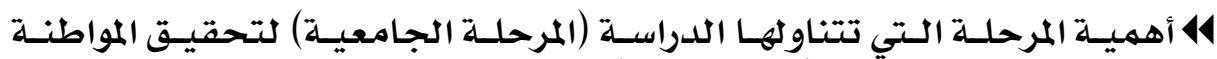

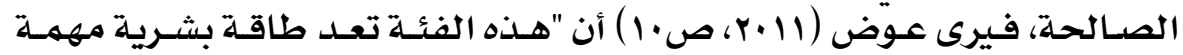

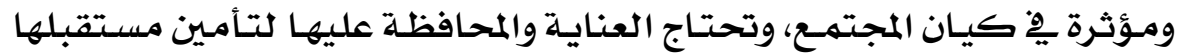

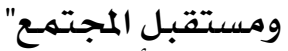

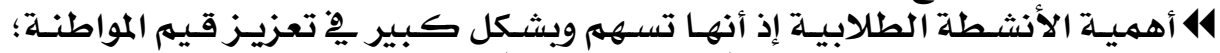

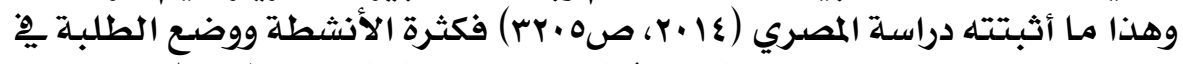

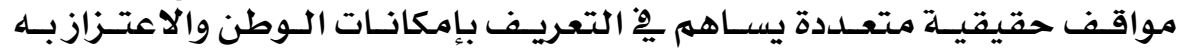
والمحافظة عليهـ.

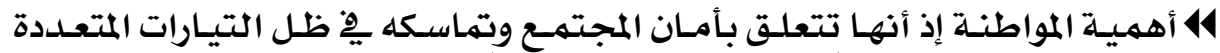

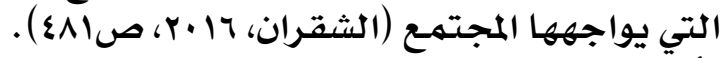

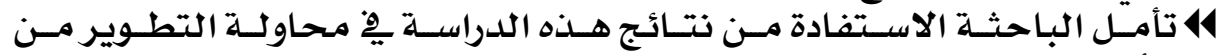

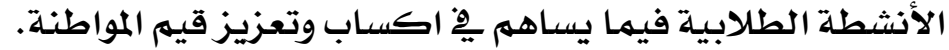

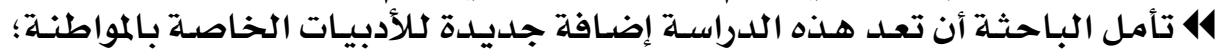

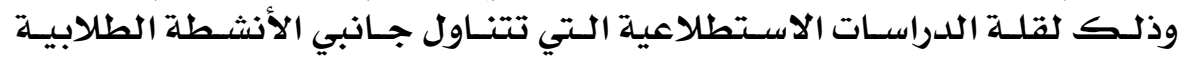
والمواطنة.

\section{• حدود الدراسة}

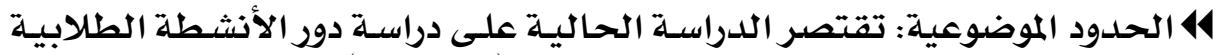

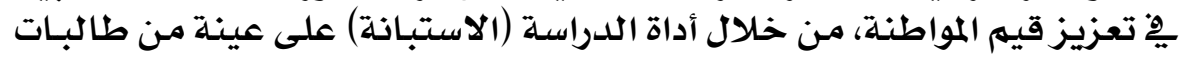

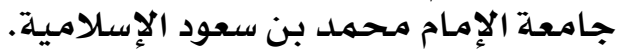

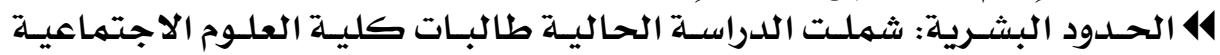

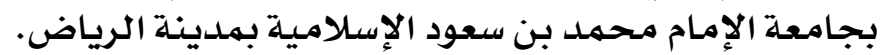

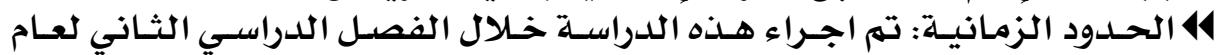

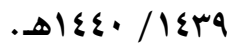

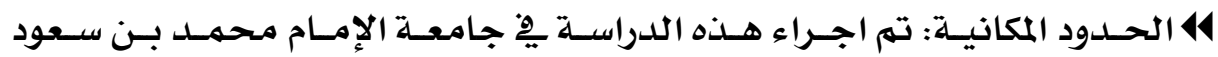

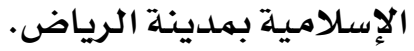

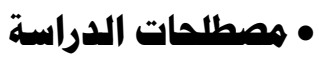
• الأنشطة الطلابية:

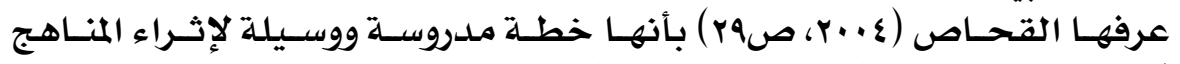

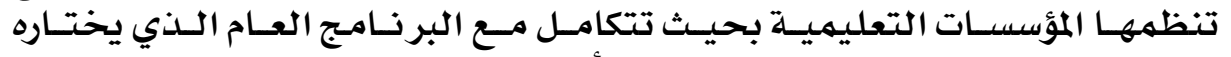

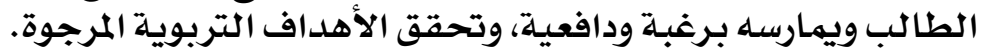

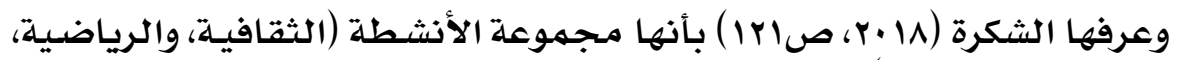

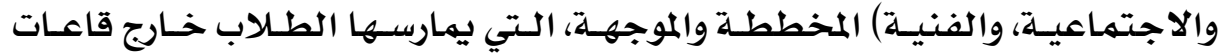

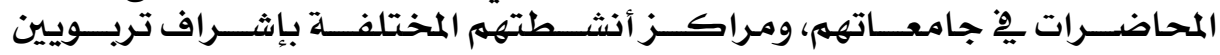
متخصصين.

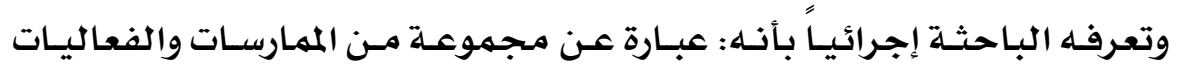

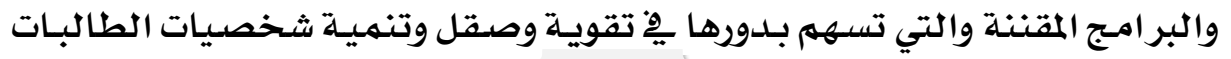




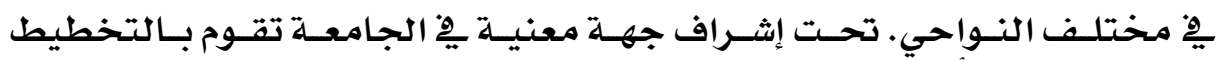

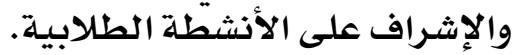

• المواطنة:

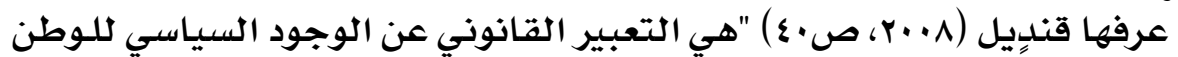

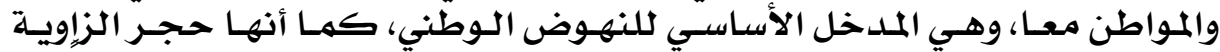

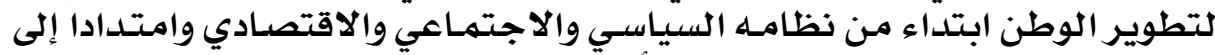

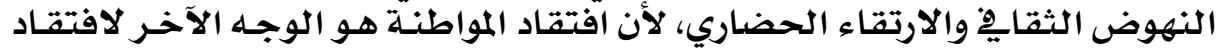

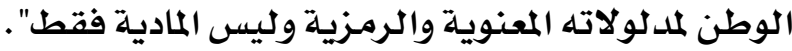

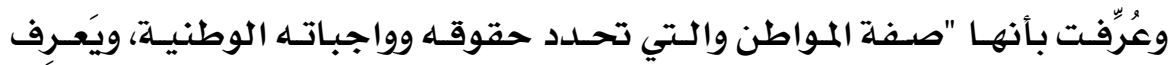

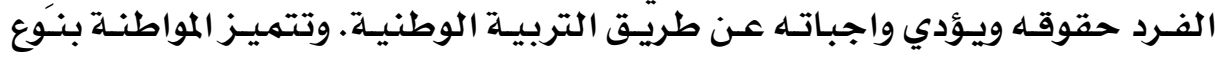

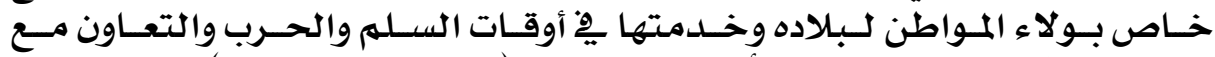

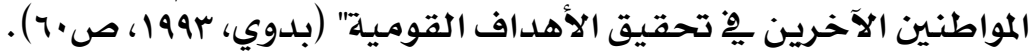

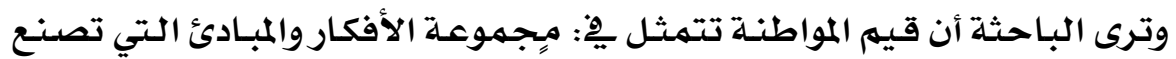

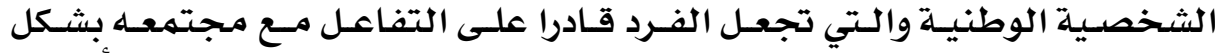

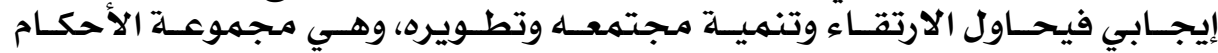

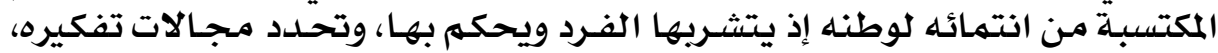

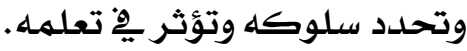

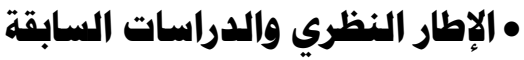

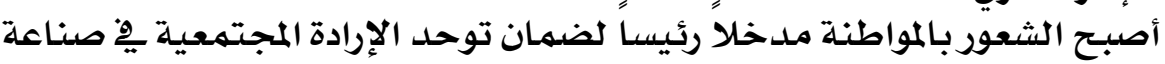

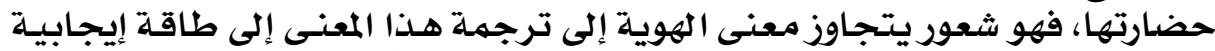

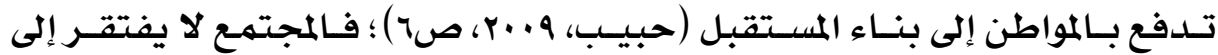

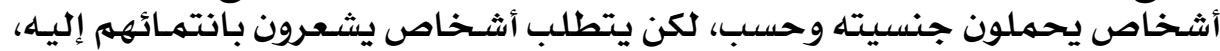

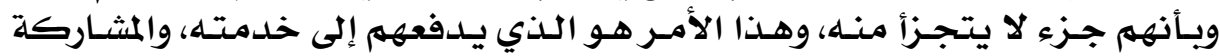

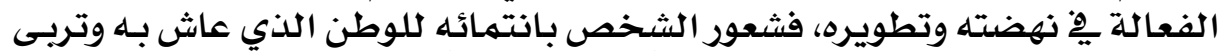

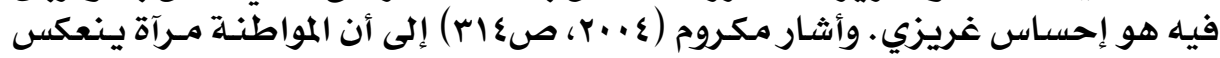

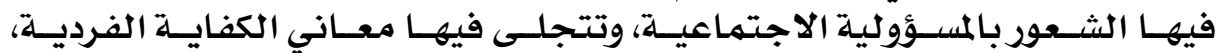

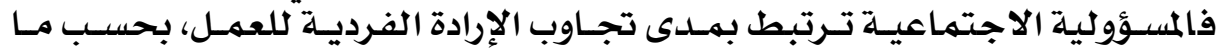

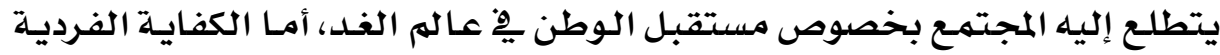

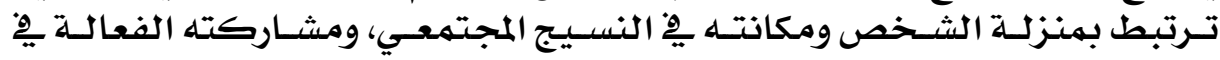
تقصي غايات الإنهاء.

\section{• هفهمو المواطنة}

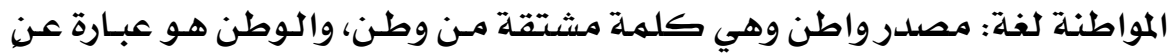

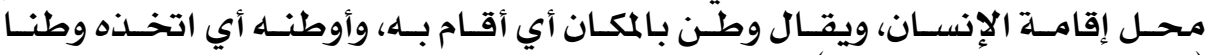

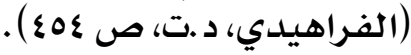

\section{V०}




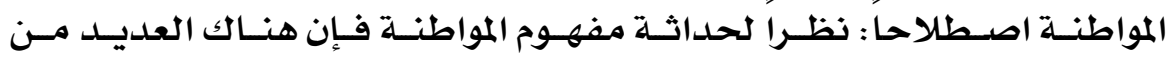

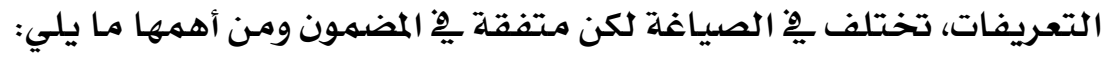

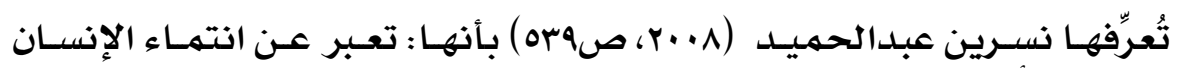

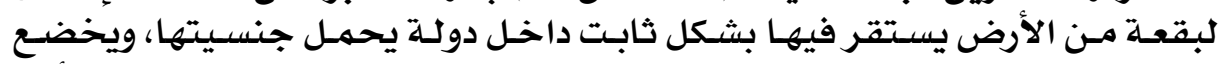

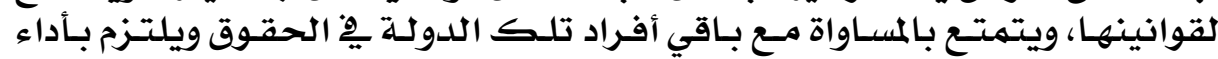

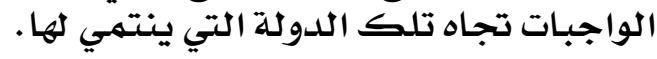

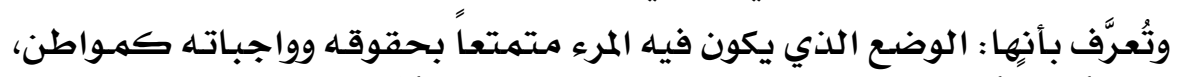

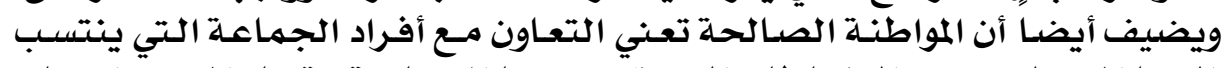

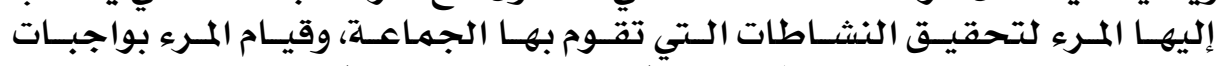

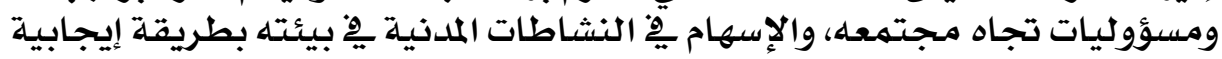

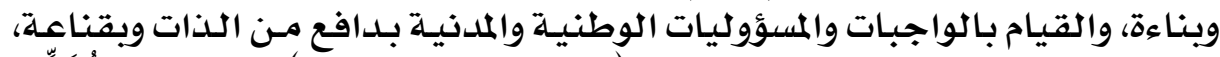

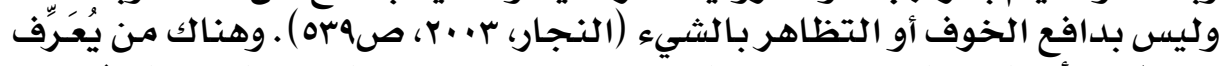

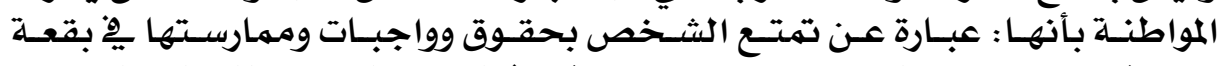

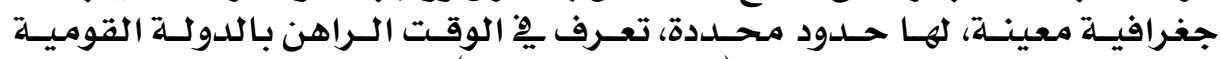

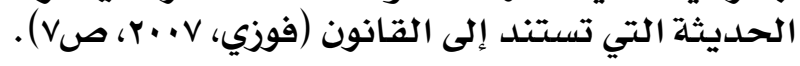

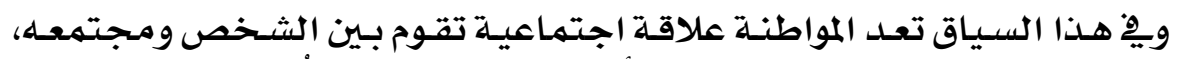

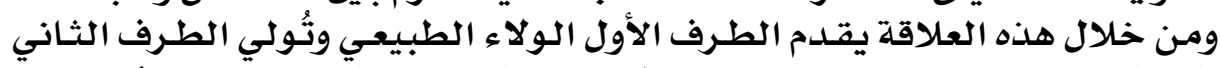

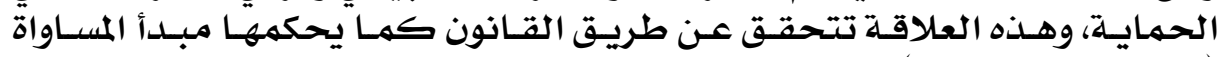

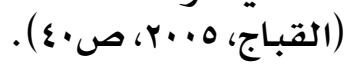

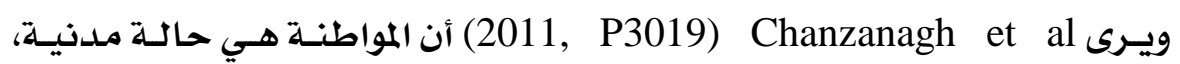

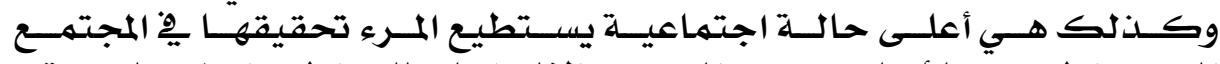

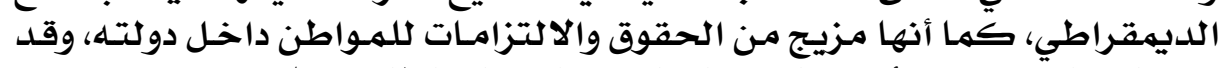

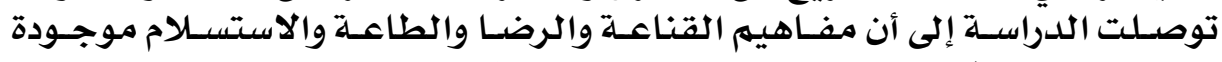

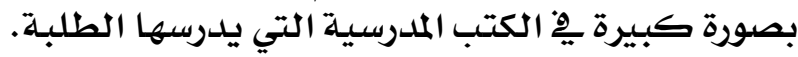

ومـن خـلال مـا سـبق يهكن القـول بـأن المواطنـة بهفهومهـا الشـامل هـي: معرفـة

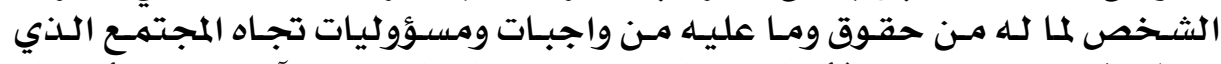

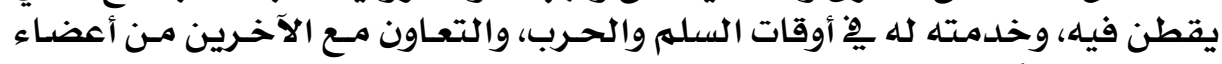

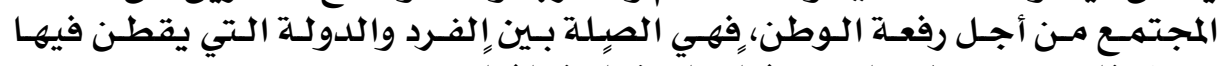

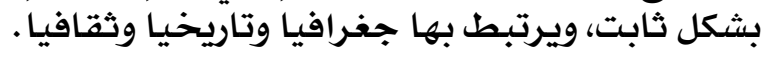

• هفهوم قيم المواطنة:

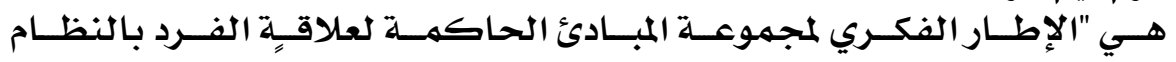

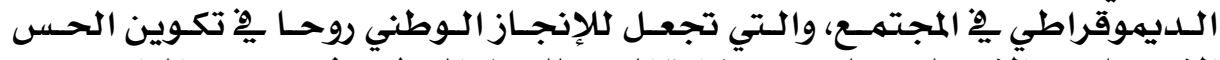

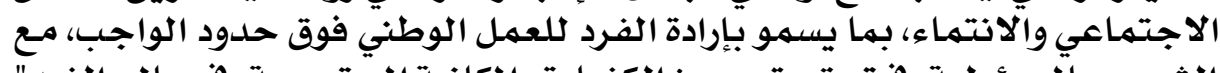

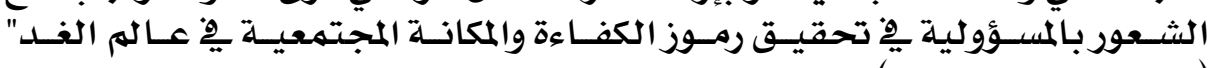

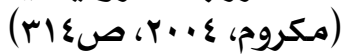

\section{$\checkmark 7$}




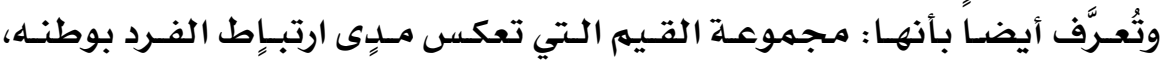

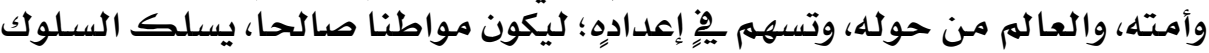

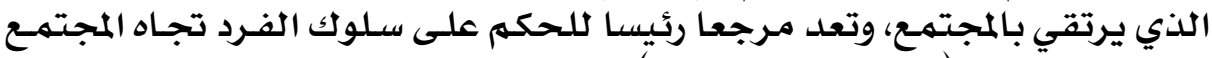

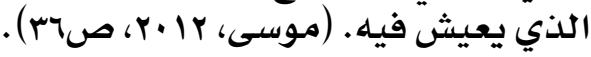

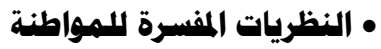

• نظرية جون ديري

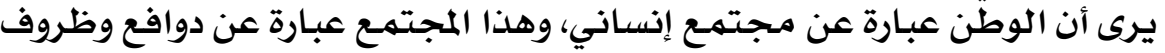

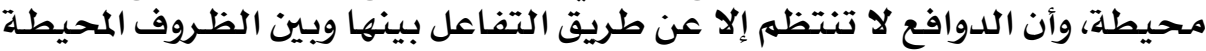

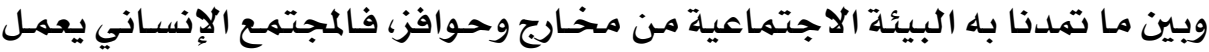

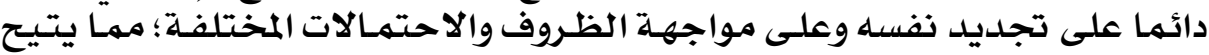

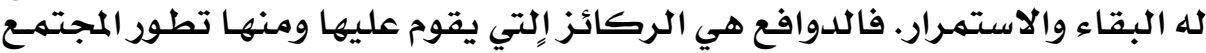

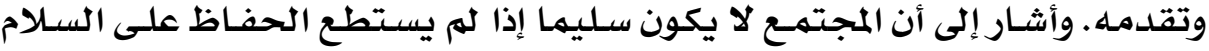

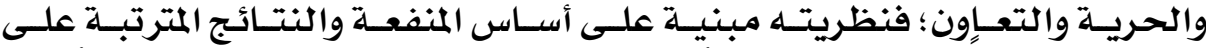

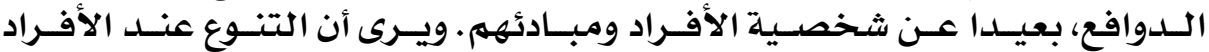

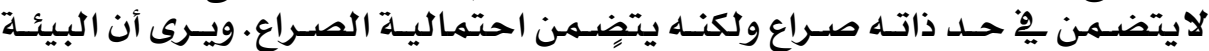

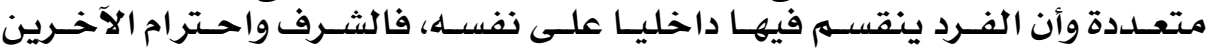

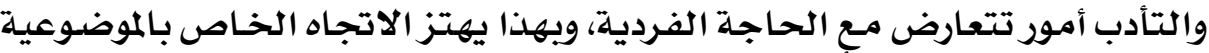

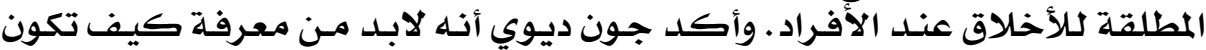

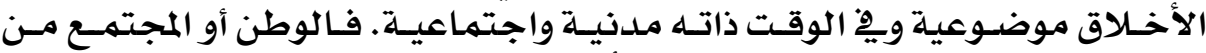

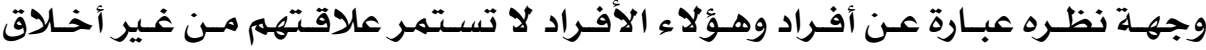

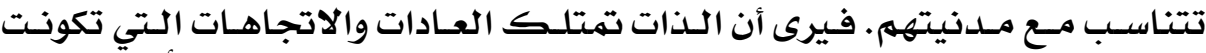

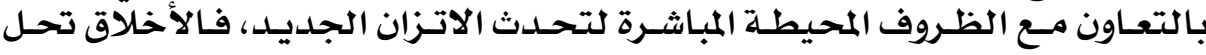

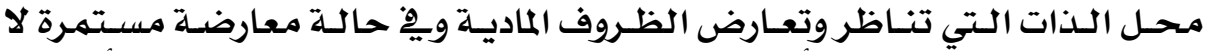

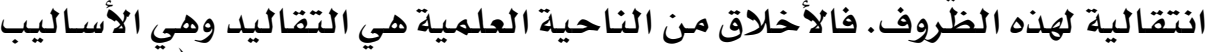

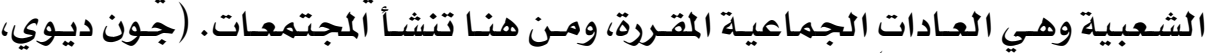

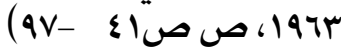

\section{• نظرية جان جاك روسو}

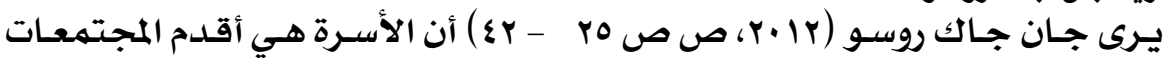

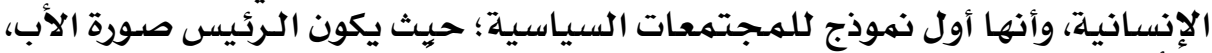

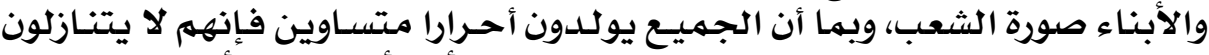

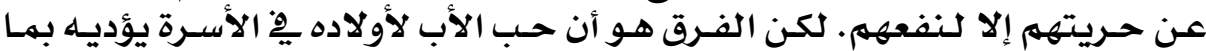

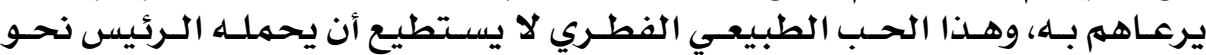

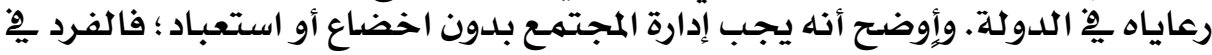

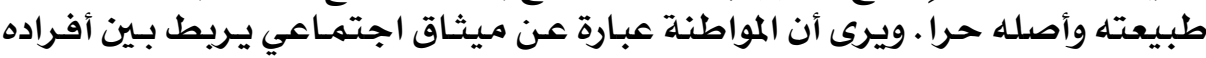

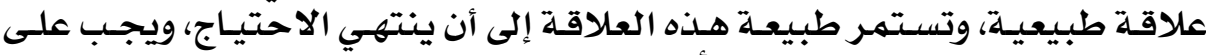

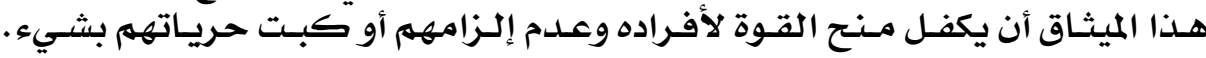

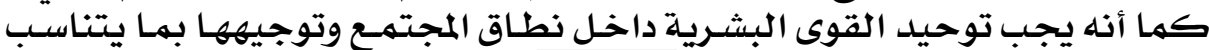

\section{VV}




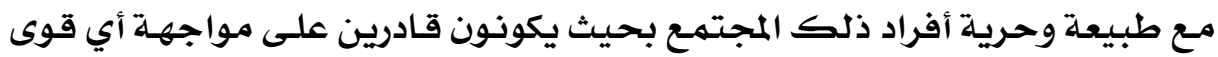

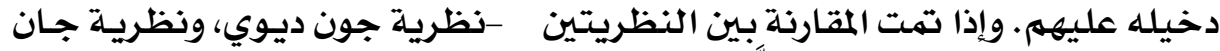

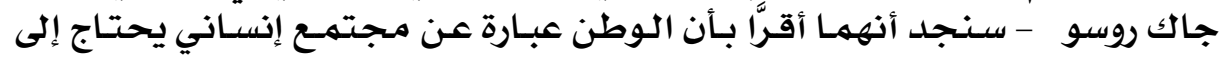

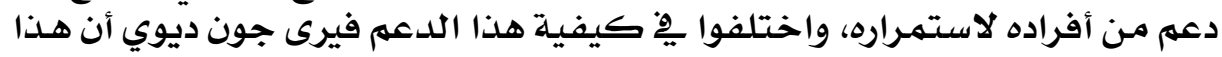

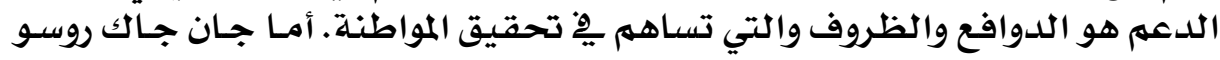

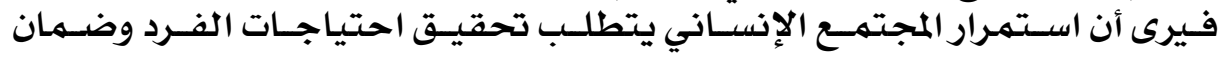
حريته.

\section{• أسس وهنطلقات قيم المواطنة}

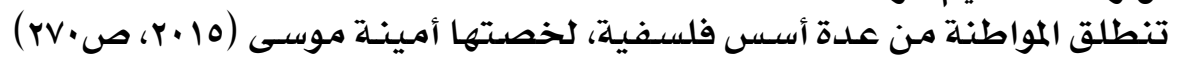
فيما يلي: تيطليق

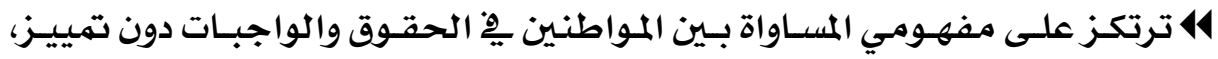

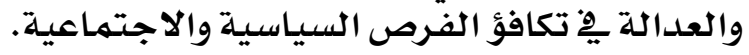

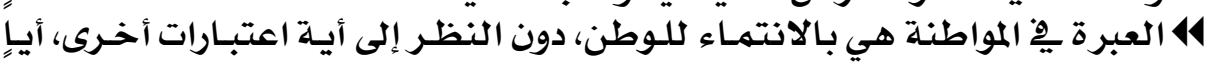

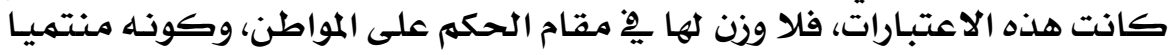

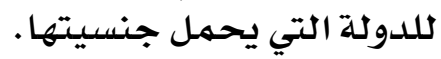

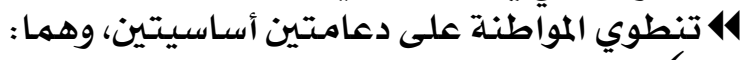

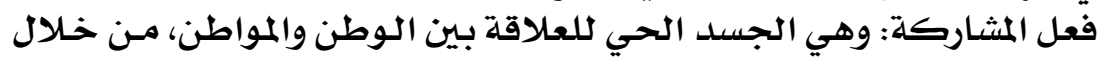

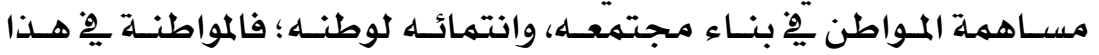

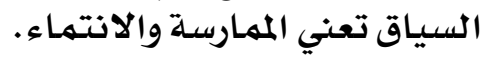

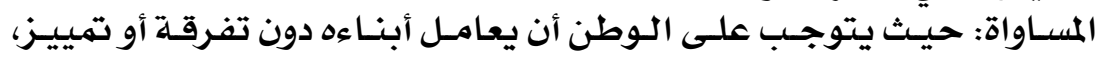

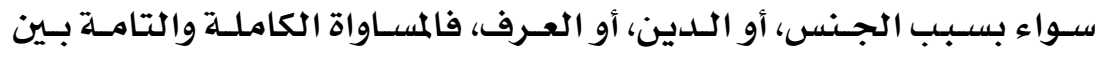

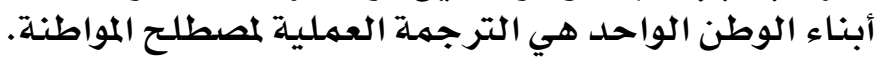

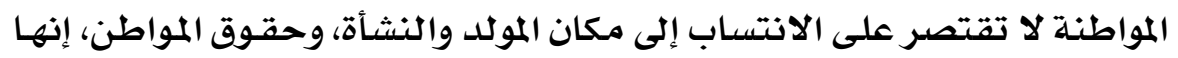

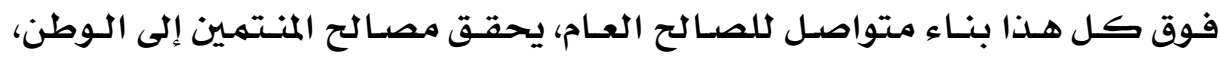

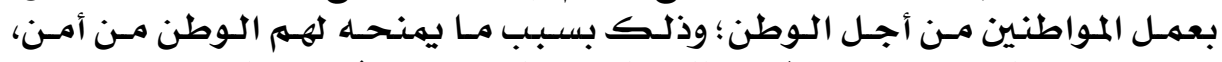

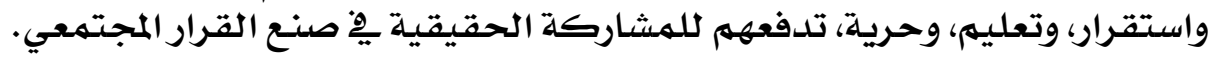

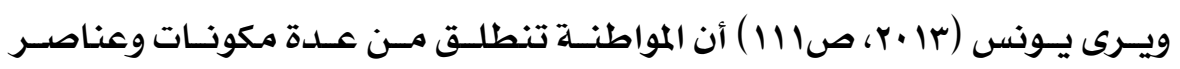

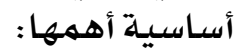

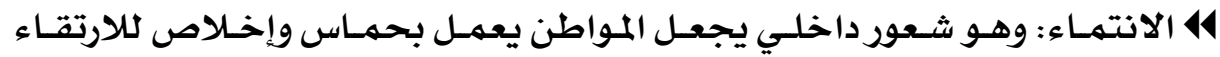

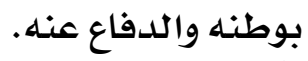

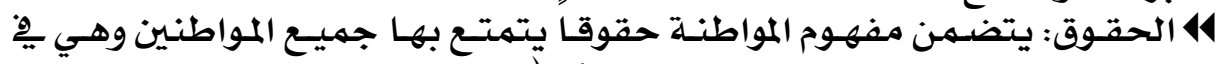

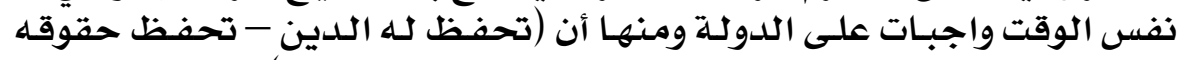

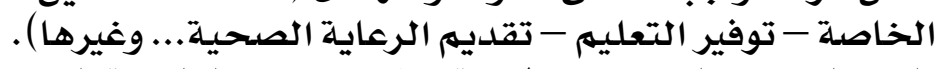

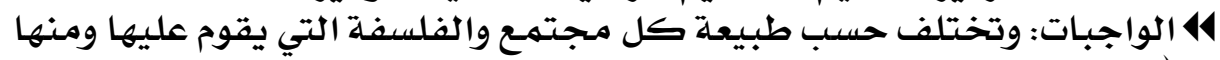

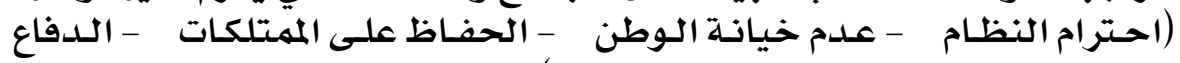
عن الوطن - المحافظة على المرافق العامـة). 


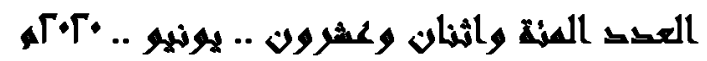

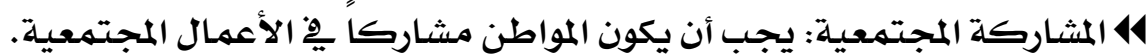

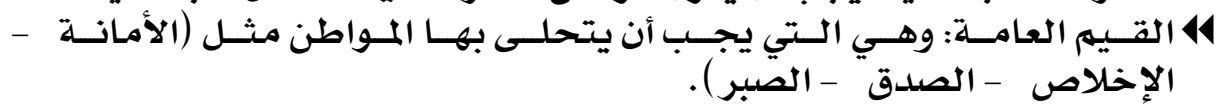

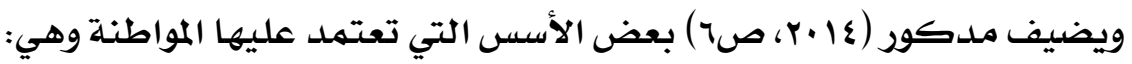

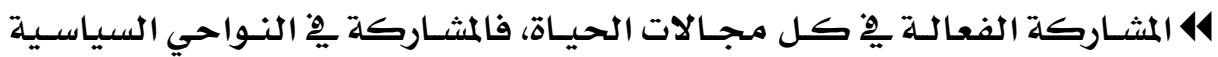

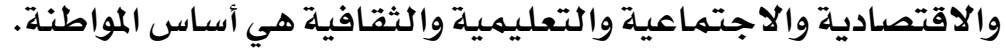
14 قبول مبدأ الاختلادف.

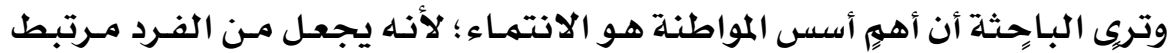

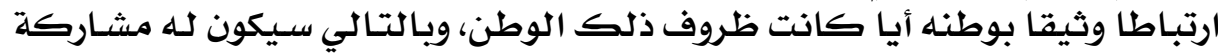

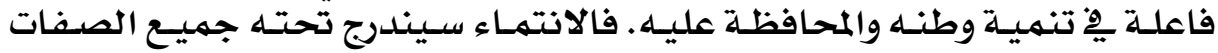

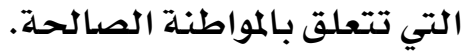

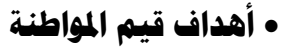

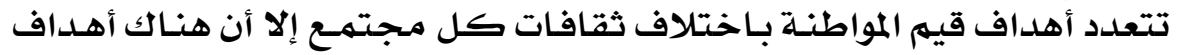

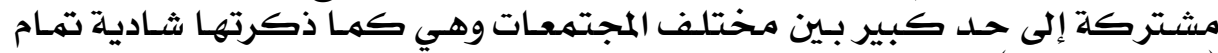

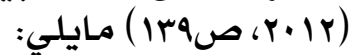

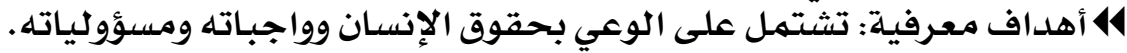

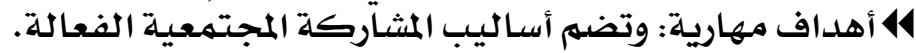

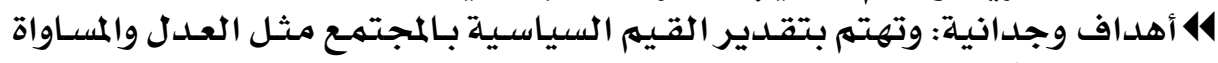

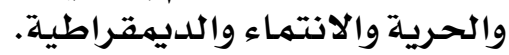

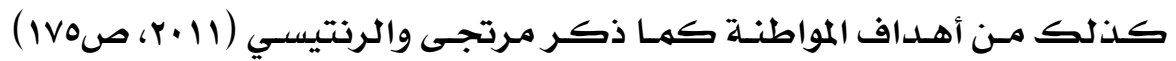

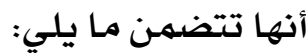

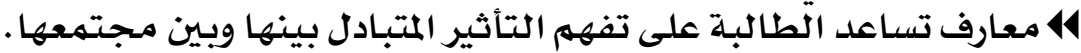

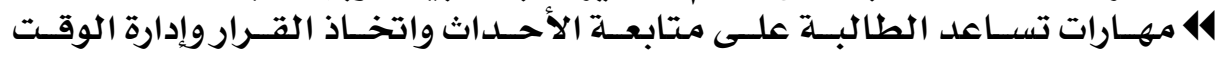
بفاعلية. ه قيم واتجاهات تجعل الطالبة تشعر بالمسؤولية والولاء للوطن وممارسـة السـلوك السوي.

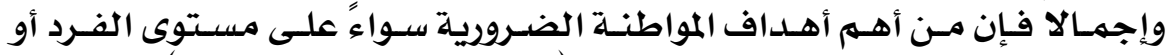

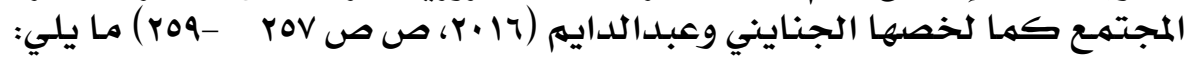

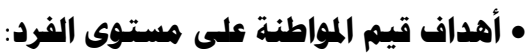

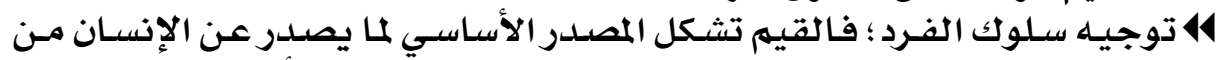

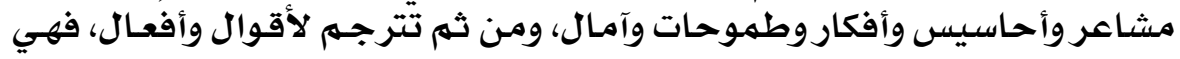
تميزه عن غيره من الناس.

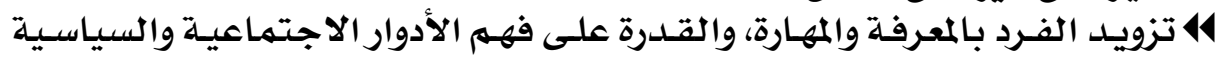

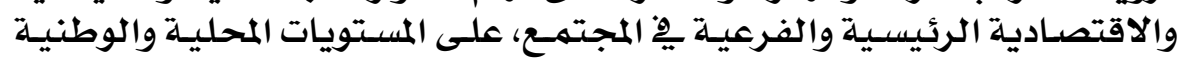
والقومية والإنسانية.

\section{V9}




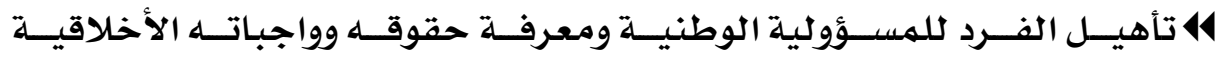

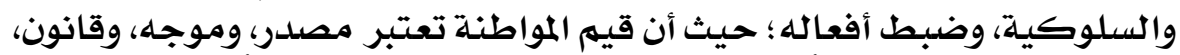

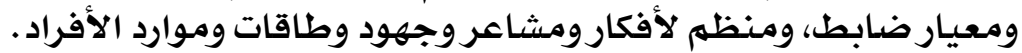

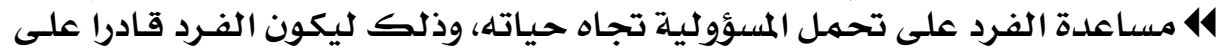

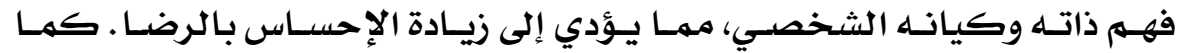

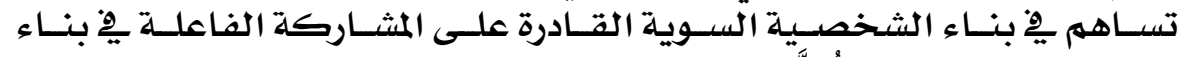

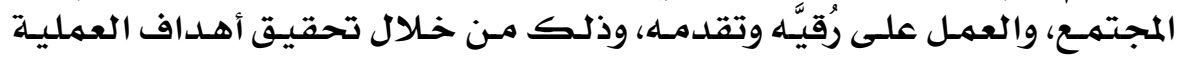

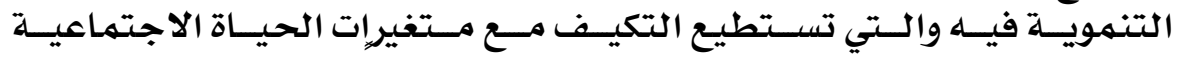

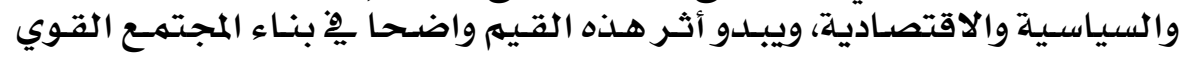

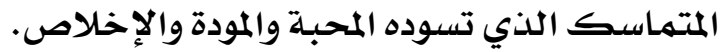

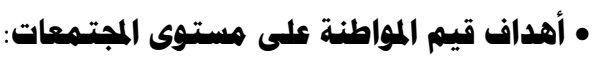

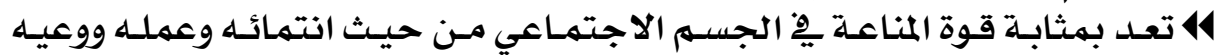

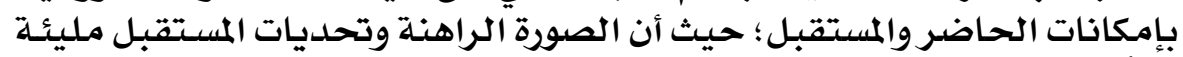

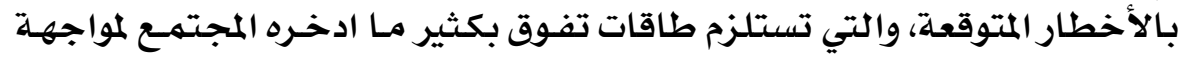

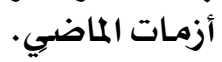

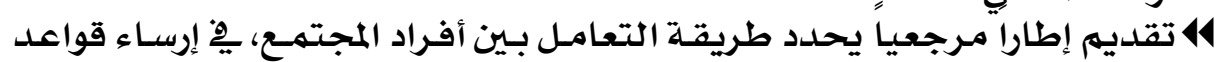

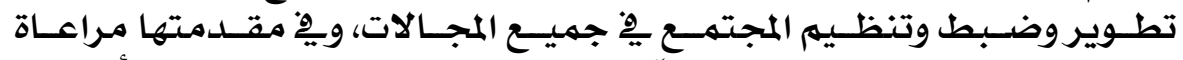

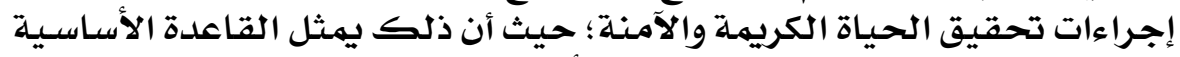

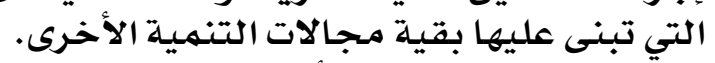

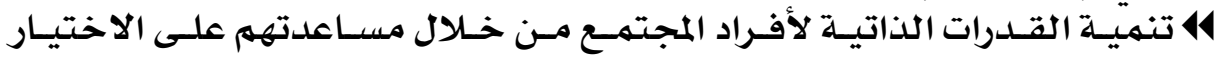

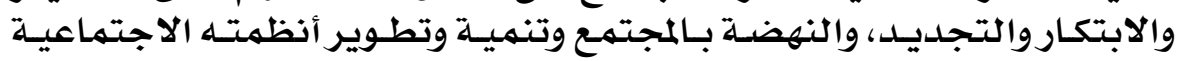

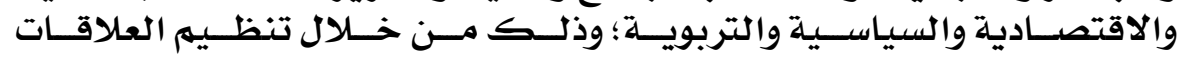

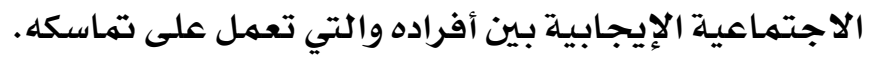

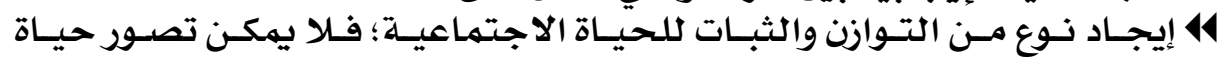

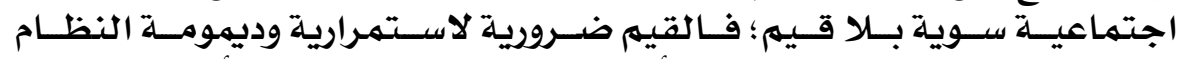

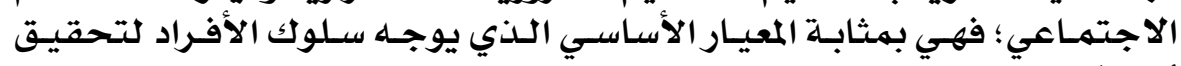

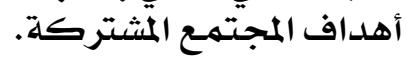

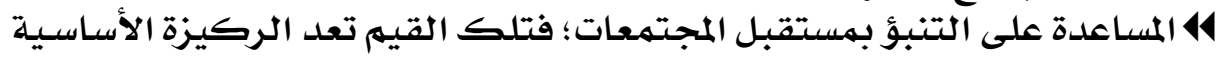

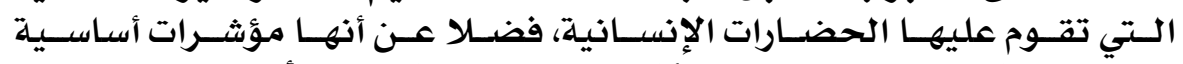

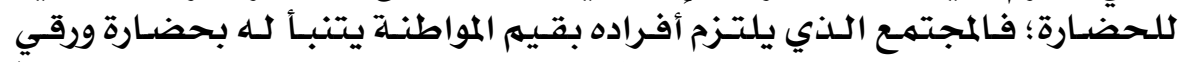

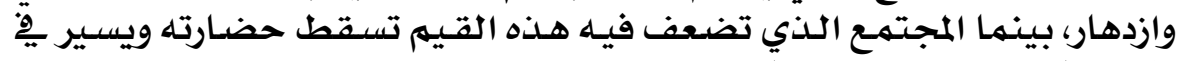

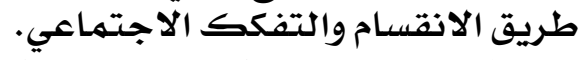

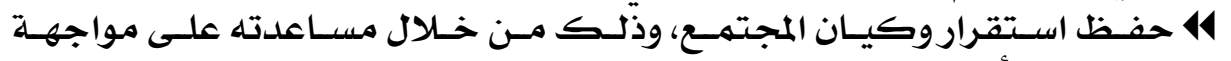

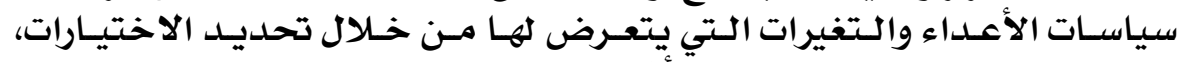

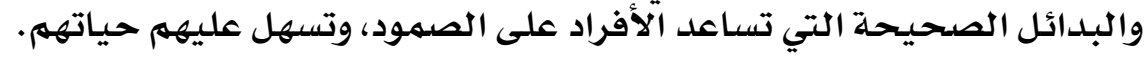

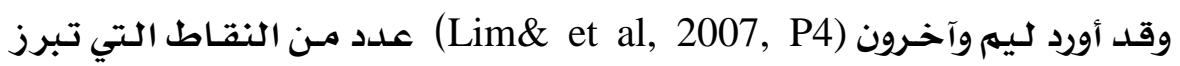
أهمية المواطنة فِِ التعليم:

\section{$\Lambda$}




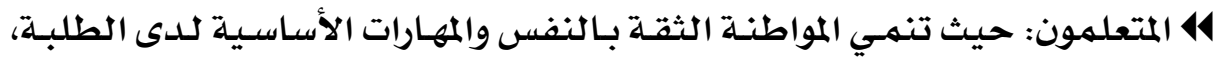

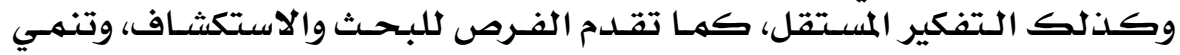

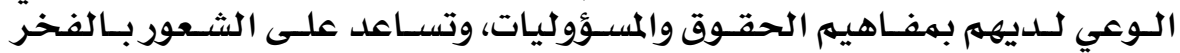
والانتهماء.

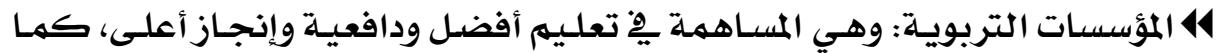

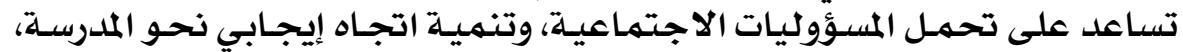

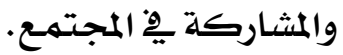

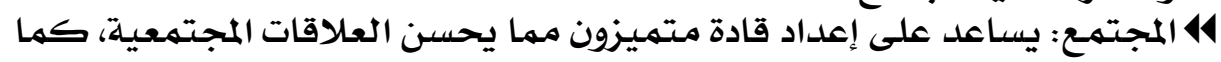

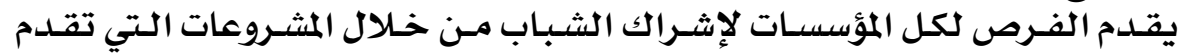

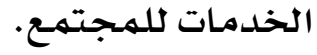

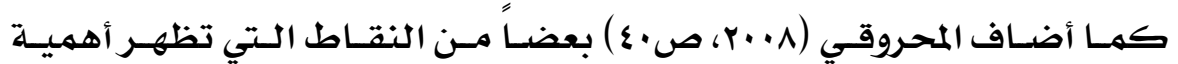

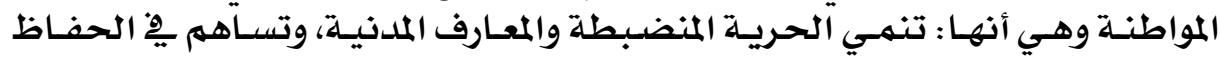

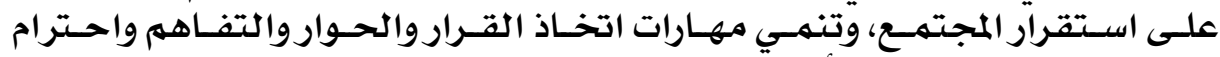
الحقوق والواجبـات لدى المجتى الأفرادي

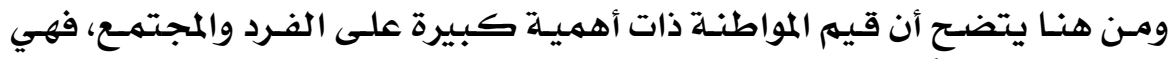

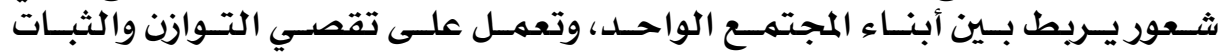

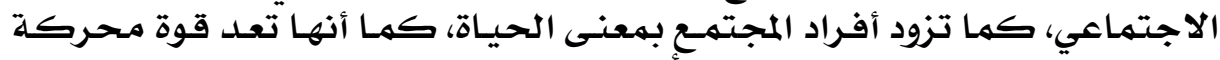

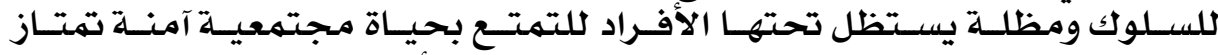

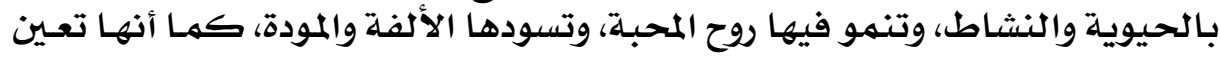

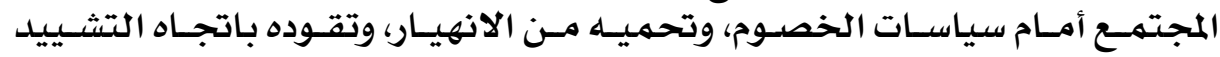

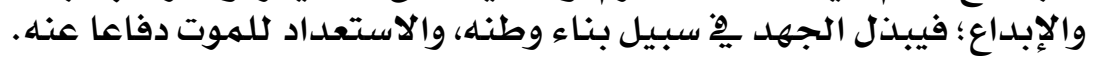

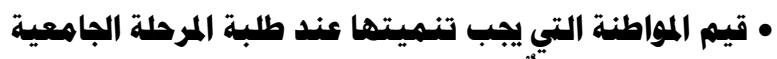

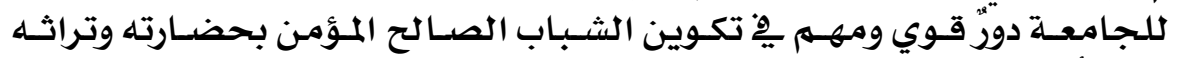

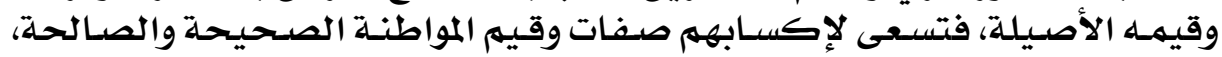

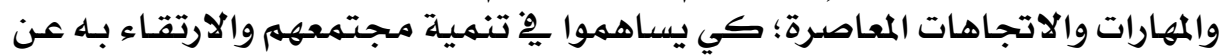

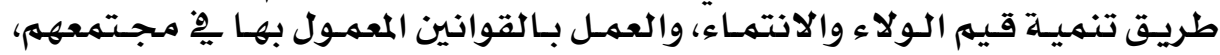

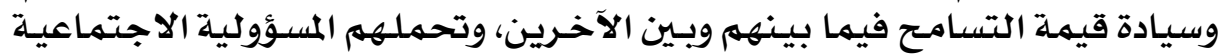

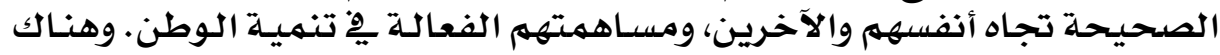

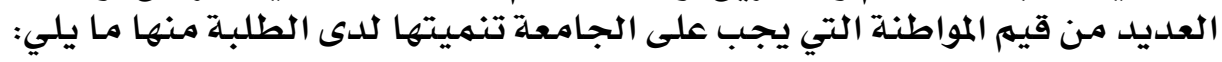

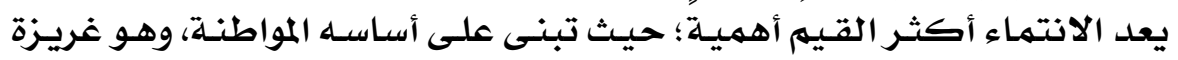

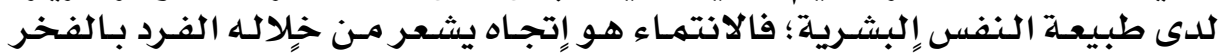

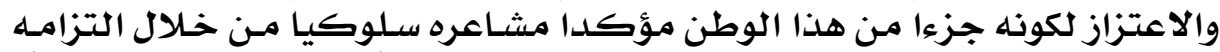

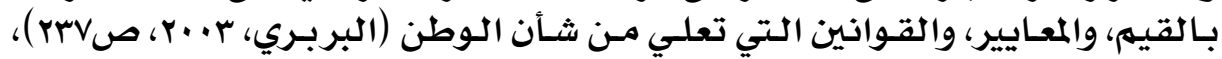

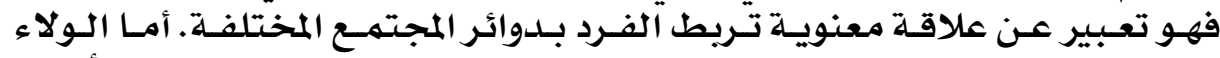

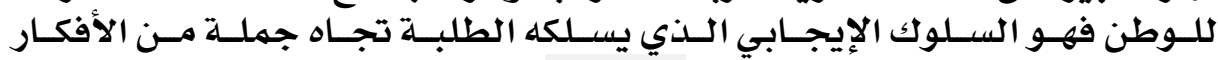

\section{入 1}




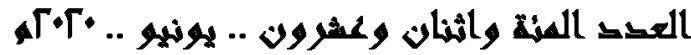

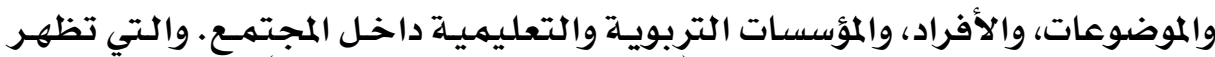

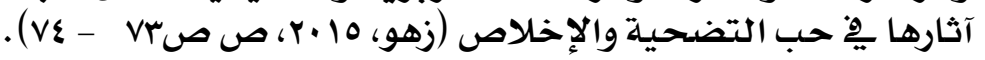

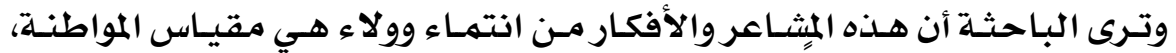

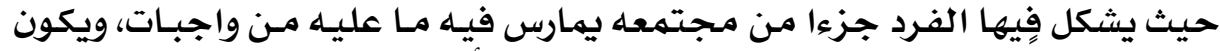

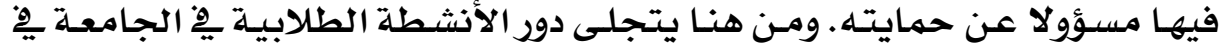

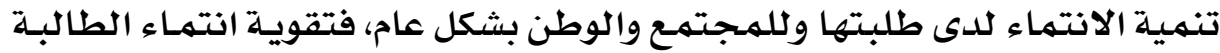

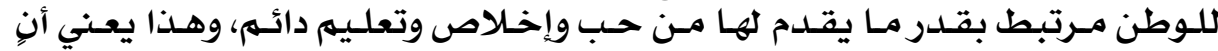

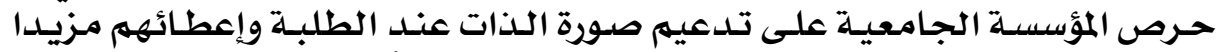

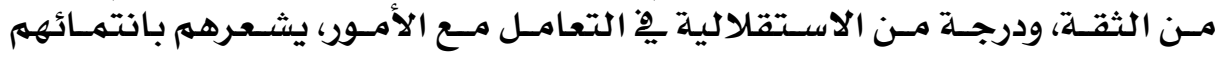

لوطنهم.

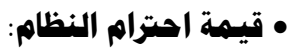

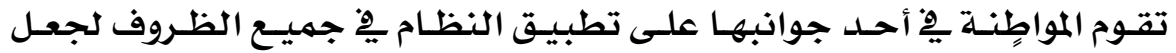

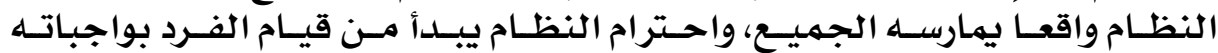

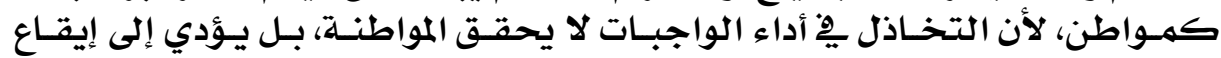

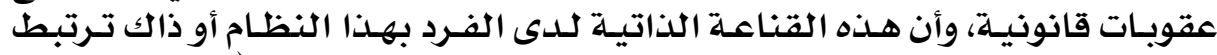

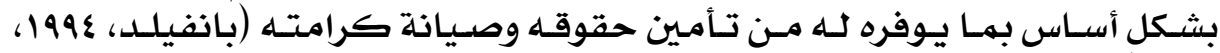
صن (17)

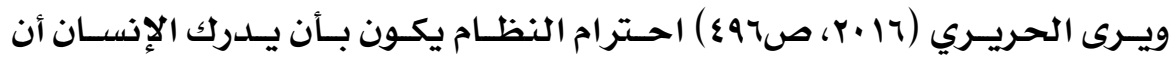

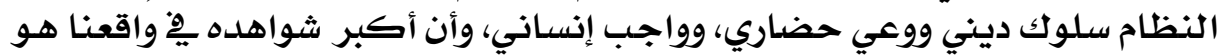

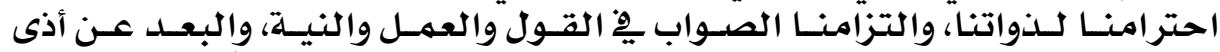

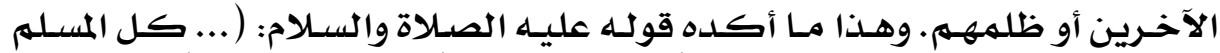

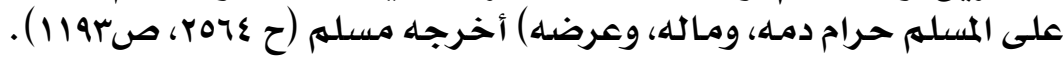

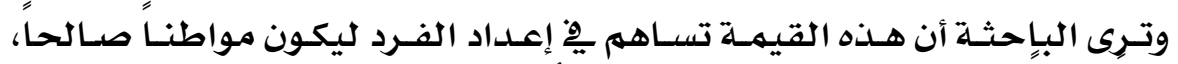

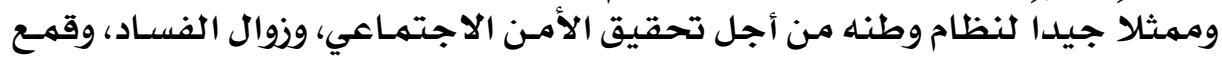
الجرييمة، وردع الجاني.

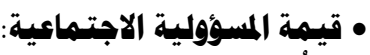

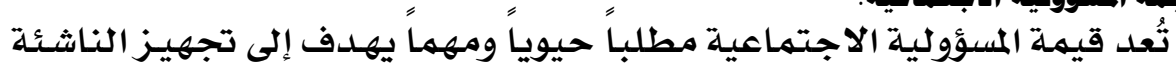

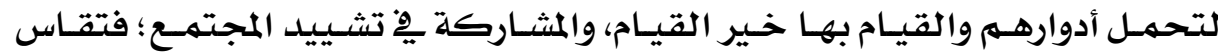

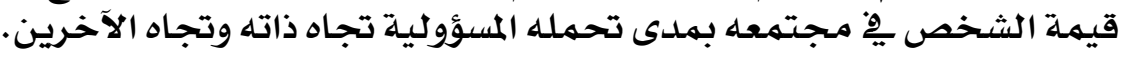

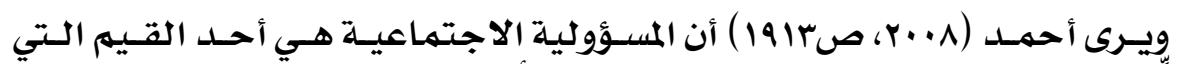

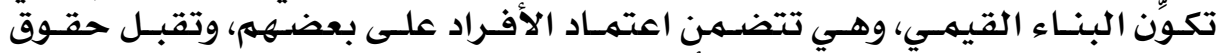

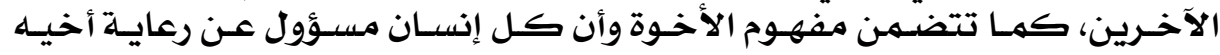
الإنسان والحفاظ عليـه.

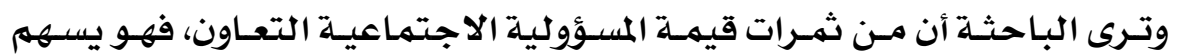

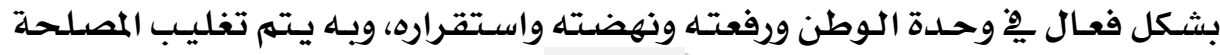

\section{$\Lambda Y$}




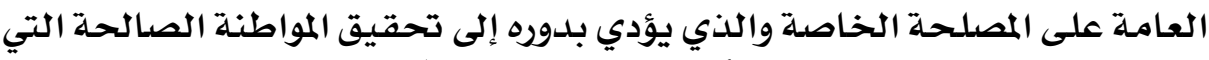

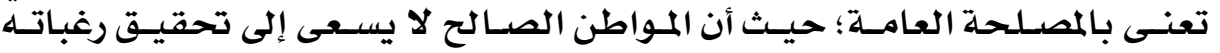

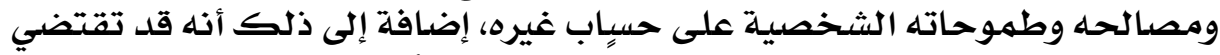

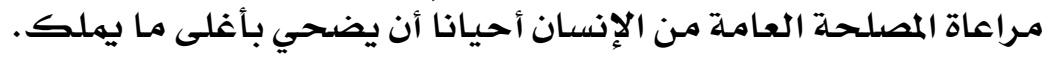

• قيسمة التساهمح:

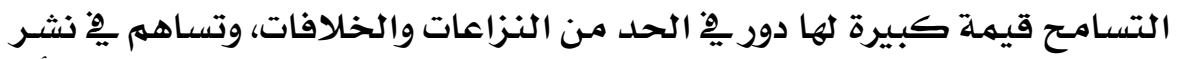

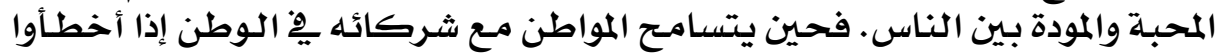

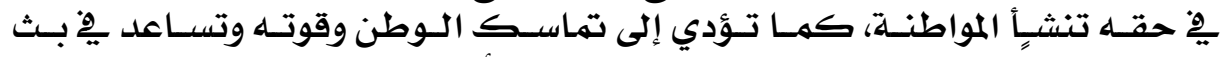

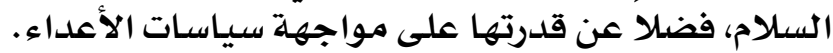

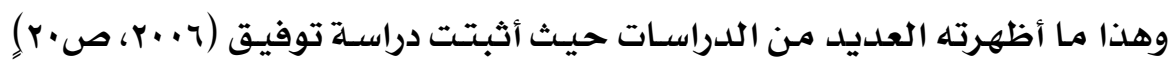

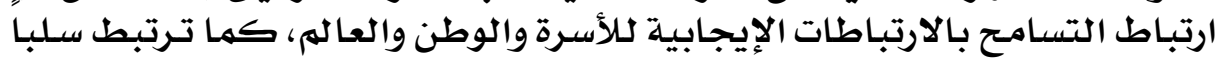

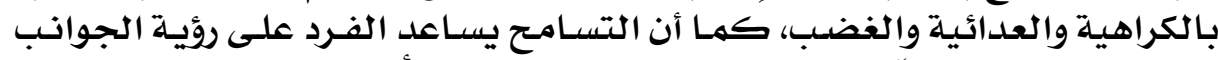

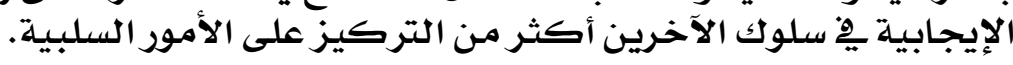

• دور الأنشطة الطلابية في تنمية قييم المراطنة

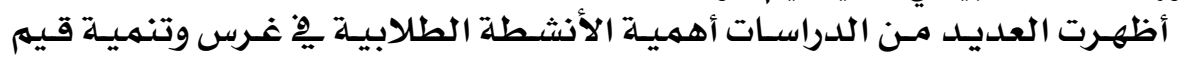

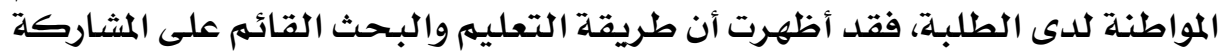

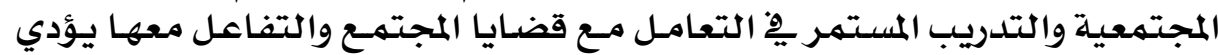

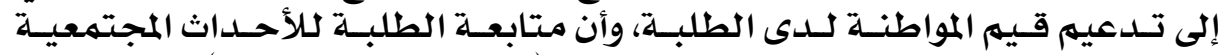

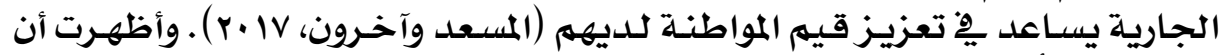

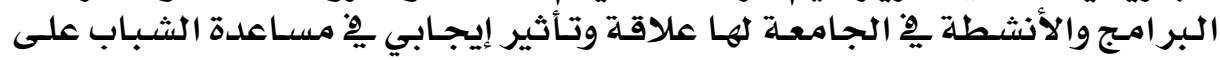

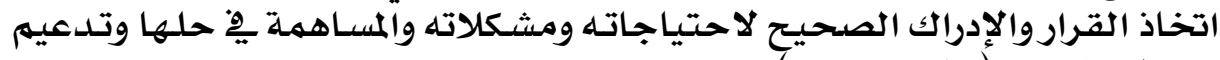

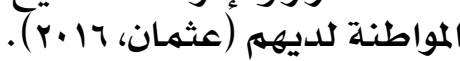

وربط هوسـندروب هيكيـو (Hausendroup Hekio, 2006) تدني مستوى قيهم

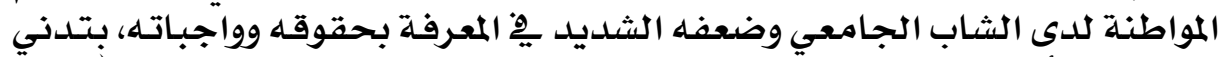

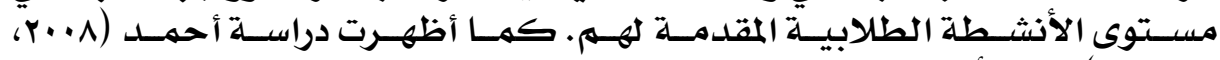

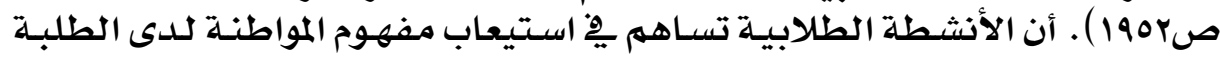

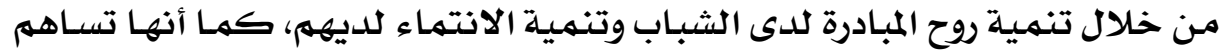

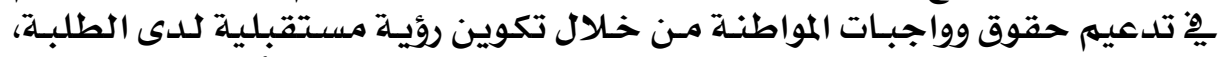

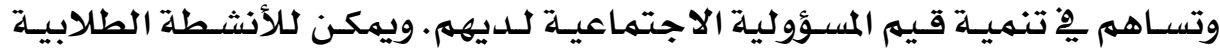

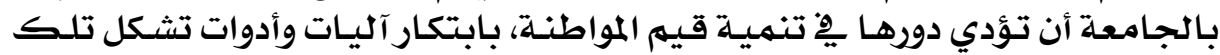

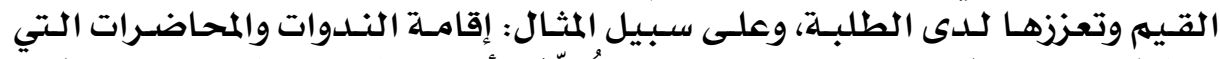

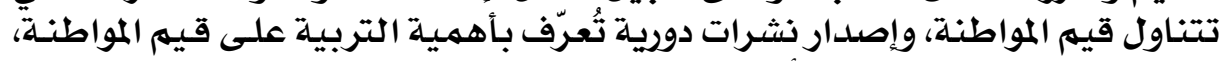

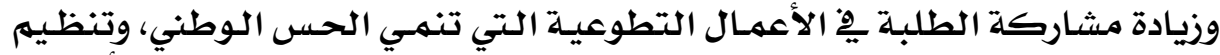

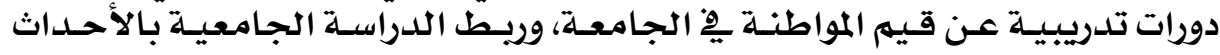

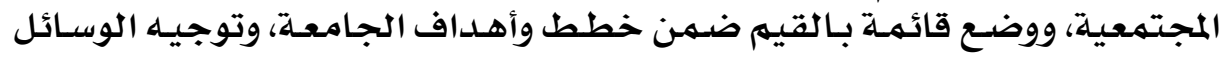

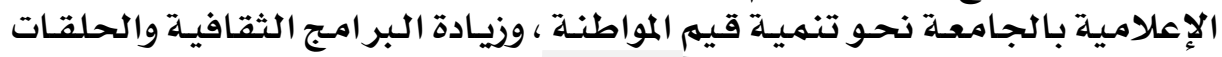

\section{AY}

\section{دراسات عربية في التربية وعلم النفس (ASEP)}




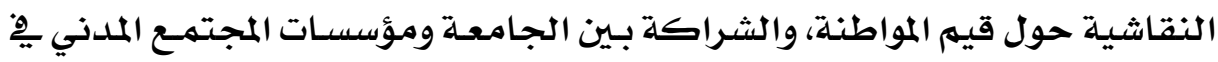
غرس قيه المواطنة لدى المئم الشباب.

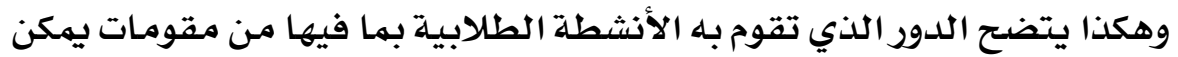

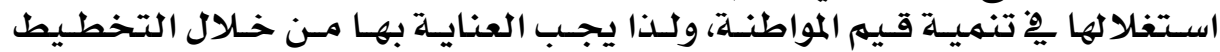

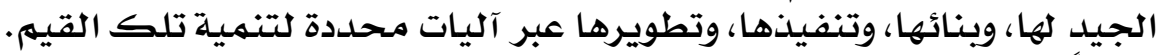

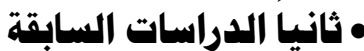

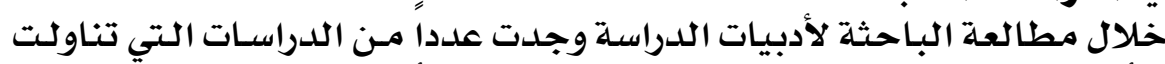

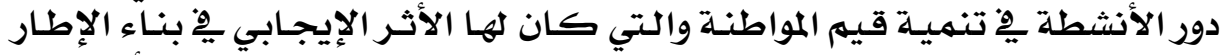

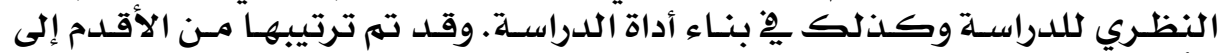
الأحدث.

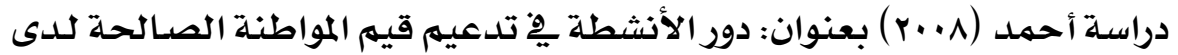

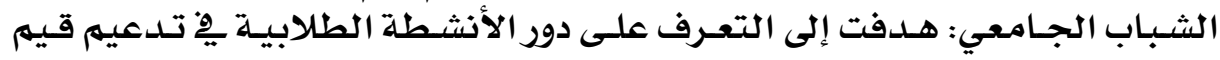

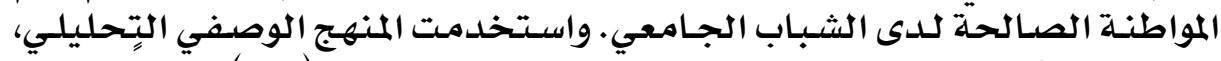

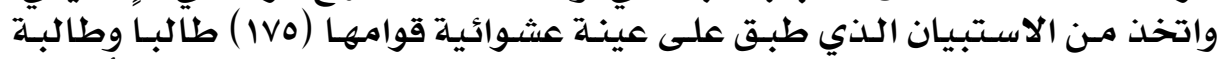

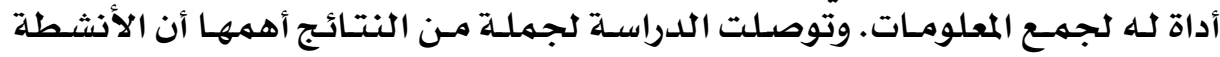

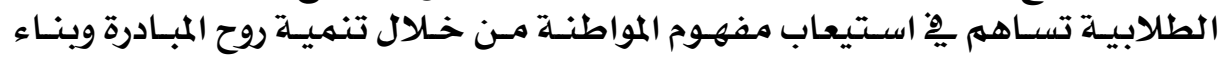

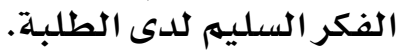

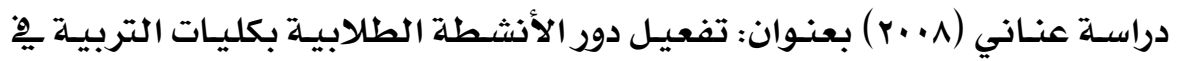

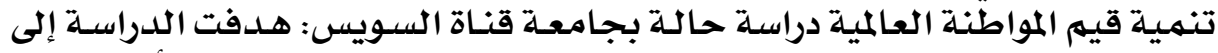

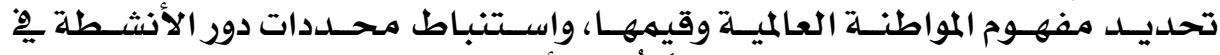

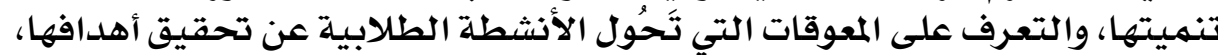

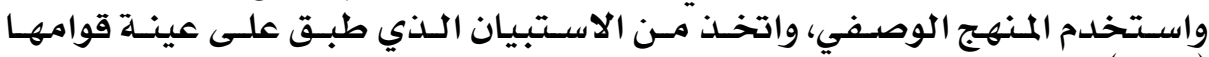

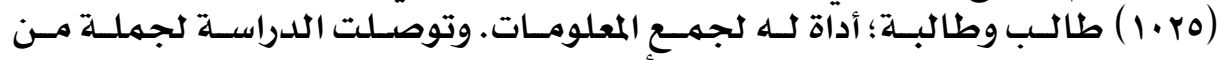

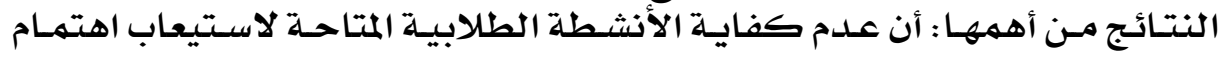

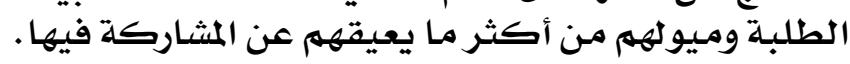

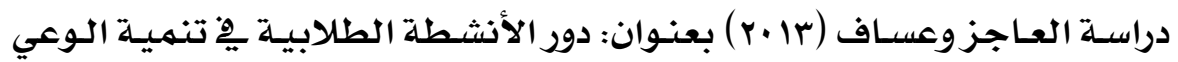

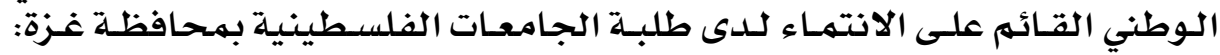

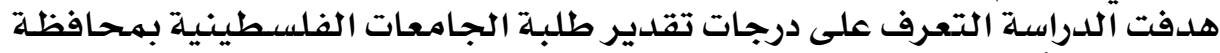

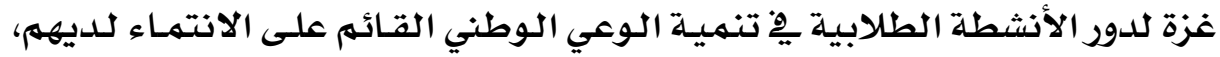

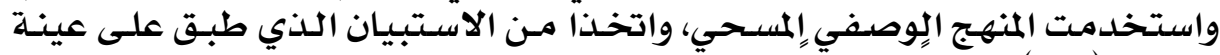

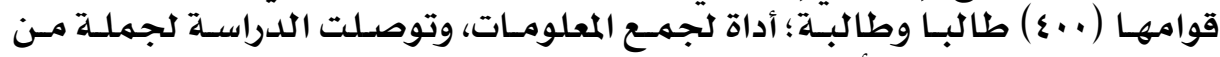

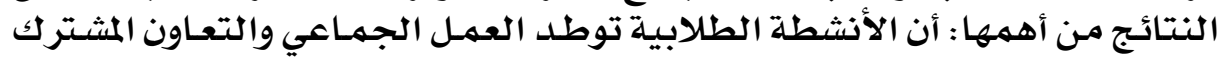

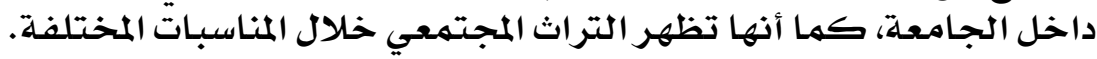

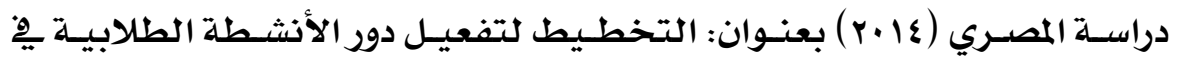

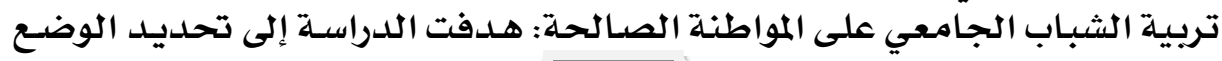

\section{$\Lambda \varepsilon$}




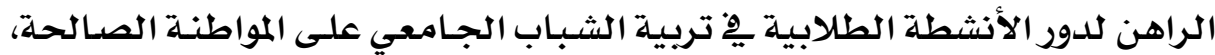

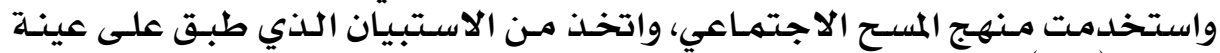

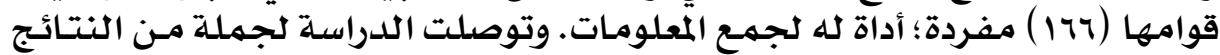

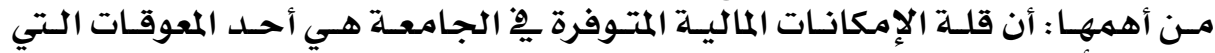

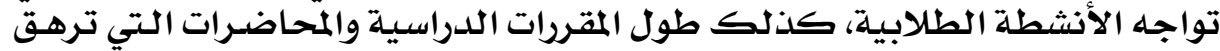
الطالب وتكلفه فوق طاقتته.

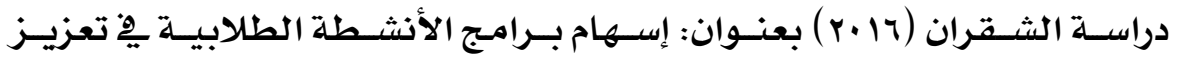

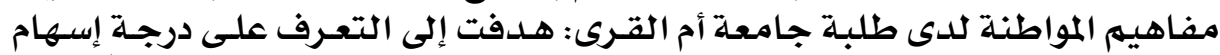

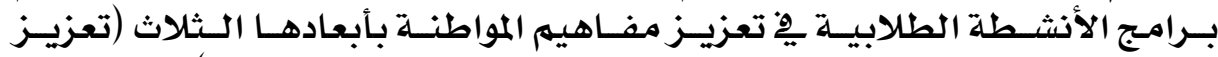

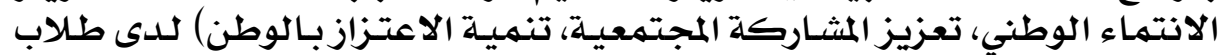

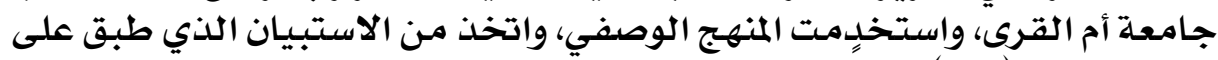

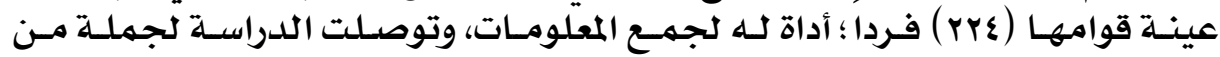

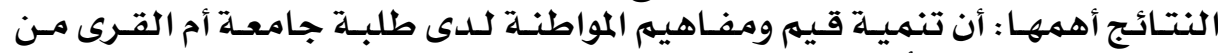

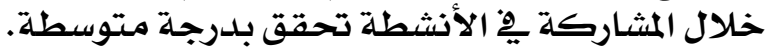

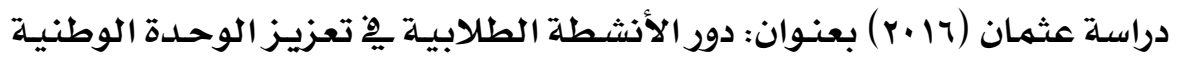

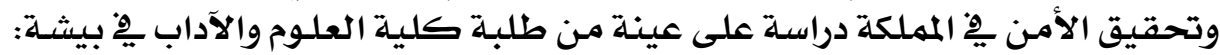

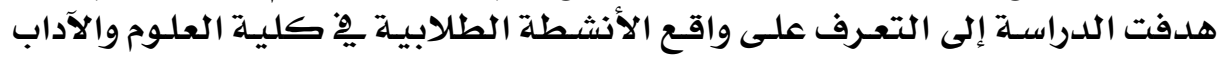

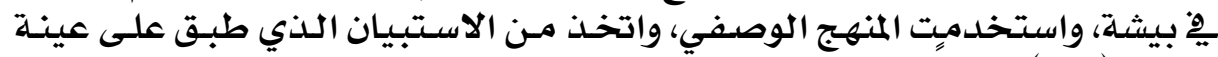

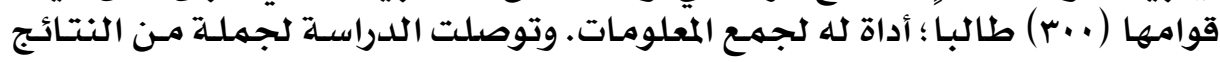

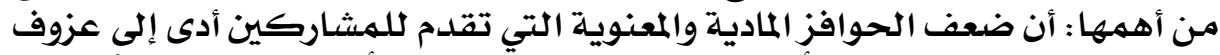

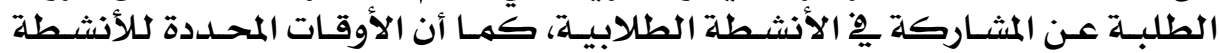

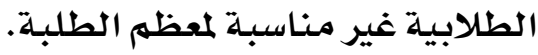

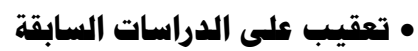

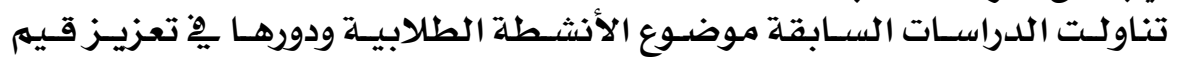

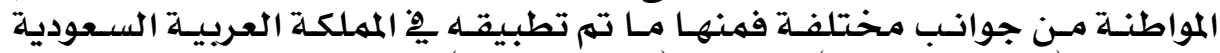

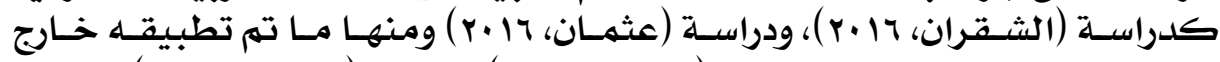

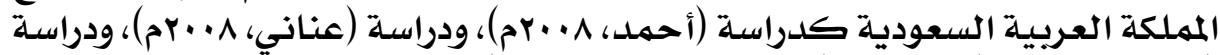

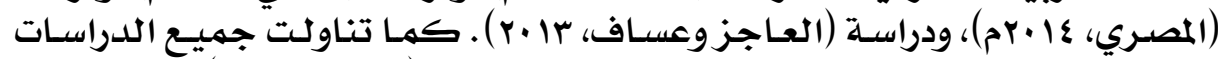

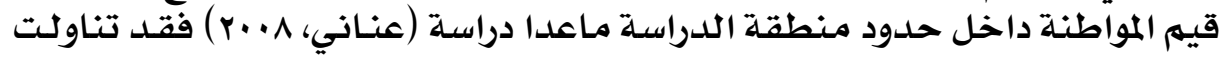

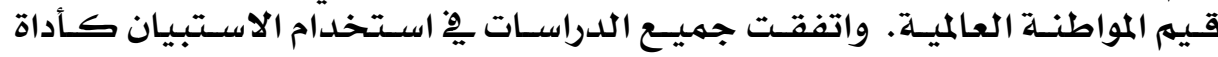

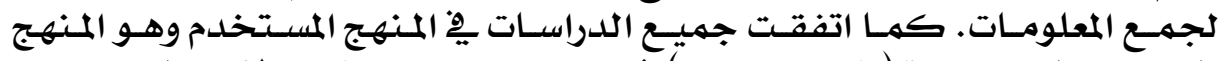

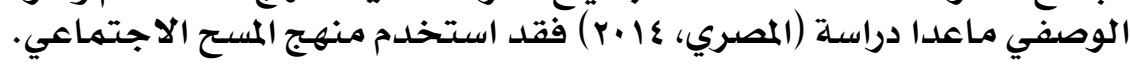

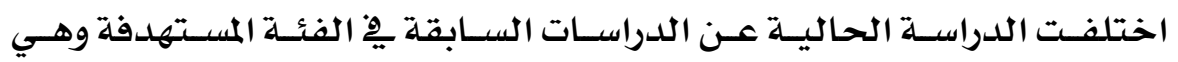

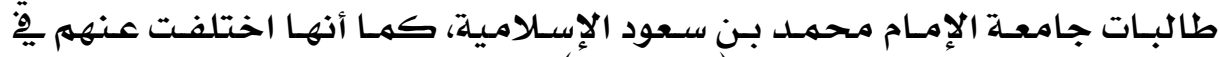
المحاور التي تناولتها أداة الدراسة (الاستبـيان) 


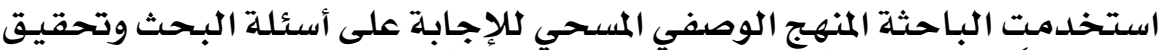

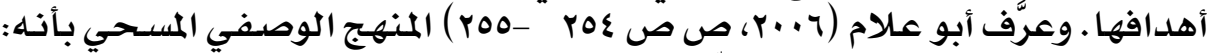

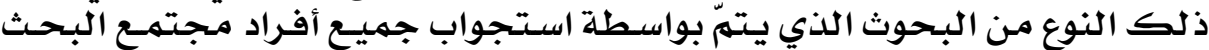

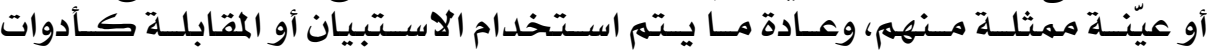

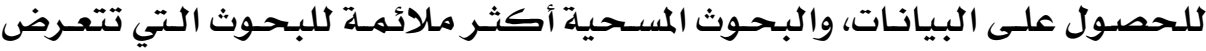

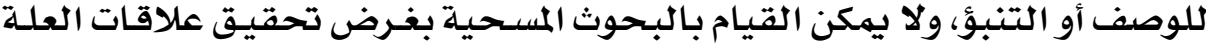

والمعلول

\section{• • هجتهع الدراسة وعينتها:}

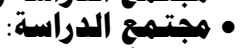

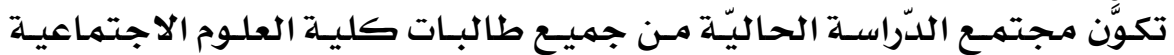

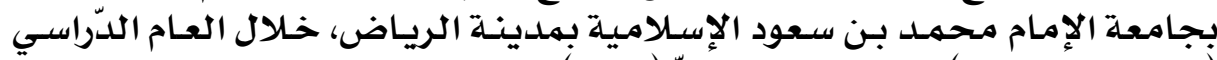

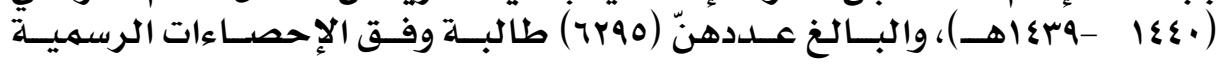

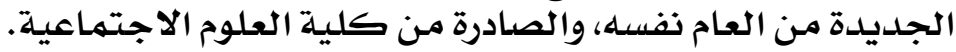

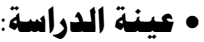

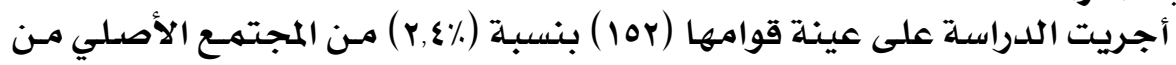

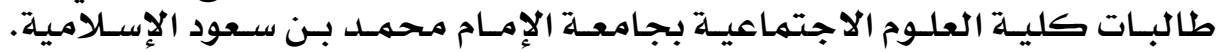

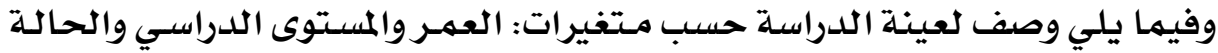

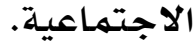

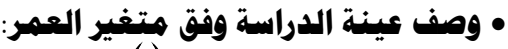
جدول (1) يوضح توزيع أفراد عينت الدراستّوفق متغير العمر

\begin{tabular}{|c|c|c|}
\hline النسبيت المئويتة & العدد العد & العمر \\
\hline$\% /\{r, 11$ & $7 \xi$ & 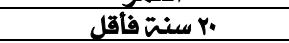 \\
\hline 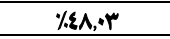 & $v_{r}$ & من الY - إلى أقل من Yo سنت \\
\hline$\%(9, \Lambda \mathrm{V}$ & 10 & من Y Yنتي فاكثر \\
\hline$\%$ & 10r & 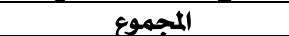 \\
\hline
\end{tabular}

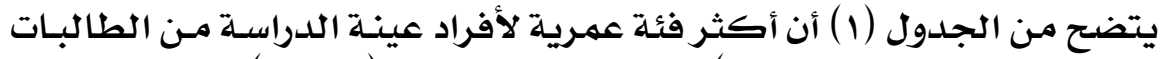

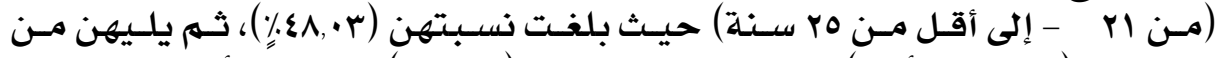

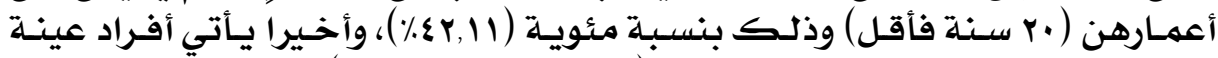

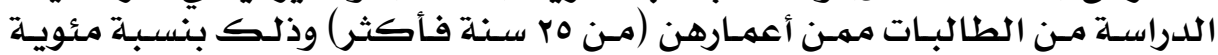
. ((\% \%, ^V)

• وصف عينة الدراسة وفق متفير المستوى الدراسي:

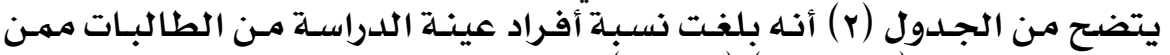

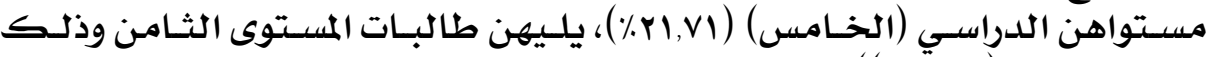

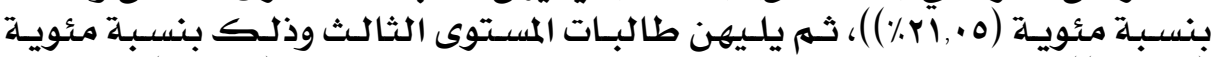

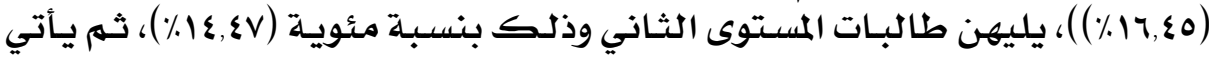

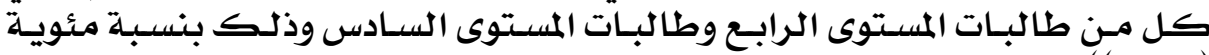

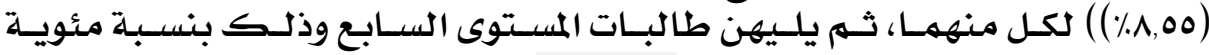

\section{$\wedge 7$}




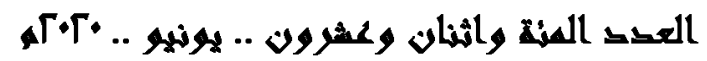

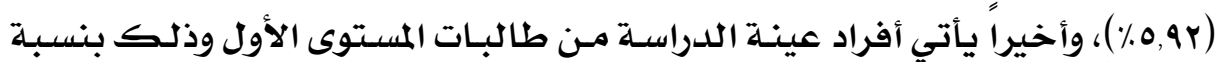

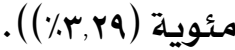

جدول (r) يوضتح توزيع أفراد عينت الدراستّوفق متفير المستوى الدراسي الميتي

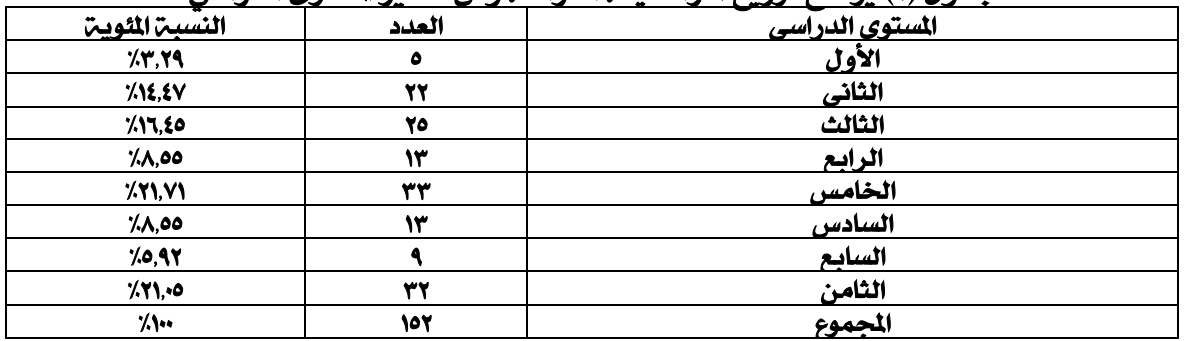

• أداة الدراسة

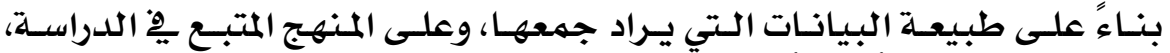

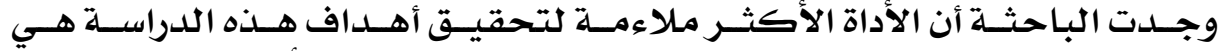

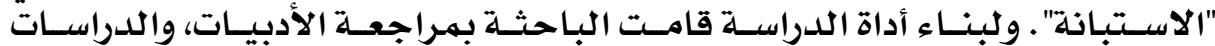

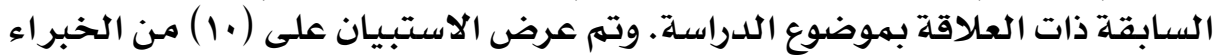

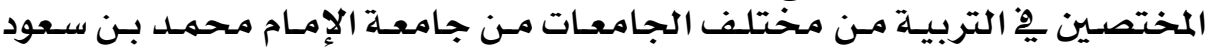

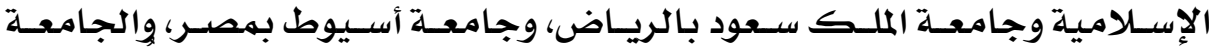

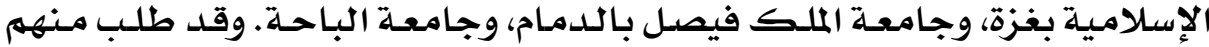

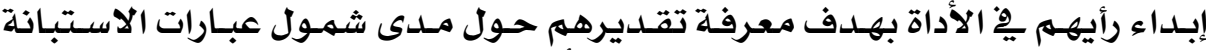

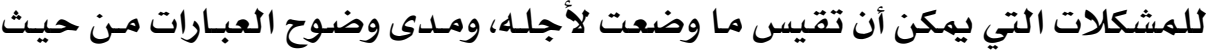

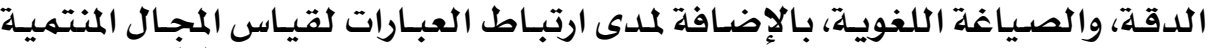

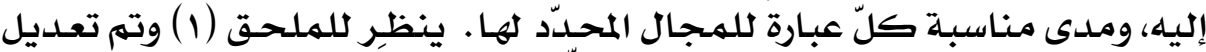

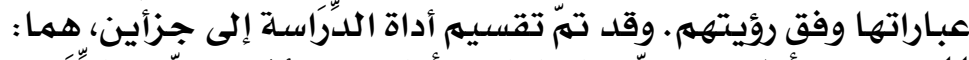

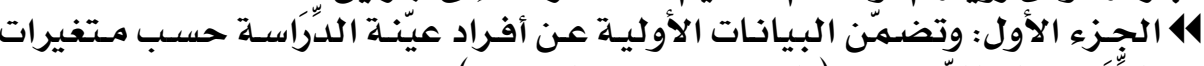

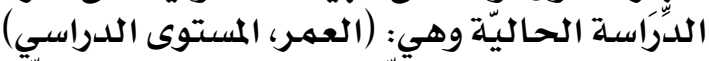

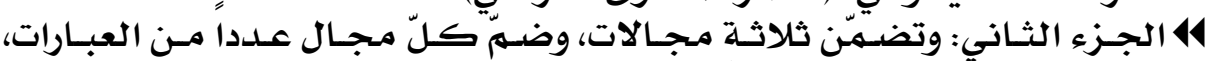

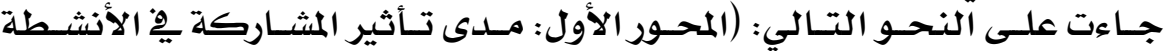

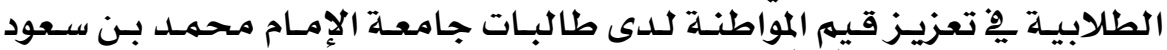

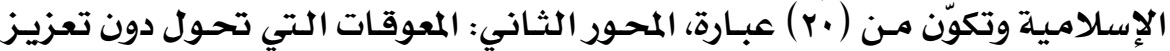

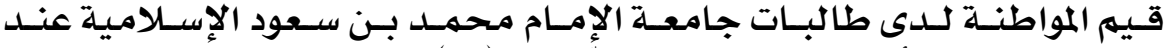

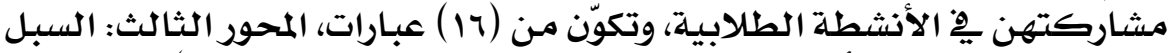

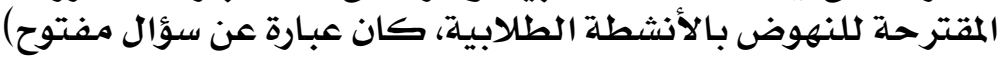

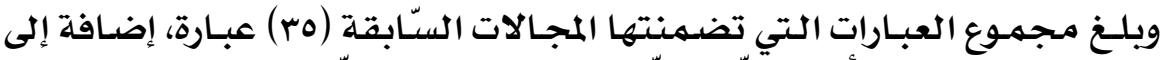

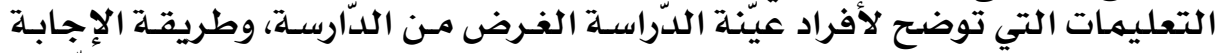

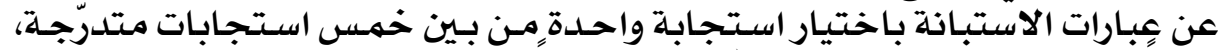

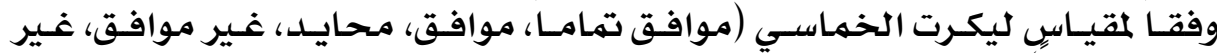

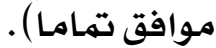




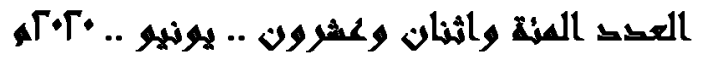

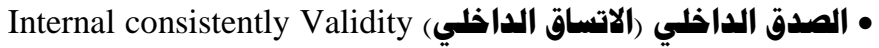

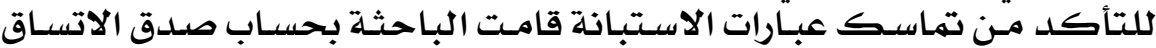

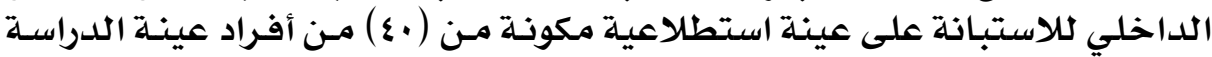

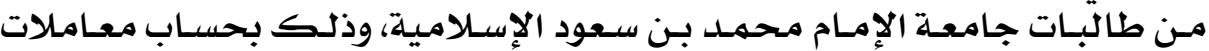

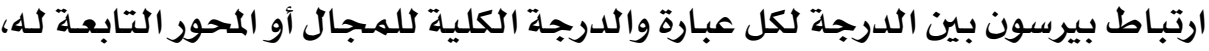

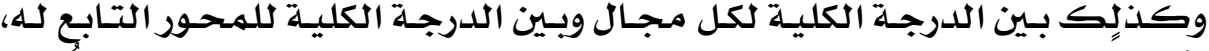

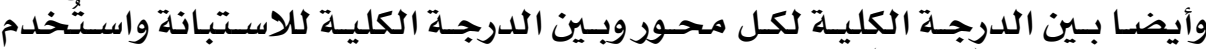

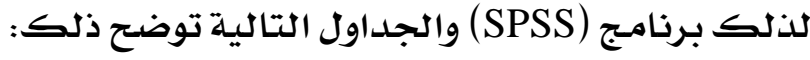

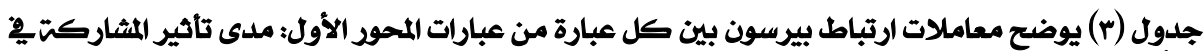

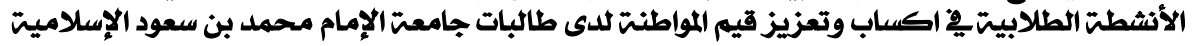

\begin{tabular}{|c|c|c|c|c|c|}
\hline مستوى الدلالية & معامل الآلارتباط للمحورد & رقم العبارة & مستوى الدلالتَالإحصائية & معامل الارتباط بالدرجت المحتية & رقم العبارة \\
\hline$\leftrightarrow, \cdots$ & , V乏 & 11 & $\leftrightarrow, \cdots \varepsilon$ & 品 & 1 \\
\hline$\leftrightarrow, \cdots$ & , A* & ir & $\leftrightarrow$ & , wV & $r$ \\
\hline$\Delta \leftrightarrow, \cdots$ & $\therefore, 19$ & ir & $\Delta, \cdots$ & . $\mathrm{Vr}$ & $r$ \\
\hline$\leftrightarrow, \cdots$ & 足 & $1 \varepsilon$ & $\leftrightarrow, \cdots$ & , VA & $\varepsilon$ \\
\hline$\leftrightarrow, \cdots$ & $\because A V$ & 10 & $\Delta<, \cdots$ & , vrr & $\circ$ \\
\hline 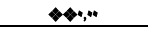 & , v. & 17 & $4, \cdots$ & $\therefore, 10$ & 7 \\
\hline$\leftrightarrow, \cdots$ & , vA & IV & $\leftrightarrow$ & 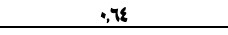 & $v$ \\
\hline$\Leftrightarrow$ & , vA & IA & 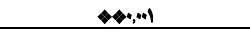 & $\because, \Delta V$ & $\Lambda$ \\
\hline$\leftrightarrow, \cdots$ & ;, Al & 19 & $\leftrightarrow, \cdots$ & 促, & 9 \\
\hline$\leftrightarrow \leftrightarrow, \cdots$ & , AM & r. & $\leftrightarrow, \cdots$ & 足, & 1. \\
\hline
\end{tabular}

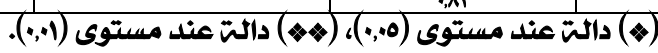

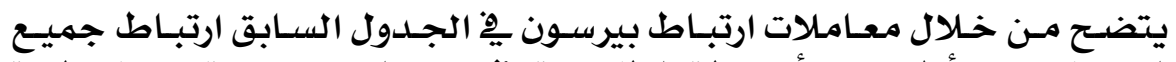

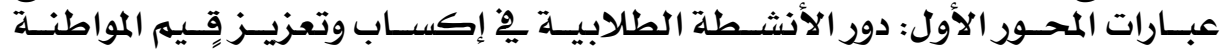

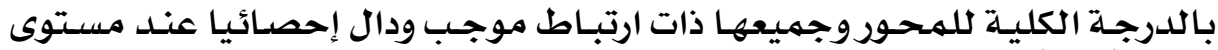

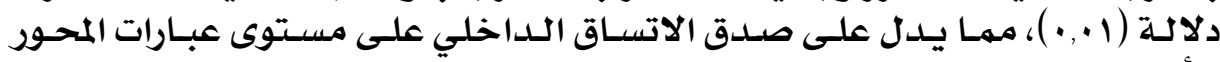

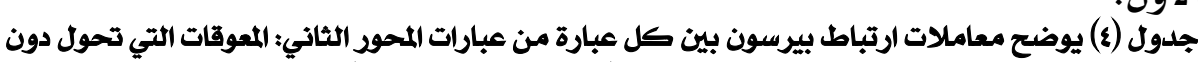

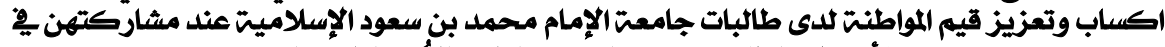

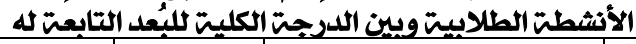

\begin{tabular}{|c|c|c|c|c|c|}
\hline مستوى اللايلالة & 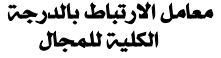 & رقم العبارة & مستوى الدلالات الإحصائية & معامل الآليتباط باللدرجت المجال & رقم العبارة \\
\hline \multicolumn{6}{|c|}{ المجال الأول: المعوقات المرتبطت بالناحيت الماديتً } \\
\hline 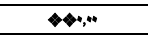 & $\cdot \mathrm{WV}$ & $r$ & $\leftrightarrow, \cdots$ & $\cdot, 19$ & 1 \\
\hline \multicolumn{6}{|c|}{ الججال الثاني: الإعوقات المرتبطتة بالطالب } \\
\hline 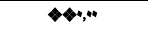 & •, V. & $\mathrm{v}$ & $\leftrightarrow$ & :or & $r$ \\
\hline (4)." &,$\%$ & $\Lambda$ & \$r, & $\begin{array}{c}, 87 \\
\end{array}$ & $\varepsilon$ \\
\hline$\leftrightarrow \leftrightarrow, \cdots$ & , \&Y & 9 & $\leftrightarrow$ & $\bullet, \mathrm{V}$ & - \\
\hline & & & 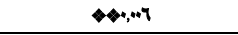 & 部 & 1 \\
\hline \multicolumn{6}{|c|}{ المجال الثالث: المعوقات المرتبطت بالمناهج الدراسيتً } \\
\hline 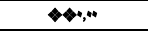 & $\cdot \mathrm{AI}$ & ir & 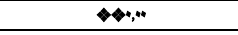 & 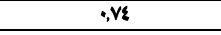 & 1. \\
\hline & & & $\leftrightarrow$ & "or & 11 \\
\hline \multicolumn{6}{|c|}{ المجال الرابع: المعوقات المرتبطت بالإشراف } \\
\hline 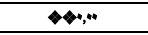 & $\overrightarrow{*, \mathrm{~V} \cdot}$ & 10 & 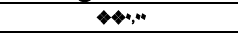 & $\cdot \mathrm{n} n$ & $\pi$ \\
\hline 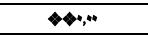 & ז', & 17 & 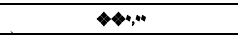 & $\cdot \mathrm{V} 7$ & $1 \varepsilon$ \\
\hline
\end{tabular}

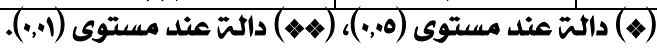




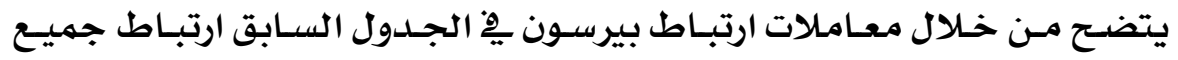

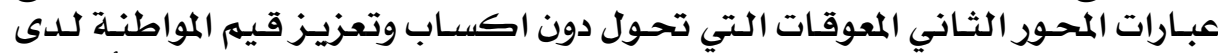

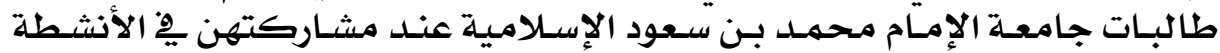

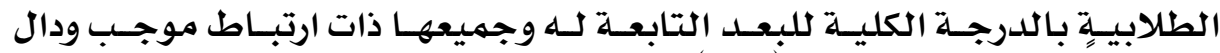

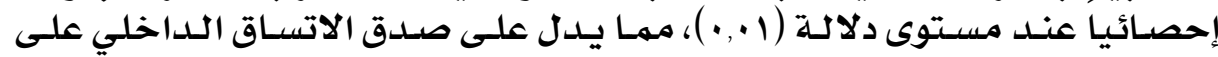
مستوى جميع عبارات المحور الثانيات مباني.

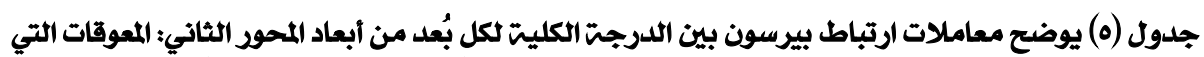

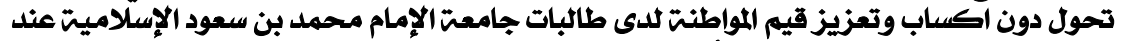

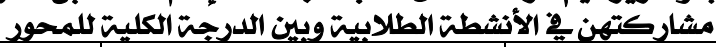

\begin{tabular}{|c|c|c|}
\hline مستوى الدلالة الإحصائية & معامل الارتباط بالدرجت الكليت للمحور & المجال \\
\hline$\leftrightarrow, \cdots$ & .,or & المجال الأول: المعوقات المرتبطت بالثناحيت الماديتة \\
\hline$\leftrightarrow, \cdots$ & $\therefore$, A & المجال الثانى: المعوقات المرتبطت بالطالب \\
\hline 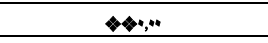 &., $\mathrm{vo}_{0}$ & المجال الثالث: المعوقات المرتبطت بالمناهج الدراسيتة \\
\hline$\leftrightarrow \leftrightarrow, \cdots$ & :VY & الججال الرابع: المعوقات المرتبطتب بالإشراف \\
\hline
\end{tabular}

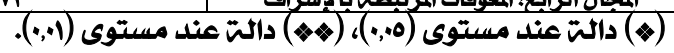

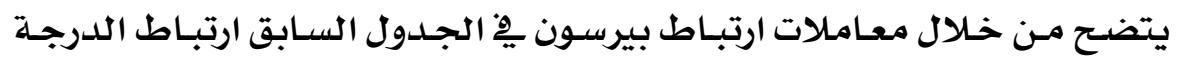

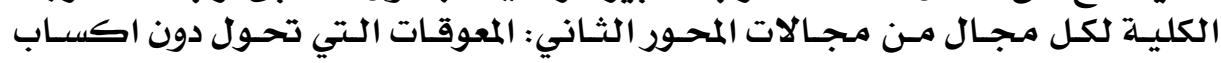

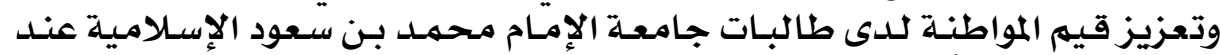

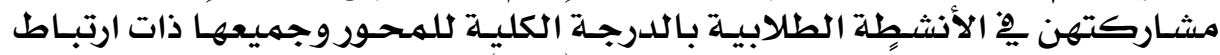

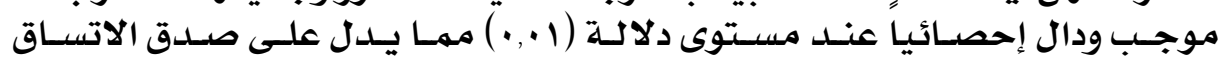

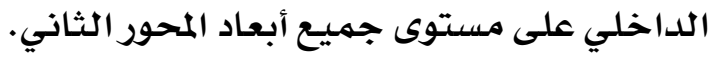

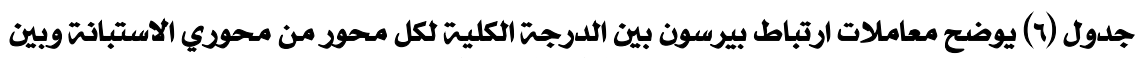

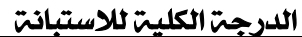

\begin{tabular}{|c|c|c|}
\hline مستوى الدلائة & معامل الارتباط بالدرجتيتة & المحود \\
\hline$\leftrightarrow$ & ז'9, & 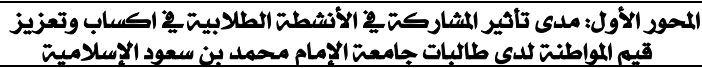 \\
\hline$\leftrightarrow \leftrightarrow, \cdots$ & TV & 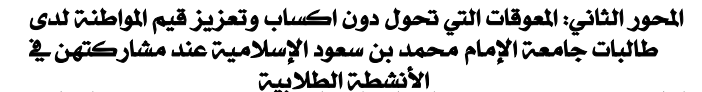 \\
\hline
\end{tabular}

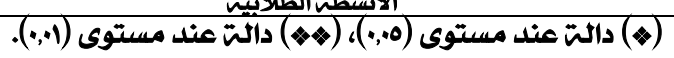

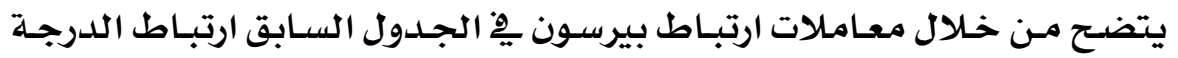

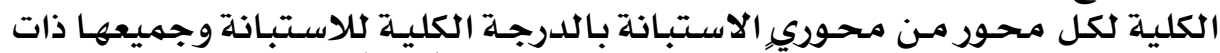

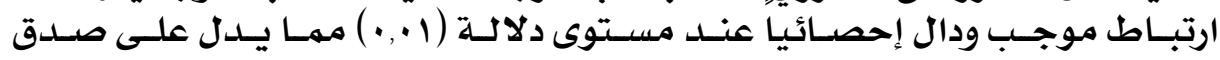

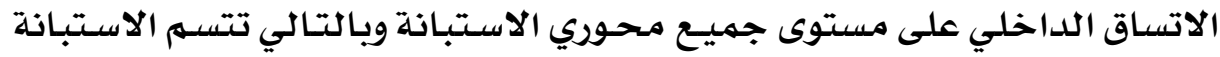

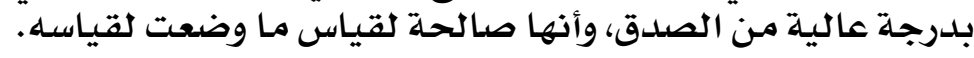

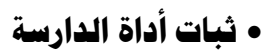

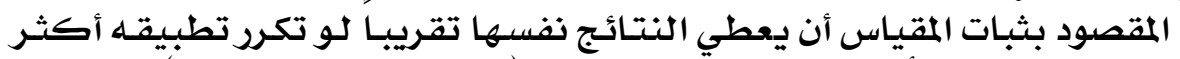

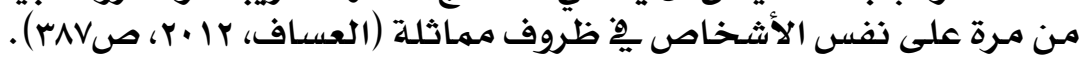

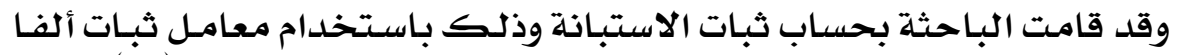

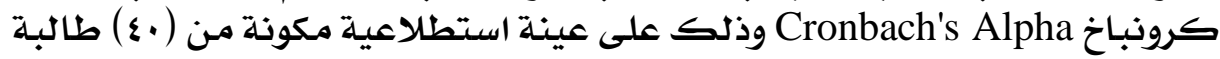

\section{$\wedge 9$}




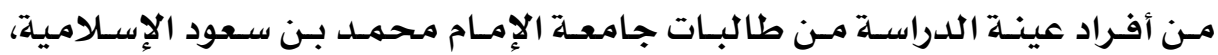

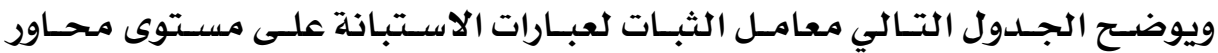
وإجمالي الاستبانة.

جدول (v) يبين قيم معاملات ثبات محوري الاستبانت وإجمالي الاستبانت باستخدام معامل الفا كرونباخ

\begin{tabular}{|c|c|c|}
\hline معامل الفاخ & 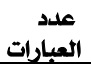 & المحور - ال \\
\hline 年 & r. & 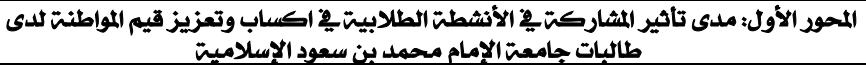 \\
\hline 浪 & 17 & 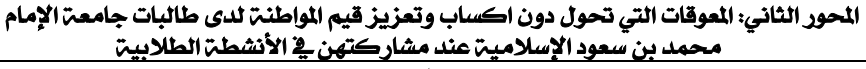 \\
\hline :, १६ & rq & إجمالى الاستبانت \\
\hline
\end{tabular}

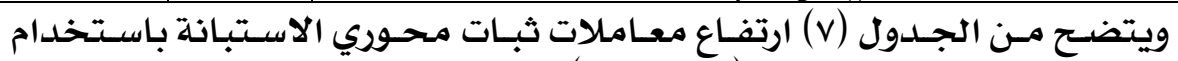

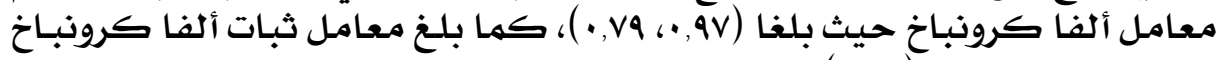

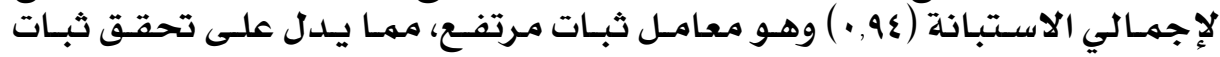
الاستبـانة بشكل عام. الاحسئ

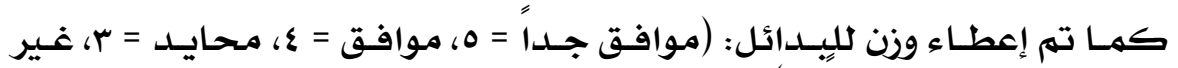

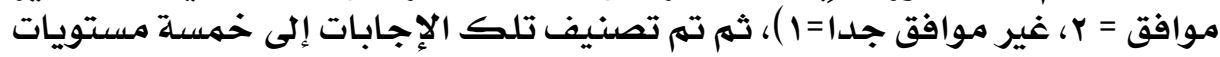

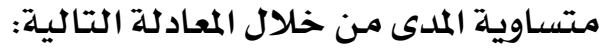

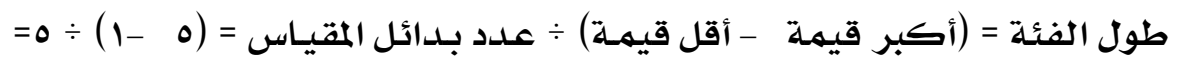

لنحصل على مدى المتوسطات التادية لكل وصف أو بـيلـ. جلول (^) يبين توزيع مدى المتوسطات وفق التدرج المستخلدم ف2 أداة البحث

\begin{tabular}{|c|c|}
\hline ملدى المتوسطات & الدرجت \\
\hline $0-\varepsilon, Y)$ & موافق جدًا \\
\hline$\left.\varepsilon, r_{*}-r, \varepsilon\right)$ & موافق \\
\hline$\left.r, \varepsilon_{+}-r, \pi\right)$ & محايد \\
\hline$r, 7 \cdot-1, \wedge 1$ & غير موافق \\
\hline $1, \Lambda_{*}-1, *$ & غير موافق جلًا \\
\hline
\end{tabular}

• الأساليب الإحصائية

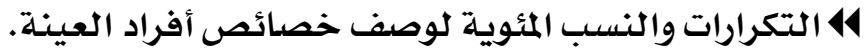

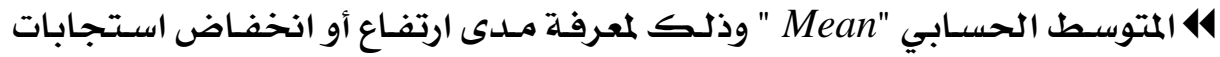

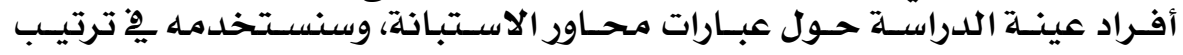

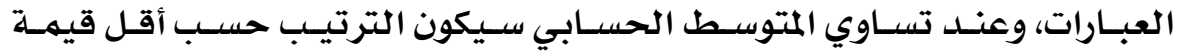

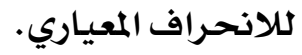

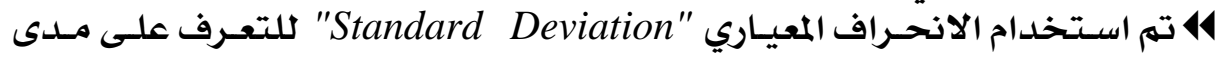

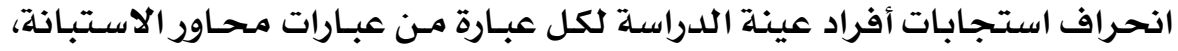

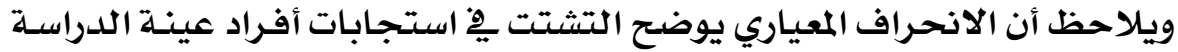

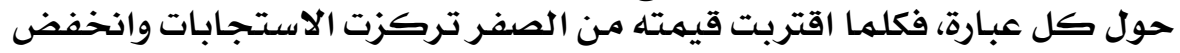
تشتتها بين المقياس.

\section{9.}




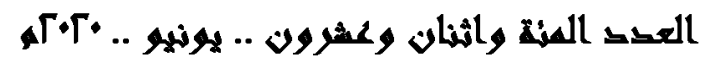

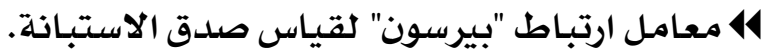

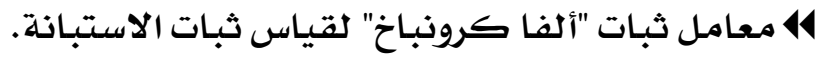

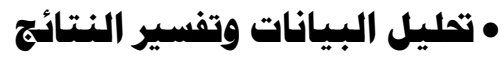

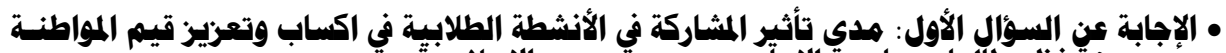

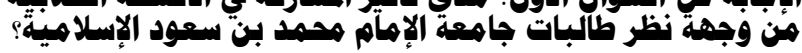

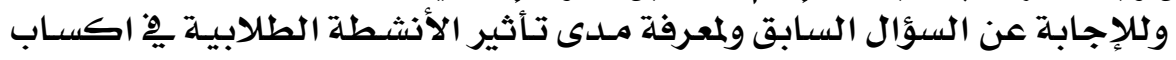

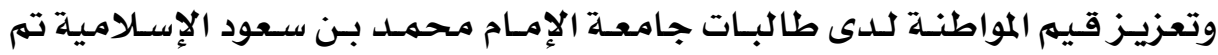

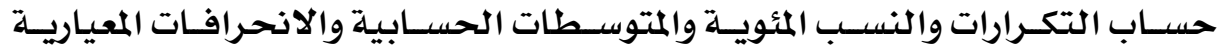

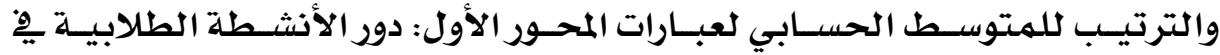

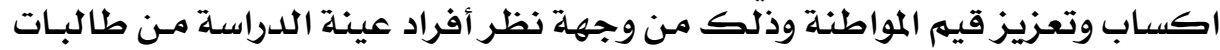

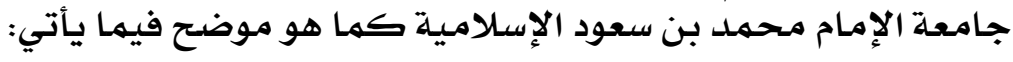

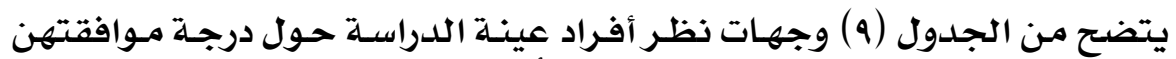

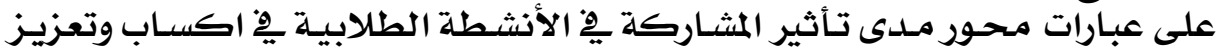

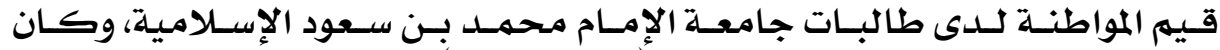

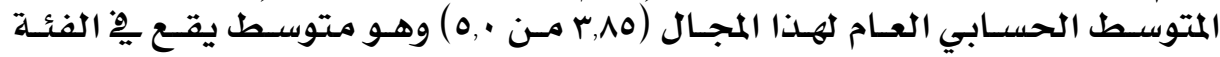

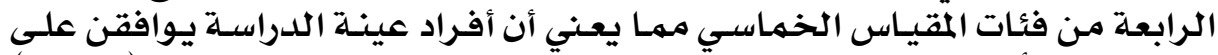

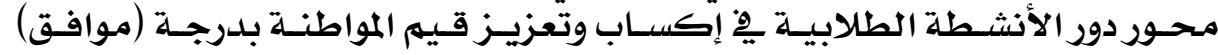

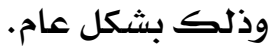

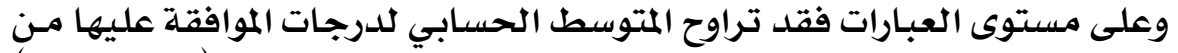

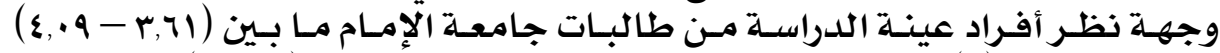

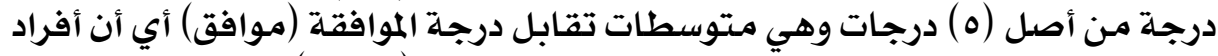

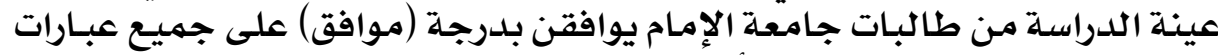

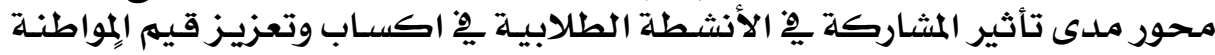

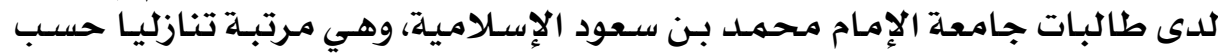

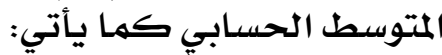

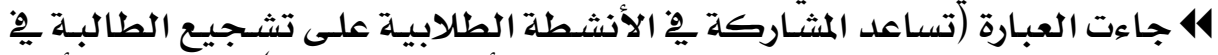

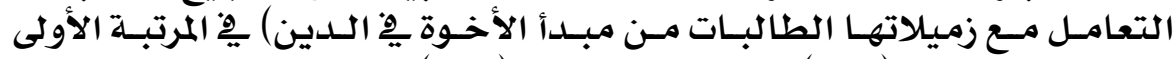

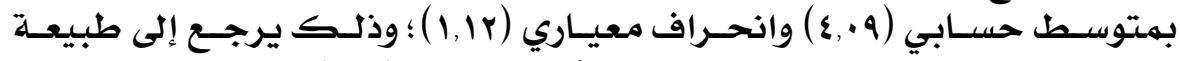

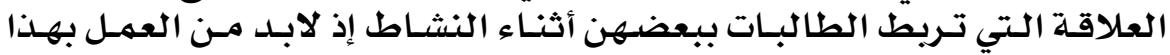

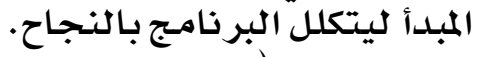

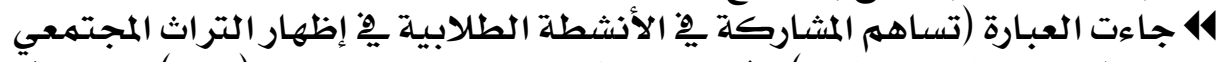

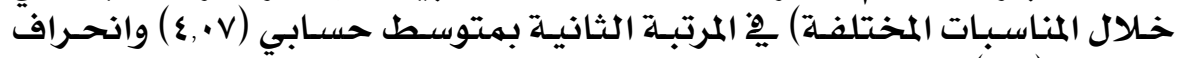

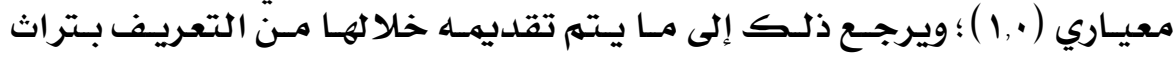

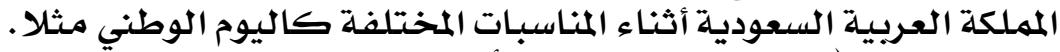

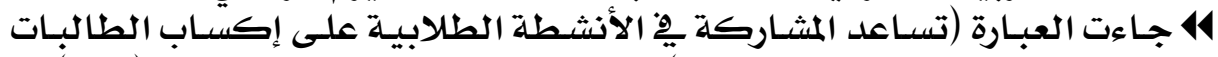

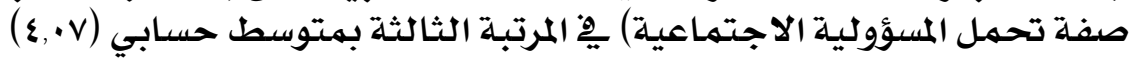

\section{1}




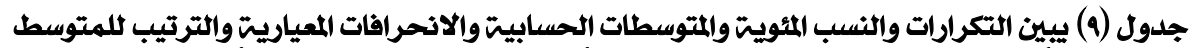

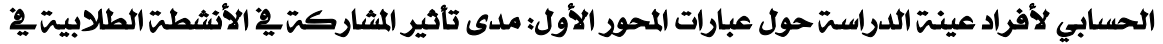
اكساب وتعزيز قيم المواطنت لدى طالبات جامعت الإلمام محمدل بن سعود الإسلاميت

\begin{tabular}{|c|c|c|c|c|c|c|c|c|c|c|}
\hline 高: & الانحراف & المتوسطابي & غير موافق & 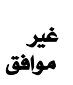 & محايد & موافق & موافق جداً & & العبارة & $p$ \\
\hline \multirow{2}{*}{ r. } & \multirow[b]{2}{*}{1,4} & \multirow[b]{2}{*}{$r, 71$} & 9 & ir & $r v$ & $\pi r$ & $m$ & | & \multirow{2}{*}{ 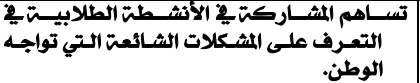 } & \multirow[b]{2}{*}{1} \\
\hline & & & $0,4 r$ & 1,00 & $r \varepsilon, r \varepsilon$ & $\varepsilon, V 4$ & r.,rq & $\%$ & & \\
\hline \multirow[b]{2}{*}{ M } & \multirow[b]{2}{*}{1,1} & \multirow[b]{2}{*}{$r, n$} & $v$ & 10 & $r r$ & 09 & rq & |ك & \multirow{2}{*}{ 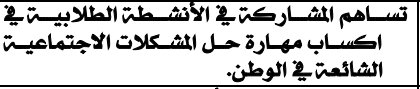 } & \multirow[b]{2}{*}{ r } \\
\hline & & & $\varepsilon, \pi$ & $9, \mathrm{AV}$ & $Y, 0$ & rA,AY & Yo,Tr & $\%$ & & \\
\hline \multirow{2}{*}{$\varepsilon$} & \multirow{2}{*}{1,4} & \multirow{2}{*}{$\varepsilon, \nabla$} & 7 & 9 & $r Y$ & 87 & 74 & ك & \multirow{2}{*}{ تسافم المشاركت الانتماء للوطن. الأثشطت الطلابيتش } & \multirow[b]{2}{*}{$r$} \\
\hline & & & $r, 90$ & $0,9 r$ & $1 \varepsilon, \varepsilon V$ & $r, r q$ & \&o,rq & $\%$ & & \\
\hline \multirow{2}{*}{ - } & \multirow{2}{*}{1,4} & \multirow{2}{*}{$r, 99$} & 1 & 9 & Y⿳ & $\varepsilon V$ & Tr & ك & \multirow{2}{*}{ 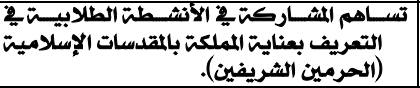 } & \multirow{2}{*}{$\varepsilon$} \\
\hline & & & $r .90$ & $0,9 Y$ & M,\&Y & $r \cdot, 9 r$ & $\varepsilon, V 9$ & $\%$ & & \\
\hline \multirow[b]{2}{*}{ in } & \multirow[b]{2}{*}{1,4} & \multirow[b]{2}{*}{ r,vr } & 7 & ir & 81 & $\varepsilon v$ & 87 & | & تســاهم المشــاركتّ & \\
\hline & & & $r, 90$ & $\vee, \wedge 9$ & ri,9V & r.qr & $r \cdot, r$ & $\%$ & المسلمين. & • \\
\hline$r$ & 1 & $\varepsilon \cdot V$ & $\bullet$ & $\varepsilon$ & rA & or & ir & ك & 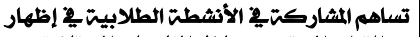 & 7 \\
\hline & 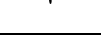 & 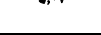 & $r, r q$ & r.tr & M,ZY & $r \xi, \wedge \vee$ & $\xi 0, \sqrt{4}$ & $\%$ & التراث المجتمعي خلال المناسبات المختلفتة. & \\
\hline & & & $\mathrm{v}$ & 1. & rq & 7. & rq & كt & 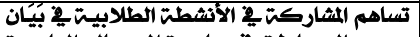 & \\
\hline 10 & 1,4 & r,vo & $\varepsilon, 71$ & 7,01 & rr,iu & ra,\&v & Yo,Tr & $\%$ & 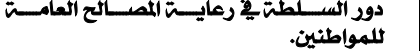 & $\mathbf{v}$ \\
\hline & & & 9 & $\Lambda$ & rq & 07 & $\varepsilon r$ & كt & تساهم المشاركتَ & \\
\hline $1 \varepsilon$ & 1,1 & r.vi & $0, a r$ & $0, \mathrm{ry}$ & $\mathrm{rr}, \mathrm{u}$ & $\mathbf{r q , \Lambda \varepsilon}$ & YA,Yq & $\%$ & حفظ النظام. الاجتماعيـت السـليمت الباعثـت على & $\wedge$ \\
\hline & & & $\Lambda$ & ir & $r r$ & 09 & 0. & | & تساهم المشاركت بِ الأثشطت الطلابيتة & \\
\hline 9 & $1,1 \%$ & r,Aт & $0, \mathrm{YI}$ & $v, \wedge 9$ & $10,1 \%$ & rA,AY & rY,A9 & $\%$ & الاجتماعي. & 9 \\
\hline & & & 7 & 11 & $r$ & $\varepsilon 1$ & V乏 & كإ & 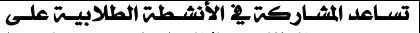 & \\
\hline 1 & זו, & 2,4 & r.90 & V,Y\& & 17,17 & ru,qv & $\varepsilon \wedge, \Psi \Lambda$ & $\%$ & 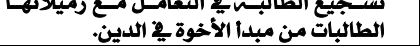 & 1* \\
\hline 11 & 1,10 & r.vo & $\Lambda$ & IV & ro & or & \$o & كأك & تساعد المشاركتي يُ الأثشطت الطلابيت على ربط & (1) \\
\hline 11 & 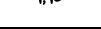 & $1,1,0$ & $0, \mathrm{rT}$ & $11,1 \mathrm{M}$ & 17,80 & $r v, 0$ & $Y 9,71$ & $\%$ & الطالبات بقضايا المجتمع السعودي. & 11 \\
\hline & & & 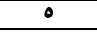 & 9 & $\varepsilon r$ & \$0 & 01 & | & 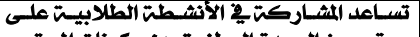 & \\
\hline 1. & 1,4 & $\boldsymbol{r}, \mathbf{\wedge \varepsilon}$ & r,Yq & $0,9 r$ & $r V, T r$ & $r 9,71$ & rr,oo & $\%$ & ترسيخ الوحدة الوطنيتَ بين مكونات المجتمـع & ir \\
\hline Ir & UV & rva & $\mathrm{v}$ & 17 & $r \varepsilon$ & $\varepsilon Y$ & or & | & تساعد المشاركت كِّ الأثشطت الطلابيت على تغيير & re \\
\hline & & & $\varepsilon, \pi$ & 1,.0r & rr,rr & rV ז & $\boldsymbol{r}, \wedge \boldsymbol{\Lambda}$ & $\%$ & العادات الاجتماعيت السلبيت مِ المجتمع. & \\
\hline 19 & IV & r & 1. & 17 & $r \varepsilon$ & or & $\varepsilon+$ & | t & 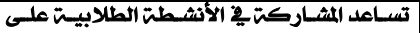 & $1 \varepsilon$ \\
\hline & & $1, \pi$ & $7,0 \Lambda$ & 1.,or & YY,YV & $r \varepsilon, Y$ & rT,rY & $\%$ & ضرورة المحافظت على ثروات الوطن. & 16 \\
\hline & & & 9 & 9 & $r r$ & 09 & or & | & تساعد المشاركت بِ الأنشطت الطلابيت على رفع & \\
\hline$v$ & $1,1 \%$ & $r, \Lambda 9$ & $0,4 r$ & 0,9 r & $10,1 \%$ & rA,AY & $r \varepsilon, r$ & $\%$ & العامتترى الومي بضرورة الحفاظ على الممتلكات & 10 \\
\hline "I & 1.9 & $\mathrm{ru}$ & $\Lambda$ & 9 & $r r$ & or & \&o & | إك & 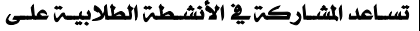 & 77 \\
\hline$\pi$ & 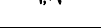 & ה & $0, \mathrm{rY}$ & $0,9 \mathrm{r}$ & $\mathrm{YI}, \mathrm{V}$ & $r v, 0$ & $Y 9,71$ & $\%$ & تنميت التوازن بين حقوق الفرد وواجباته. & 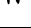 \\
\hline & & & $\varepsilon$ & IV & ra & $\varepsilon 1$ & $\varepsilon 1$ & | & تساعد المشاركتي ف الأثشطت الطلابيت على إبراز & \\
\hline iv & 1,4 & r,ve & r.tr & $11,1 \mathrm{M}$ & Yo,tr & $r \cdot, r$ & r.,r & $\%$ & 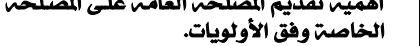 & iv \\
\hline & & & $\Lambda$ & 0 & 10 & $7 \varepsilon$ & 7. & | & 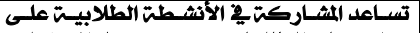 & \\
\hline$r$ & 1,0 & $\varepsilon, \vee$ & $0, Y Y$ & r.rq & ৭,Av & $\varepsilon r, 11$ & $\mathrm{rq,2V}$ & $\%$ & 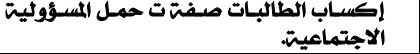 & M \\
\hline & & & 1. & ir & YI & or & ov & كt & 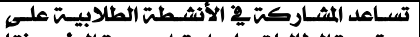 & \\
\hline$\wedge$ & 1,19 & $\mathrm{r}, \mathrm{\Lambda \Lambda}$ & 7,01 & $v, \wedge 9$ & $\mathbf{I r}, \wedge \mathrm{r}$ & $r \&, r$ & $\mathrm{rV}, 0$ & $\%$ & ترآديتيت الطالبالبات على احترام حريت الرأي وفقا & 19 \\
\hline 7 & III & ras & $\mathrm{v}$ & II & $\mathrm{rA}$ & or & of & St & تسـاعد المشـاركتـــ الأثــطت الطلابيـت على & y. \\
\hline 1 & 1,11 & T,Aד & $\varepsilon, \pi$ & V,r\& & M,\&Y & $r \varepsilon, r$ & ro,or & $\%$ & غرس قيم التسامح وقبول الآخر. & $r$ \\
\hline & $1,1$. & r,^o & & & & & 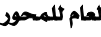 & & المتو & \\
\hline
\end{tabular}




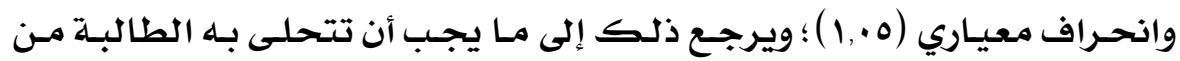

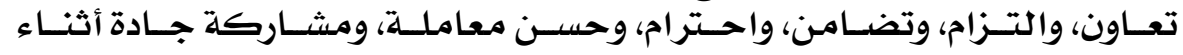

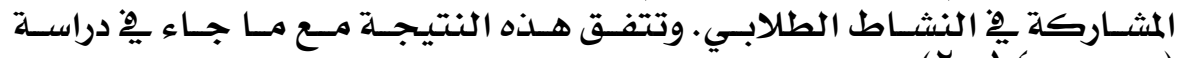
(المصري،

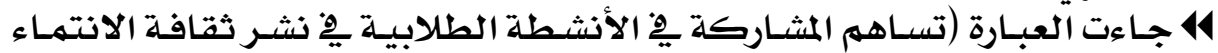

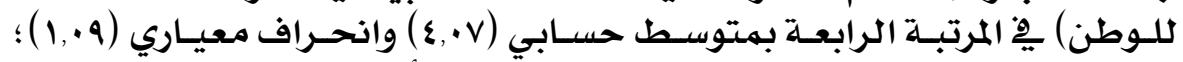

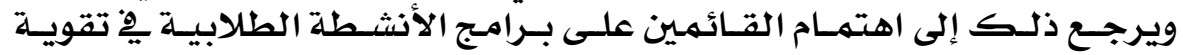

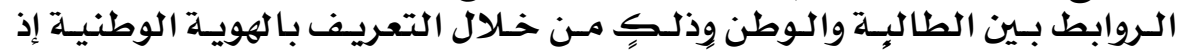

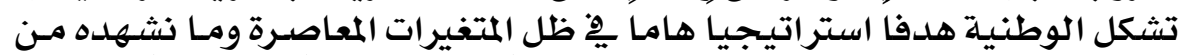

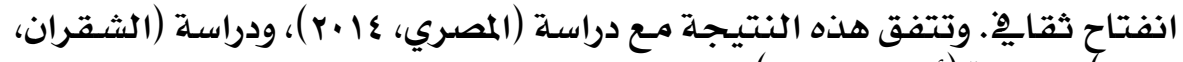

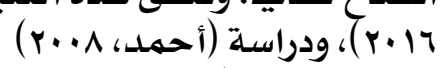

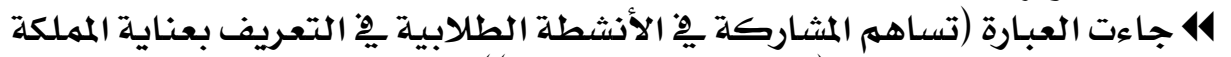

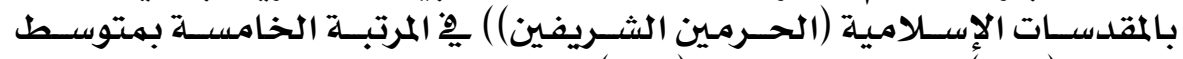

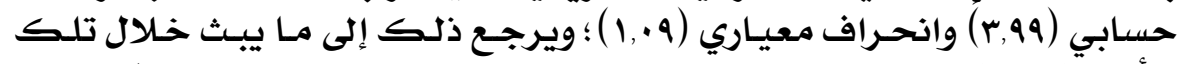

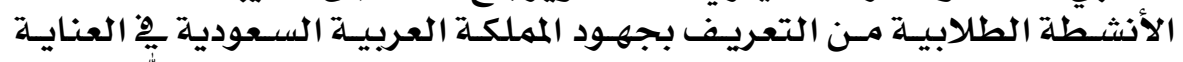

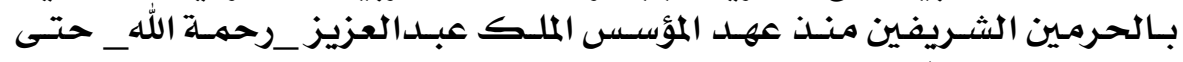

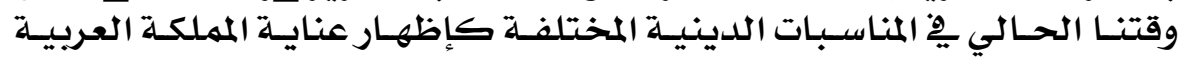

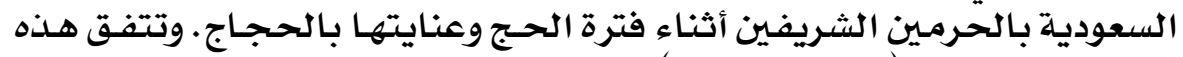

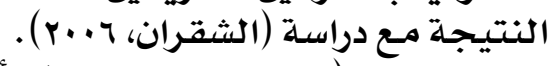

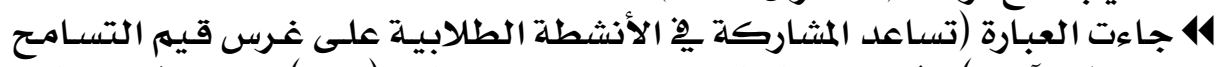

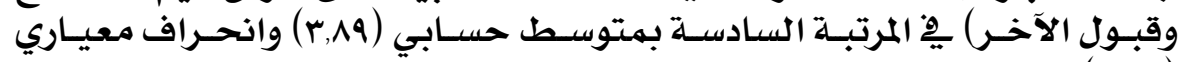

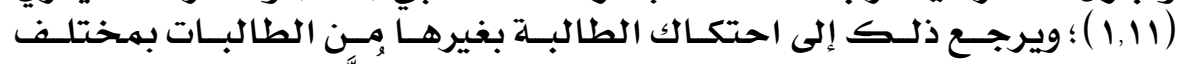

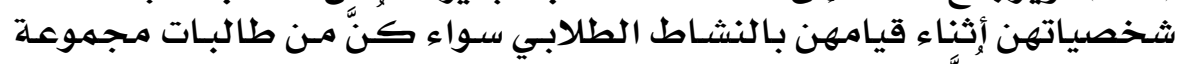

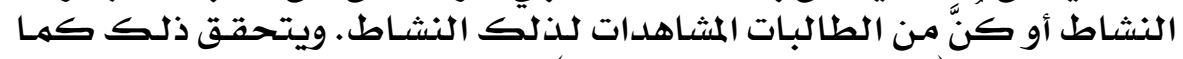

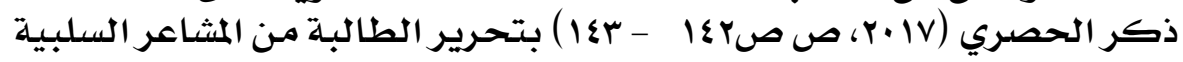

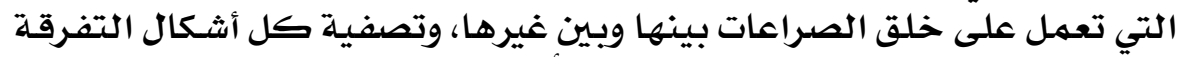

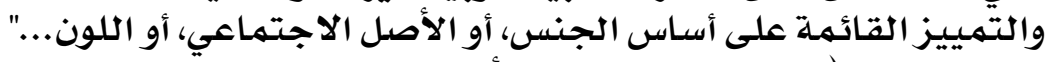

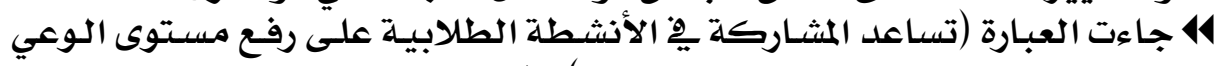

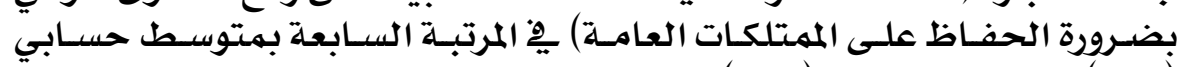

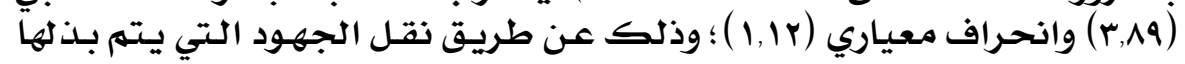

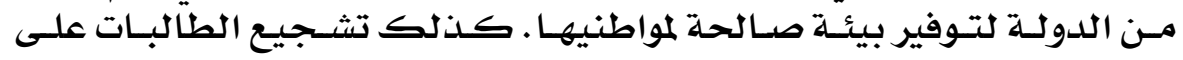

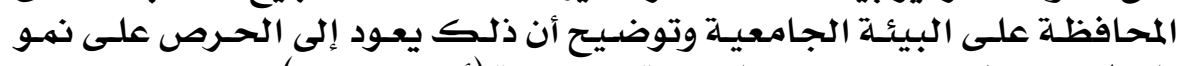

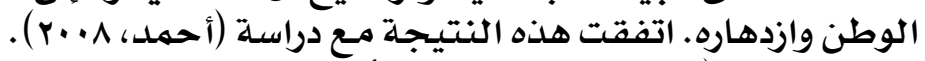

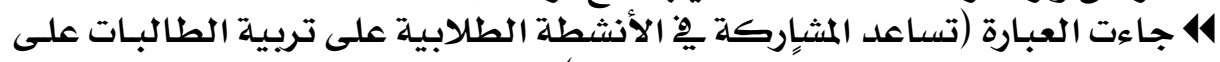

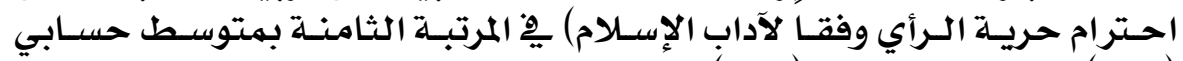

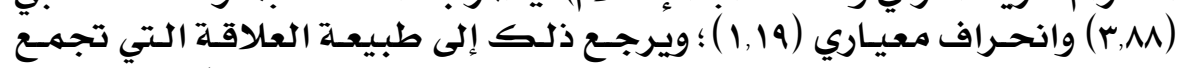

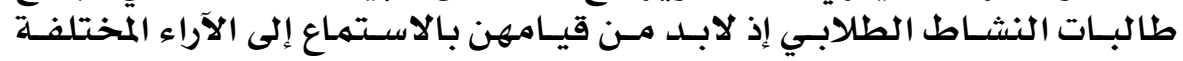

\section{4}




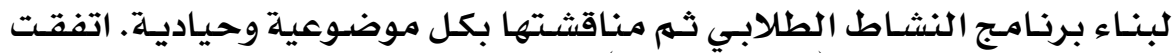

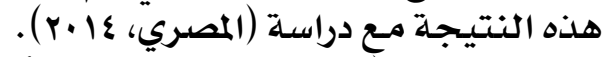

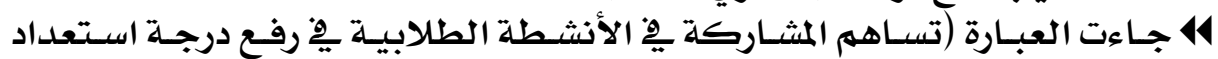

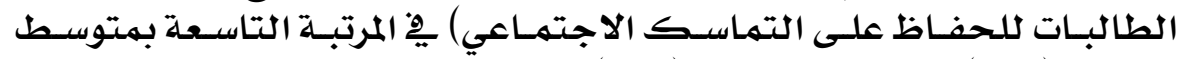

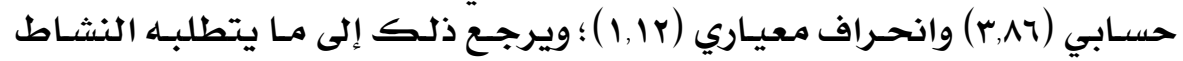

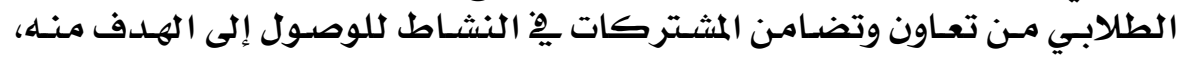

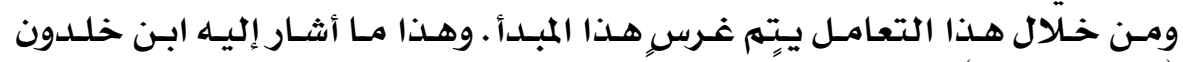

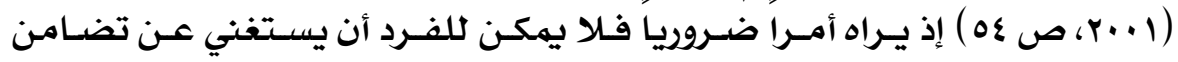

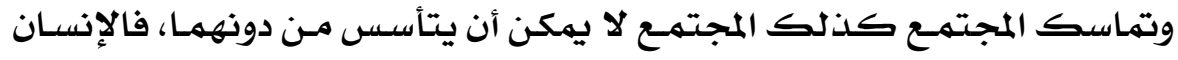

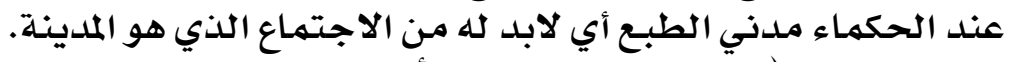

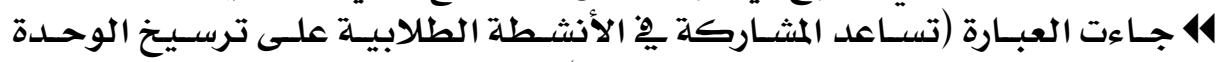

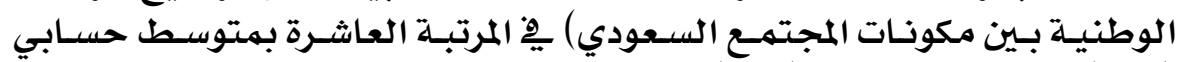

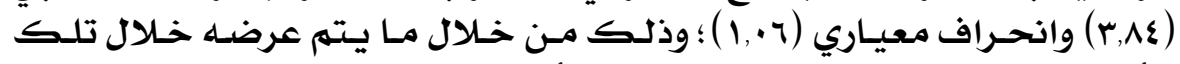

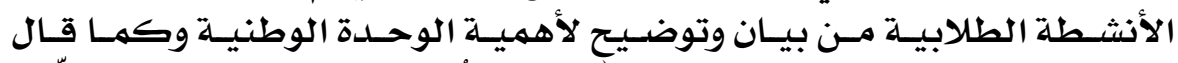

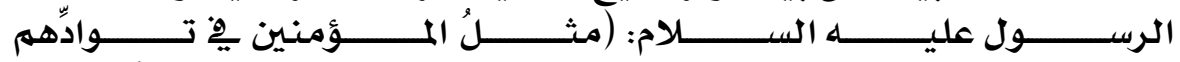

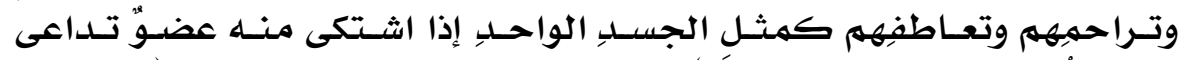

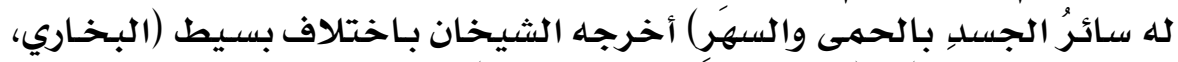

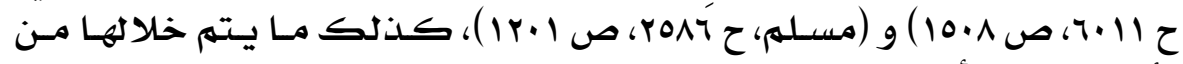

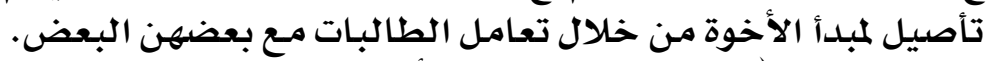

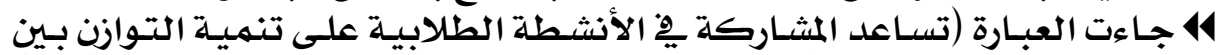

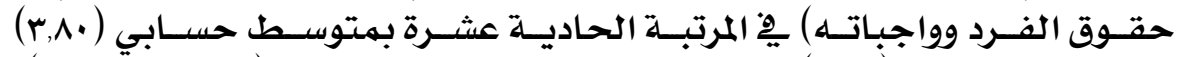

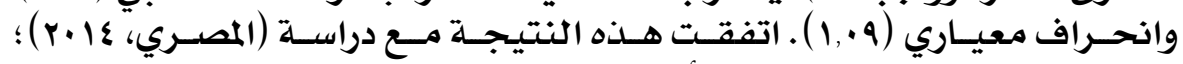

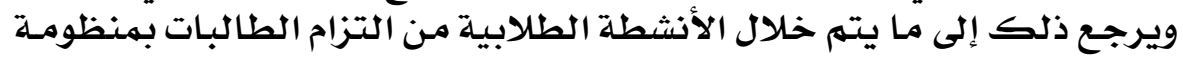

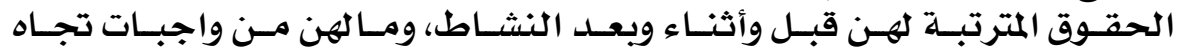

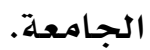

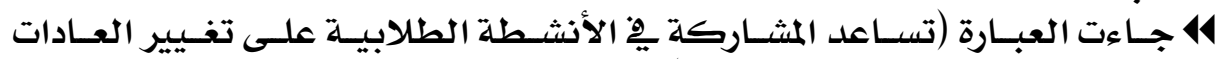

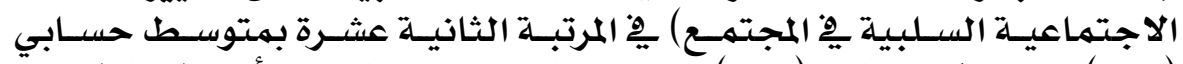
(r,VN)

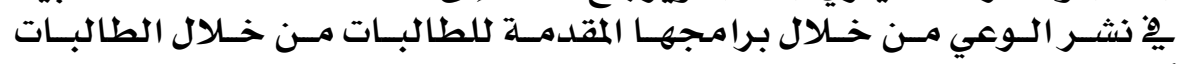

أنفسهن.

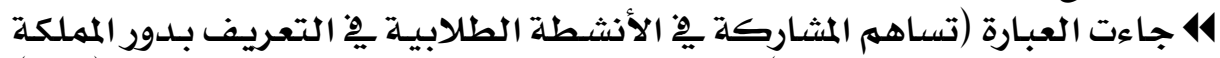

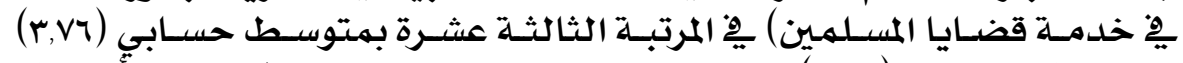

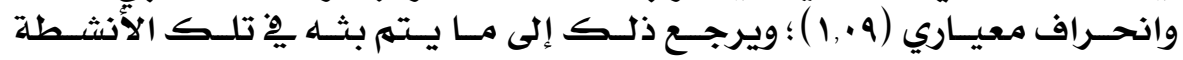

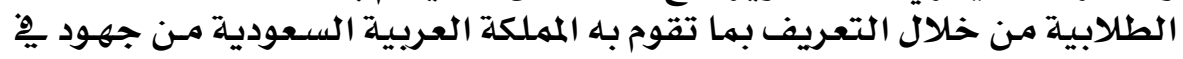

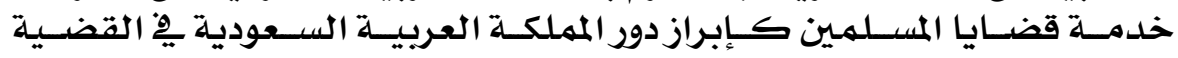

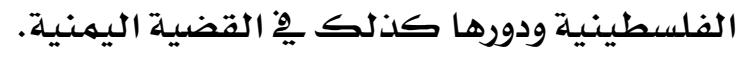

\section{$9 \varepsilon$}




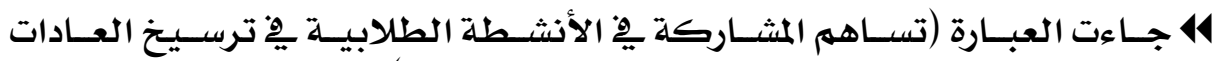

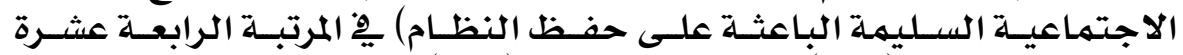

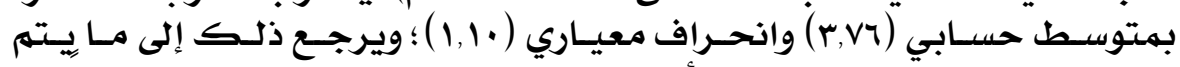

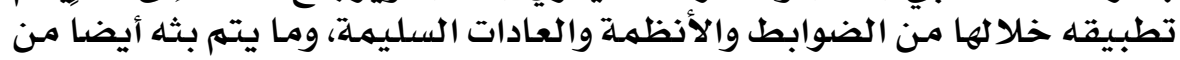

خلا لها . تصله

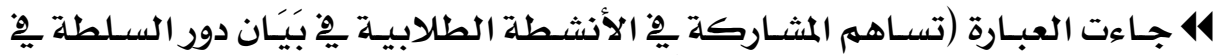

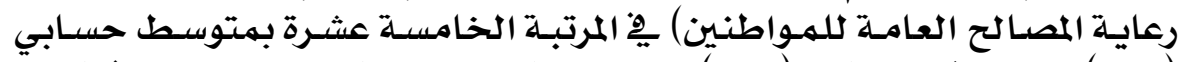

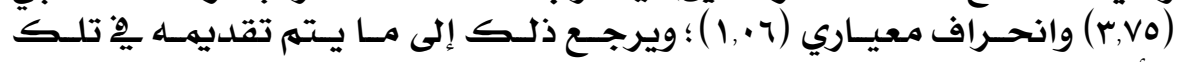

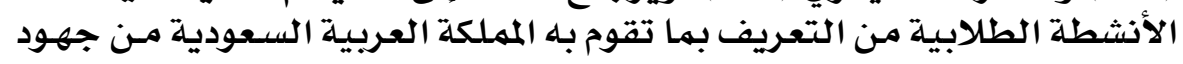

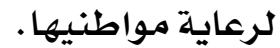

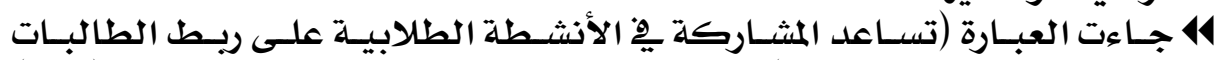

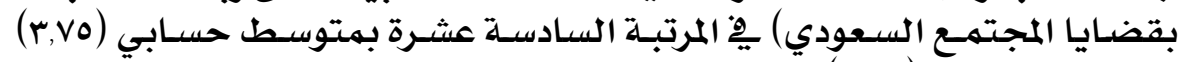

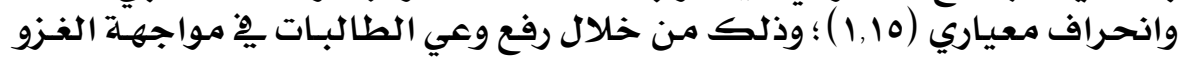

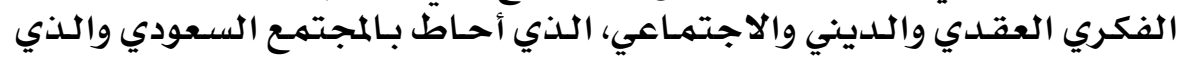

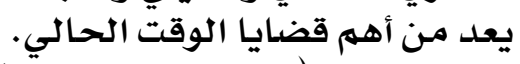

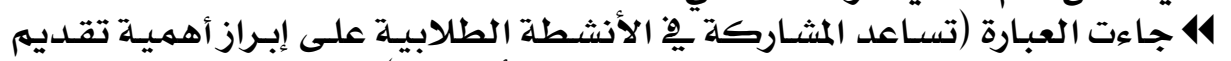

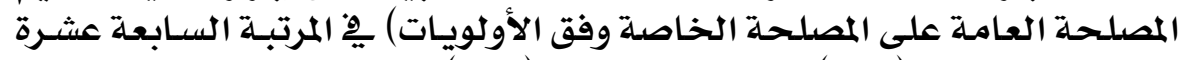

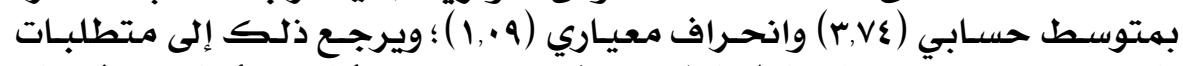

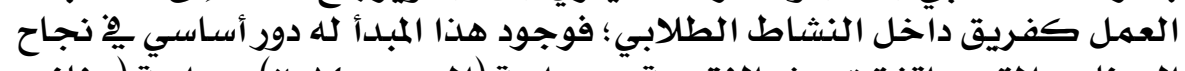

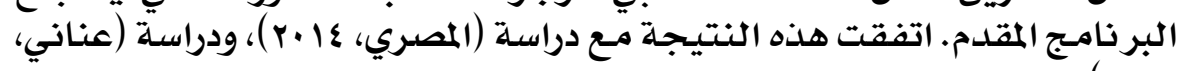
(r...人

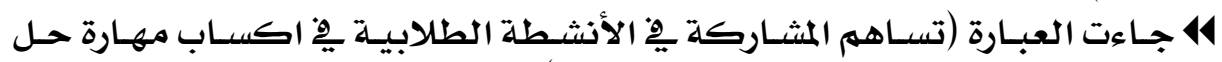

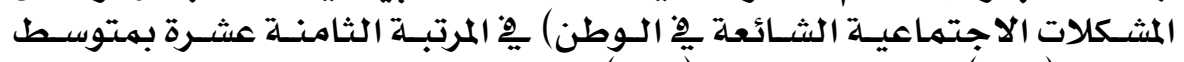

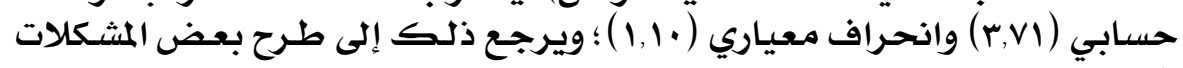

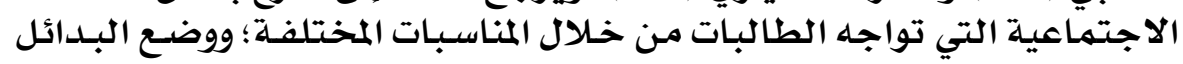

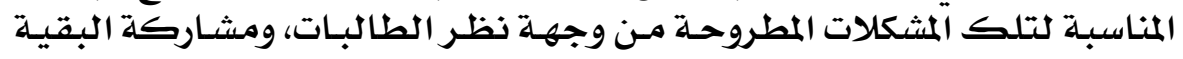

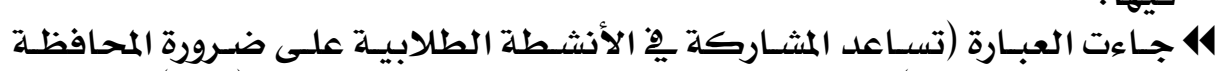

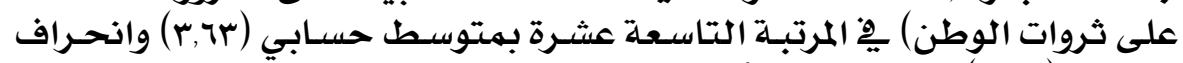

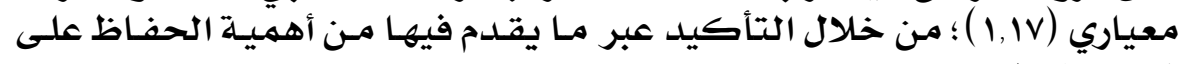

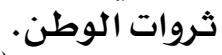

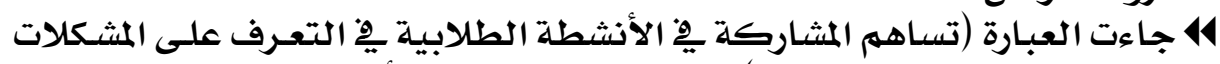

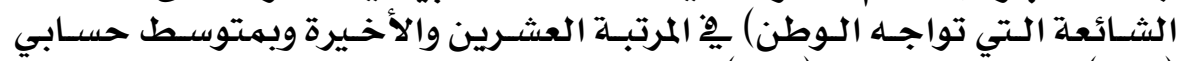

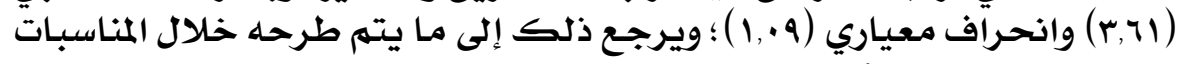

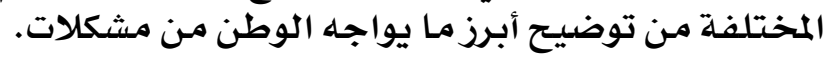

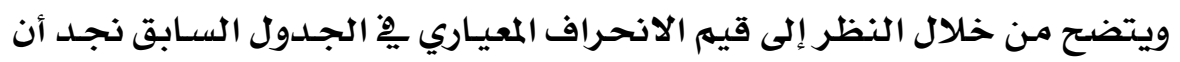

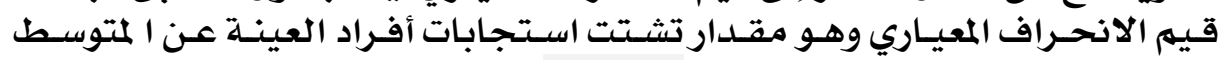

\section{$9 \theta$}




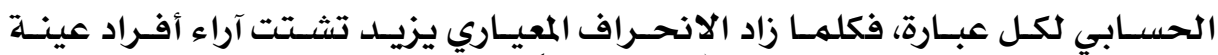

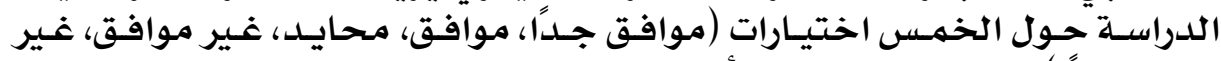

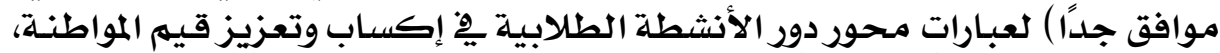

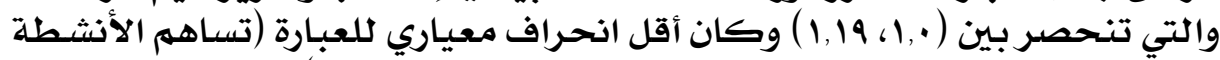

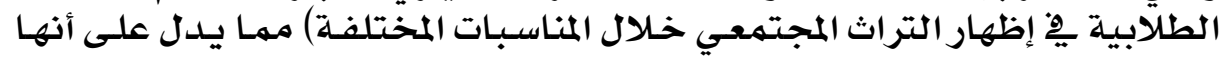

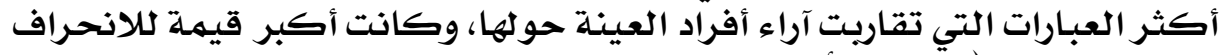

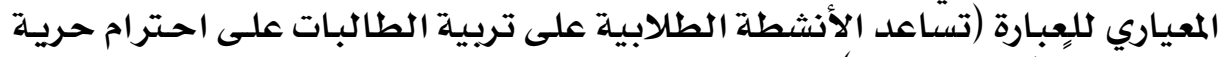

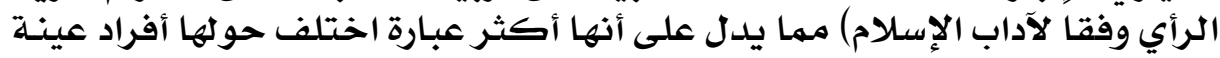
الدراسية.

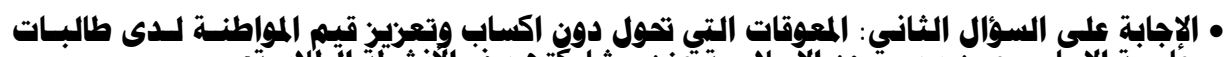

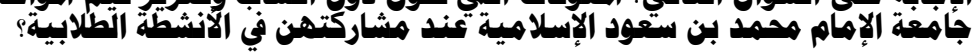

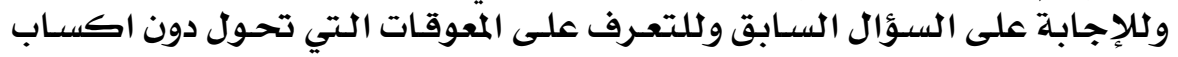

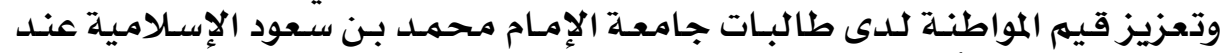

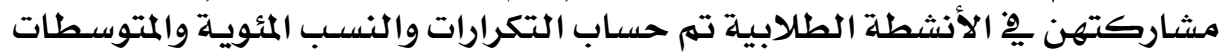

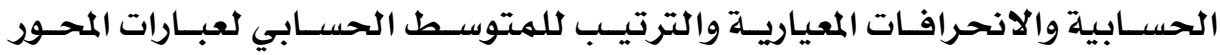

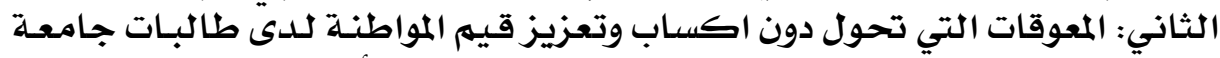

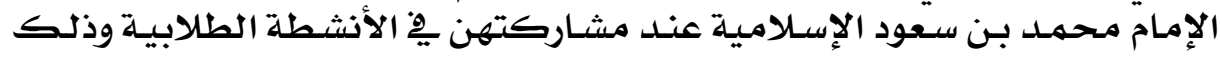

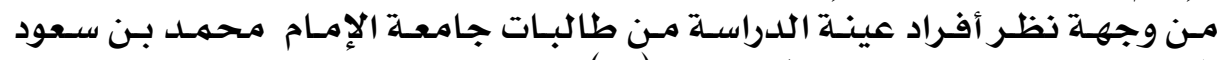

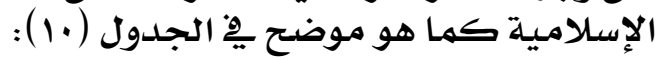

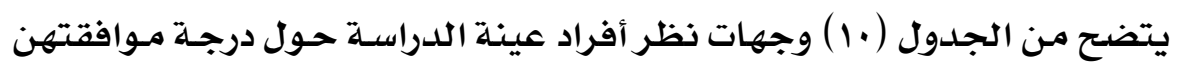

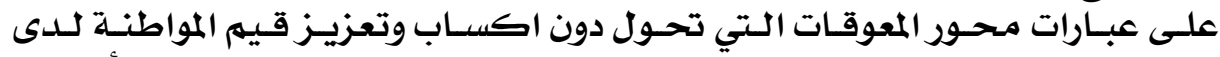

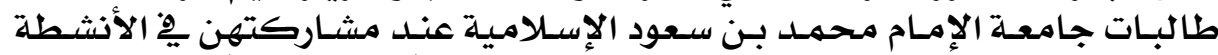

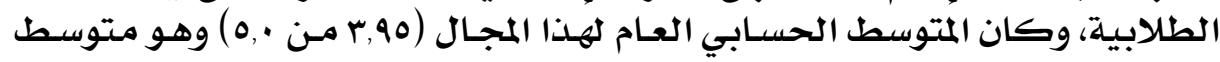

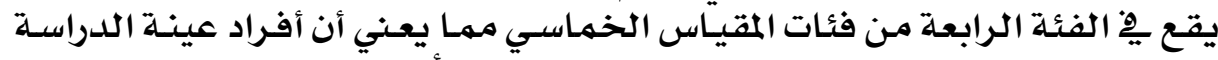

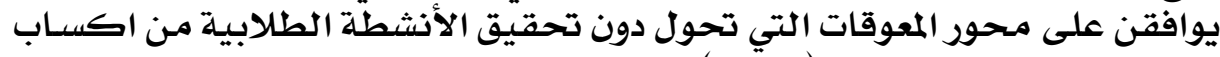

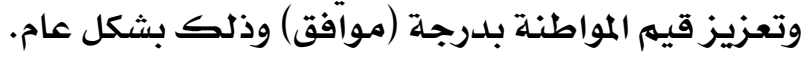

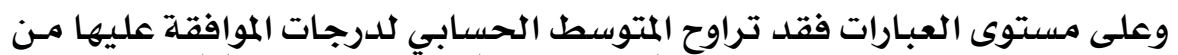

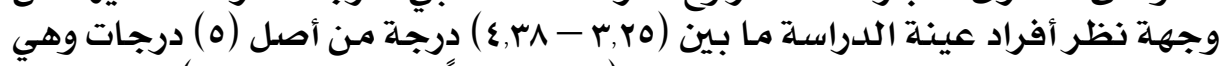

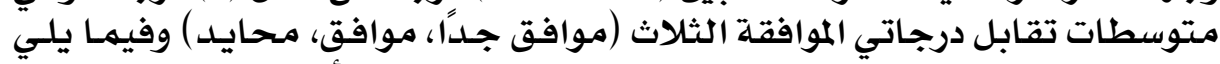

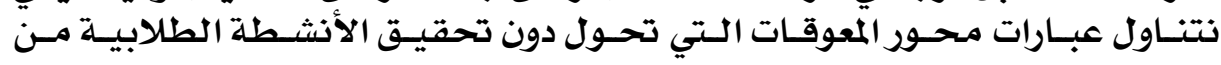

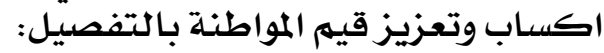

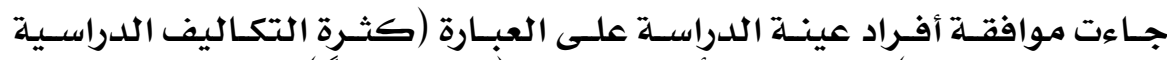

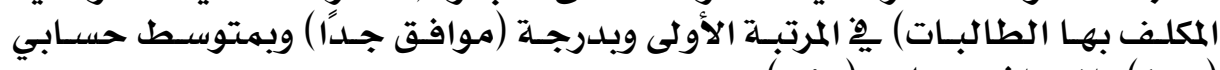

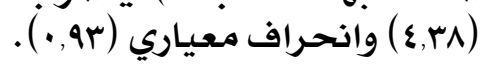

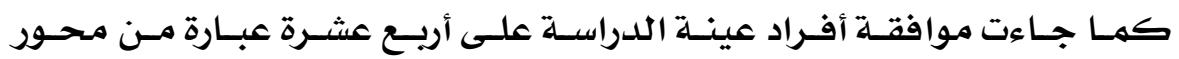

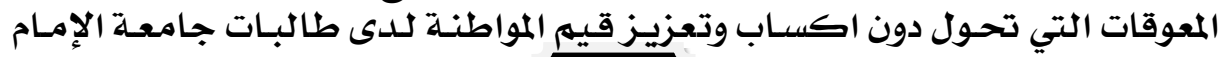

\section{7}




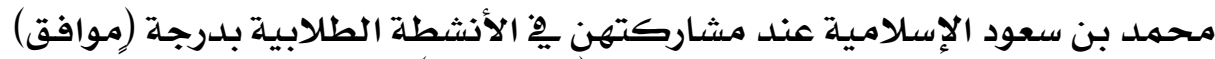

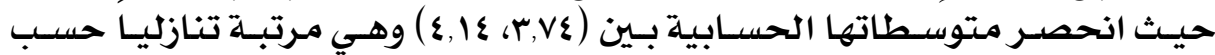
المتوسط الحسبابي كمها يأتي:

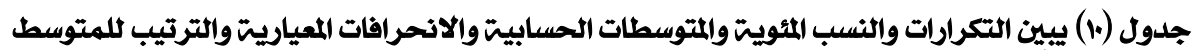

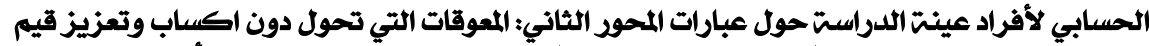

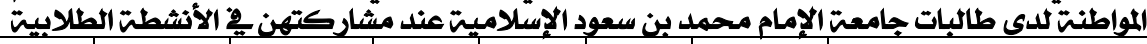

\begin{tabular}{|c|c|c|c|c|c|c|c|c|c|c|}
\hline 诵: & الانحراف & المتوسطابي & غير موافق جلًا & فير موافق & 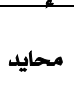 & 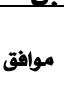 & \multicolumn{2}{|c|}{ موافق جدًا } & 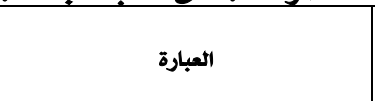 & p \\
\hline \multicolumn{11}{|c|}{ المجال الأول: المعوقات المرتبطت بالناحيت الماديت } \\
\hline \multirow{2}{*}{$1 \varepsilon$} & \multirow{2}{*}{ I,YY } & \multirow{2}{*}{$r, v r$} & 11 & ir & $m$ & \$o & or & ك & \multirow{2}{*}{ 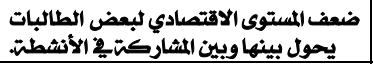 } & \multirow{2}{*}{1} \\
\hline & & & $V, Y \varepsilon$ & $\mathrm{V}, \wedge 9$ & $r, r q$ & $r 9,71$ & $r \varepsilon, \wedge v$ & $\%$ & & \\
\hline \multirow{3}{*}{9} & \multirow{2}{*}{1,4} & \multirow{2}{*}{$\varepsilon, 4$} & 0 & $\Lambda$ & $m$ & \&o & $\pi$ & كـ & \multirow{3}{*}{ 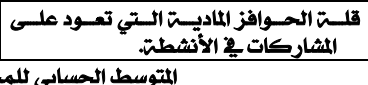 } & \multirow{2}{*}{ Y } \\
\hline & & & $r, r q$ & $0, Y M$ & $r \cdot r q$ & $r 9,71$ & $\varepsilon 1, \varepsilon 0$ & $\%$ & & \\
\hline & $1,1 \varepsilon$ & $r, \wedge 9$ & \multicolumn{7}{|c|}{ المتوسط الحسابي للمجال الأول: المعوقات المرتبطت بالناحيت الماديت } & \\
\hline \multicolumn{11}{|c|}{ المجال الثاني: المعوقات المرتبطت بالطالب } \\
\hline \multirow{2}{*}{9} & \multirow{2}{*}{; 97} & \multirow{2}{*}{$\varepsilon, 4$} & $r$ & 7 & rv & $\xi \mathrm{V}$ & 7. & كـ & \multirow{2}{*}{ 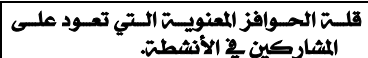 } & \multirow{2}{*}{$r$} \\
\hline & & & I,rY & r,90 & Y\&,Y\& & r:ar & ra,zv & $\%$ & & \\
\hline \multirow{2}{*}{ r } & \multirow{2}{*}{1} & \multirow{2}{*}{$\varepsilon, 1 \varepsilon$} & $r$ & 11 & 17 & of & $u$ & كـ & \multirow{2}{*}{ 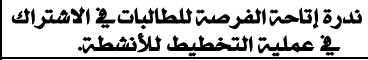 } & 4 \\
\hline & & & $1,9 \mathrm{~V}$ & $V, Y \varepsilon$ & 1,0r & ro,or & $\varepsilon \varepsilon, \mathrm{V} \varepsilon$ & $\%$ & & 2 \\
\hline & & & ir & ry & ra & \&. & YA & كـ & تدني التحصيل الدراسي بسبب المشاركتة & \\
\hline 17 & l, Yr & r,Yo & A,00 & $\mathrm{rl}, 0$ & Yo,Tr & rr,rY & $\mathrm{M},\{\mathrm{r}$ & $\%$ & مِّة الأثشطتّ. & 0 \\
\hline$x$ & 18 & \& & $r$ & ir & ry & $\varepsilon \wedge$ & Tr & ك & | ضعف تلبيـت الأثشطت لرغبـات الطالبـات & 7 \\
\hline $\mathrm{v}$ & 1,28 & 2,4 & $1,9 \mathrm{~V}$ & $V, \wedge 9$ & $\mid V, I I$ & $\mathrm{mi}, 01$ & $\{1,\{0$ & $\%$ & وحاجاتهن. & 1 \\
\hline Ir & & & 1 & r. & $r$. & $r v$ & \$9 & كـ & تؤثر ممارست الأثشطت على وقت الراحتة & y \\
\hline$\pi$ & $T, Y$ & $\mathbf{P}, \mathbf{\Lambda} \mathbf{I}$ & $r, 90$ & Ir, & 19,V乏 & $Y \xi, Y \xi$ & rA,AY & $\%$ & المخصص للطالبات. & $v$ \\
\hline$\hat{A}$ & 10 & $4, Y$ & 0 & 9 & ro & or & $\pi$ & ك & قلت معرفت الطالبات باهميت الأثشطت ف2 & 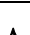 \\
\hline$n$ & 1,0 & $2,+1$ & $r, r q$ & $0,4 r$ & 17,20 & $r \varepsilon, Y)$ & $\varepsilon \cdot, 1 \pi$ & $\%$ & بناء شخصياتهن. & $n$ \\
\hline & & & $\varepsilon$ & 1. & M & $\Delta 0$ & $\pi r$ & ك & الشــعور بالخجـل يمنــع الطالبــات مــن & \\
\hline$\varepsilon$ & $1, Y$ & $\{, 4$ & $r$ & 7,01 & Ir,AY & $\mathrm{rr,H}$ & $\varepsilon, v 9$ & $\%$ & المشاركت فِ الأنشطت. & 4 \\
\hline & $1, v$ & $r, 91$ & & & ت بالطالب & 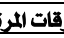 & 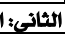 & مجار & المتوسط الحسابى & \\
\hline & & & & ج الدراسيت & تيطت بالمز & : المعوقاث : & 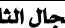 & & & \\
\hline & & & $\varepsilon$ & $r$ & $1 \varepsilon$ & $\varepsilon r$ & А9 & ك & كثـرة التكـاليف الدراسـيت المكلـف بهـا & \\
\hline 1 & ra & $\varepsilon, \mathrm{rA}$ & r, r r & $1,9 \mathrm{~V}$ & $9, \mathrm{rI}$ & $r v, T r$ & $0 \wedge, 00$ & $\%$ & الطالبات. " م " & 1. \\
\hline is & IV & raq & $\checkmark$ & ir & $r$ & m & IV & كـ & ضــــف ارتبـــاط الأثشــــة بــالمتررات & il \\
\hline$\pi$ & liv & r,90 & $\{, \pi$ & $V, \wedge 9$ & 19,V乏 & rr,u & $\{\varepsilon, \wedge$ & $\%$ & الدراسيت. & 11 \\
\hline & & & 1. & $\Lambda$ & $r r$ & $r \varepsilon$ & wV & ك & |عدم احتساب أداء الطالباتِ إلأثططت عند & Ir \\
\hline 0 & $1, Y I$ & $\varepsilon, 0$ & 7,01 & $0, Y Y$ & $10,1 \%$ & rY,rV & 0,14 & $\%$ & التقويم النهائى للتحصيل الدراسي. & ir \\
\hline & $1,1$. & $\varepsilon, 1 \%$ & & & اهـج الدرا & المرتبطة & ث: المعوة & إل الثا & المتوسط الحسابى للمج & \\
\hline & & & & لاثراف & المرتيطت & 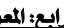 & المحاJ & & & \\
\hline I! & 1.4 & 90 & 0 & 9 & rq & o0 & of & ك & نقص المتخصصات_ِ عمليتالإشراف على & r \\
\hline 11 & 1,8 & 90 & $r, r q$ & $0,9 Y$ & $19, \wedge$ & $\mathrm{rq,in}$ & ro,or & $\%$ & الأثشطت. & $\pi$ \\
\hline 1. & 1.4 & ra & $r$ & IV & IV & $0 \wedge$ & ov & ك & 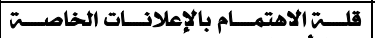 & 18 \\
\hline 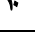 & $1,+4$ & $r, 91$ & $1,9 \mathrm{~V}$ & 11,14 & 11,14 & rA,17 & $r V, 0$ & $\%$ & |بالأشطت. & 18 \\
\hline 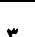 & I\& & 80 & 0 & 10 & iv & \&1 & V乏 & ك & قلت الإمكانات المتوفرة يِ الجامعت (اماكن & D \\
\hline$r$ & 1,12 & $2, \lambda$ & r,rq & $9,1 \mathrm{~V}$ & 11,14 & ri, $9 \mathrm{~V}$ & $\varepsilon \wedge, \eta$ & $\%$ & للنشاط، أجهزة، خامات، ورش). ل ل & \\
\hline 10 & IU & rys & 0 & ir & $\varepsilon 9$ & $r \varepsilon$ & o1 & ك & | ضعف المروختحِِ التعامـل عنـد مُشـرفات & 17 \\
\hline 10 & $1, n$ & $r, \sqrt{2}$ & $r, r_{9}$ & 1,00 & rY,YE & rY,rV & $r r, 00$ & $\%$ & النشاط. & \\
\hline & 1,9 & $r, q \varepsilon$ & & & بالإثراف & 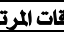 & 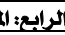 & 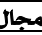 & المتوسط الحسابي ثلا & \\
\hline & 1,4 & r,90 & & & & هور & كالعام لI & تلوسي & & \\
\hline
\end{tabular}

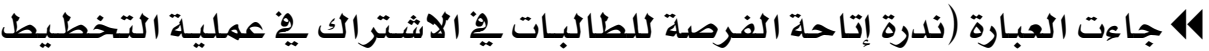

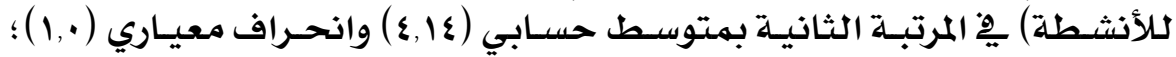

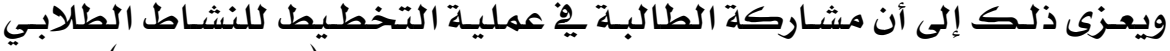

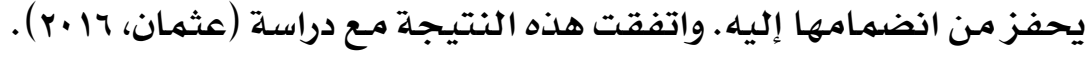

\section{$9 \mathrm{~V}$}




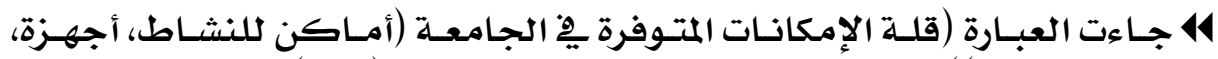

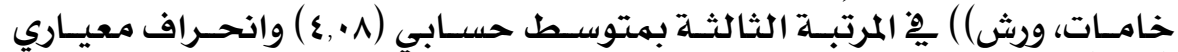

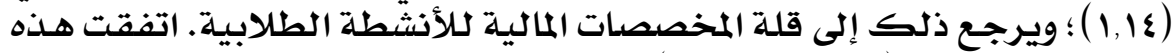

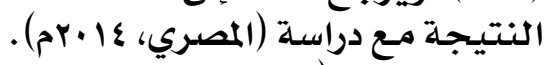

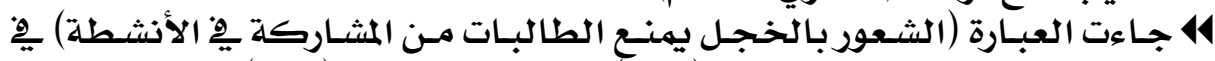

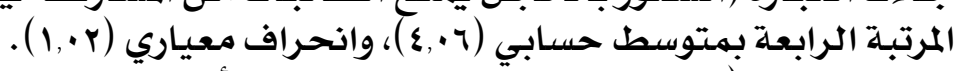

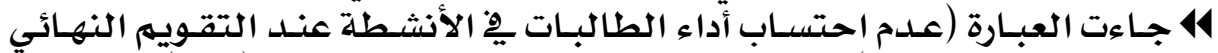

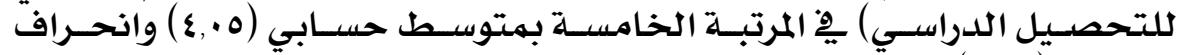

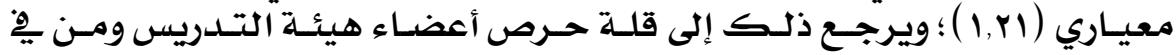

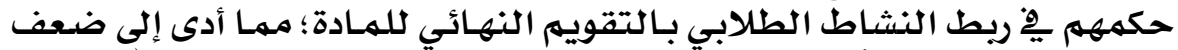

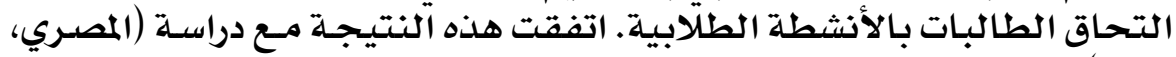

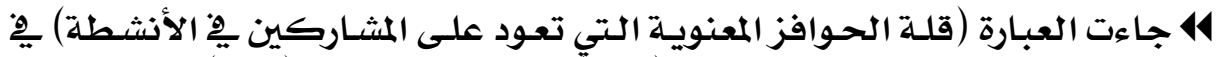

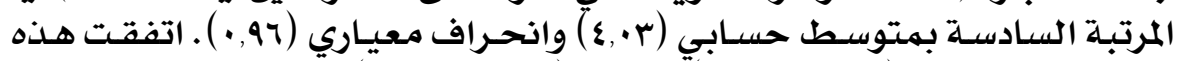

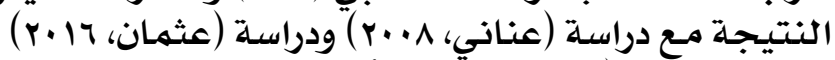

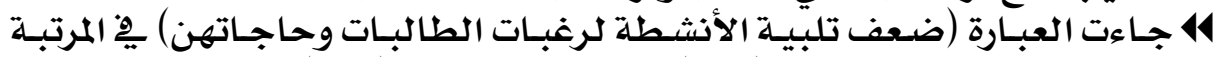

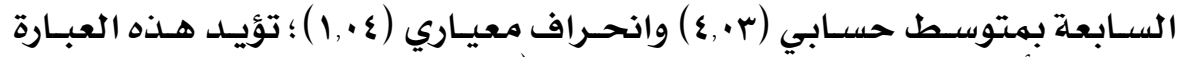

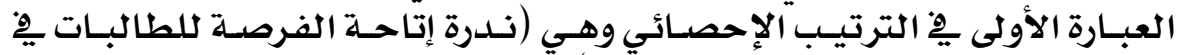

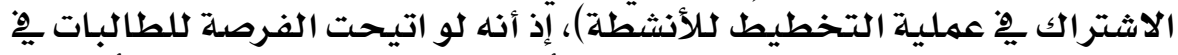

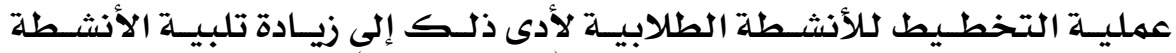

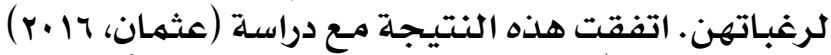

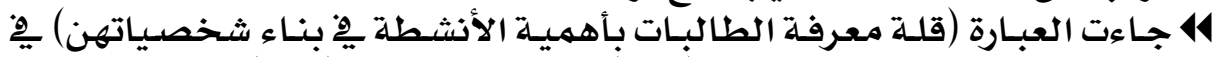

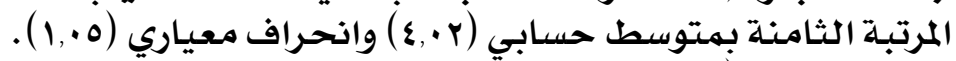

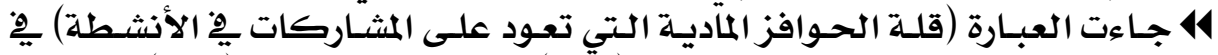

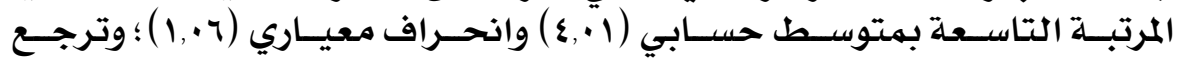

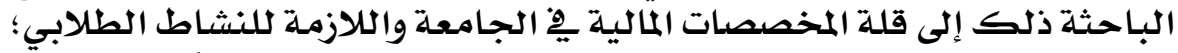

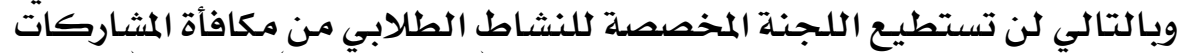

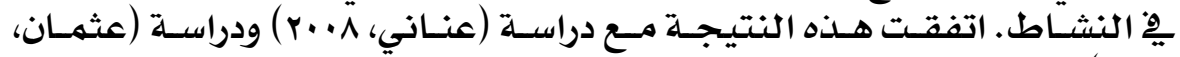

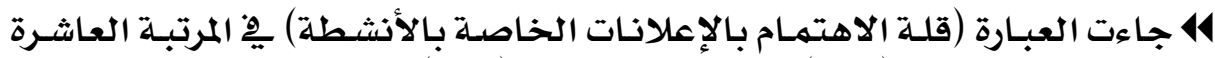

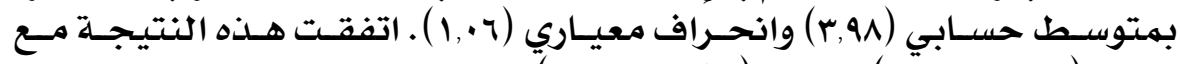

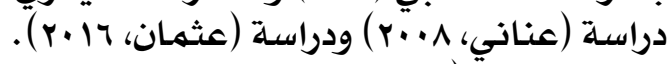

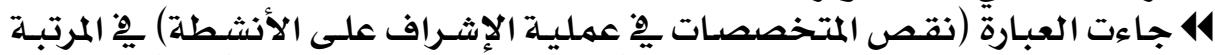

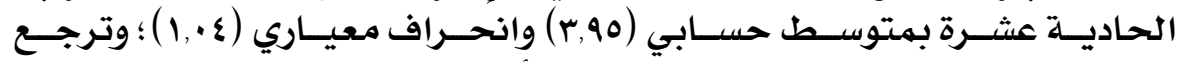

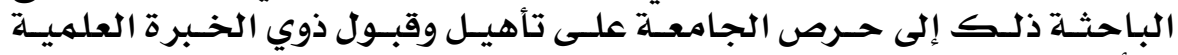

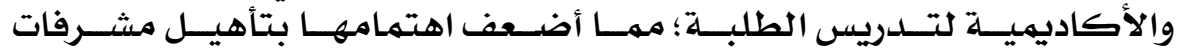

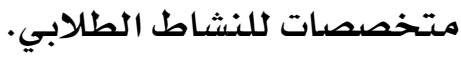

\section{1}




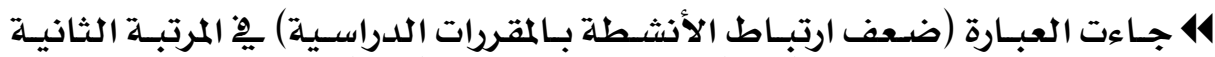

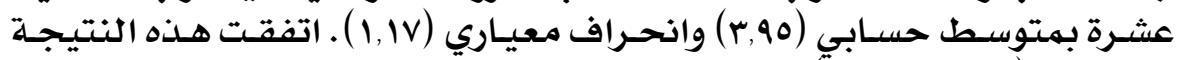

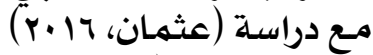

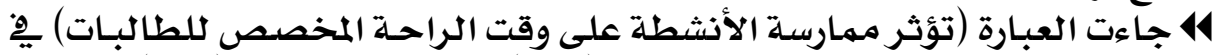

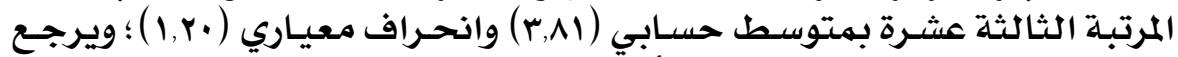

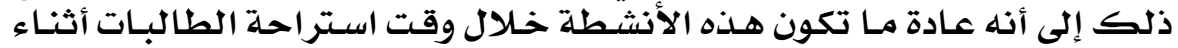

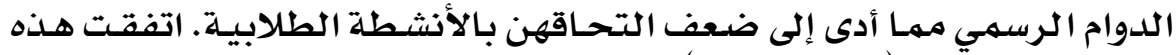

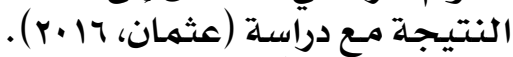

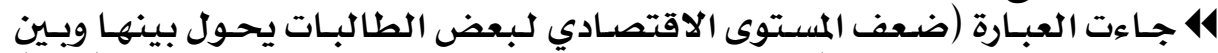

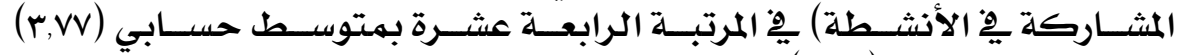

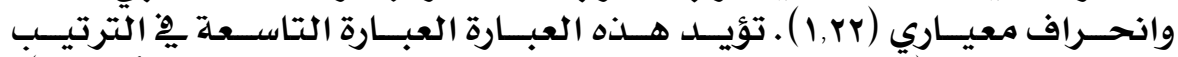

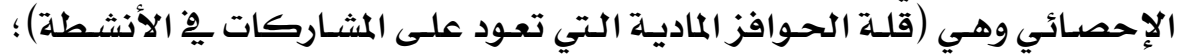

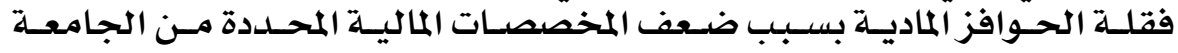

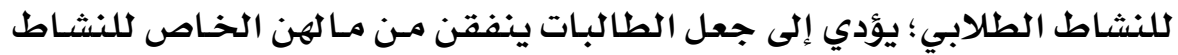

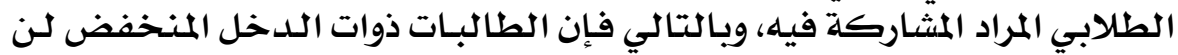

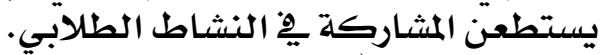

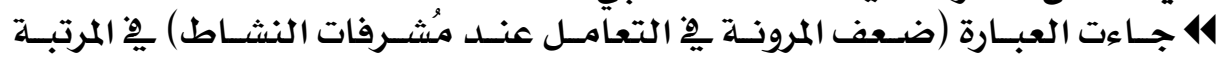

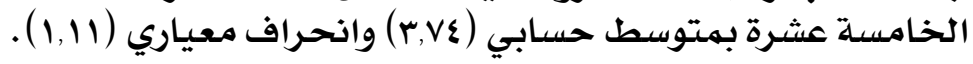

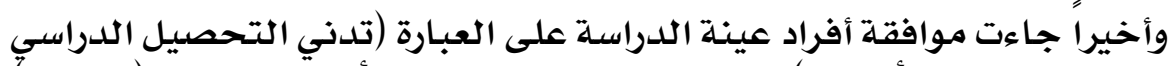

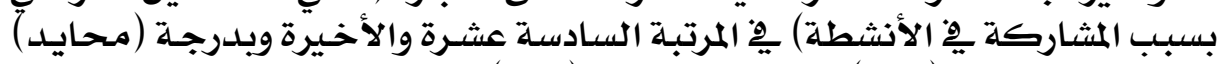

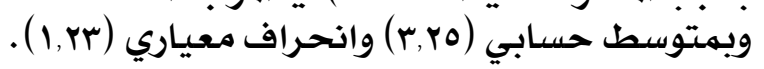

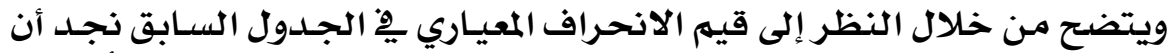

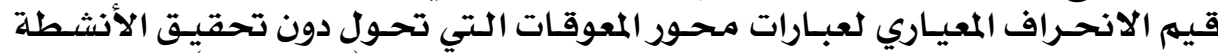

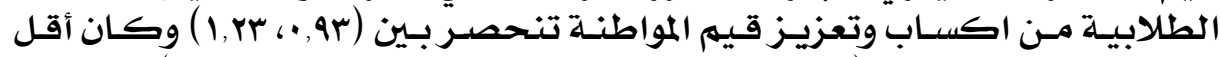

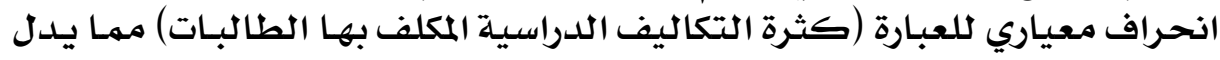

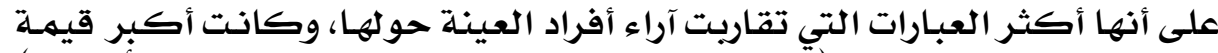

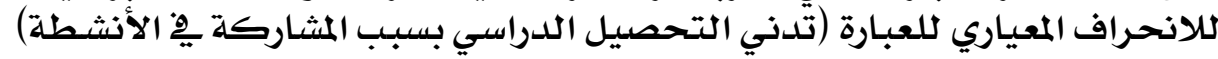

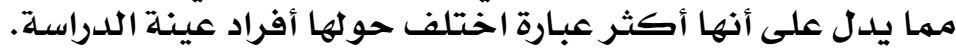

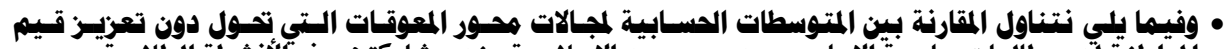

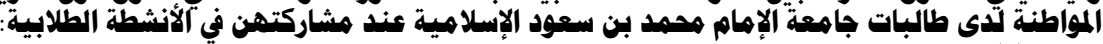

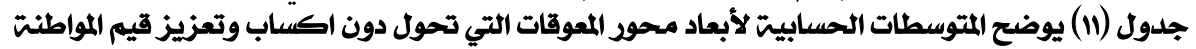

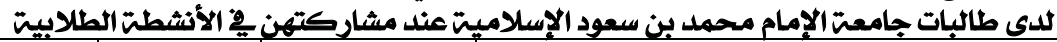

\begin{tabular}{|c|c|c|c|}
\hline الترتيب & درجت الموافقت & المتوسط الحسابي & المجالَ \\
\hline$\varepsilon$ & موافق - مافق & r,A9 & المجال الأول: المعوقات المرتبطت بالناحيت الماديت \\
\hline$r$ & 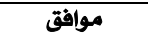 & $r, 91$ & المجال الثاني: المعوقات المرتبطت بالطالب \\
\hline$T$ & 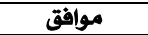 & $\varepsilon, 1 \pi$ & المجال الثالث: المعوقات المرتبطت بالمناهج الدراسيت \\
\hline$r$ & موافق & r,q६ & المجال الرابع: المعوقات المرتبطت بالإشراف \\
\hline \multicolumn{2}{|c|}{ موافق } & r,90 & 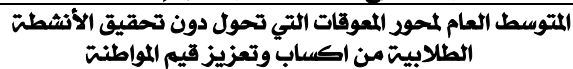 \\
\hline
\end{tabular}

\section{9}




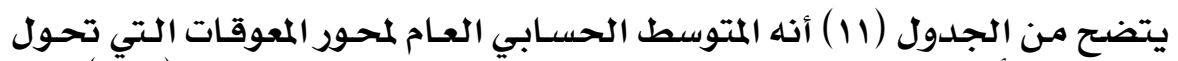

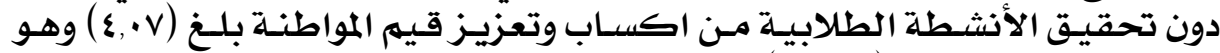

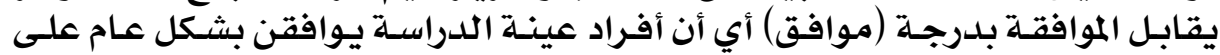

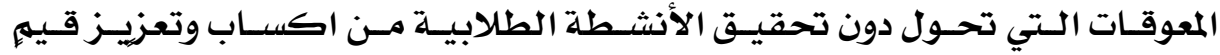

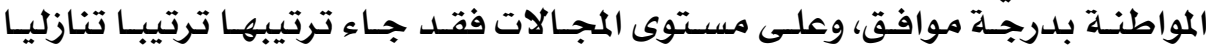

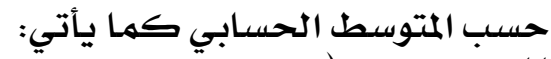

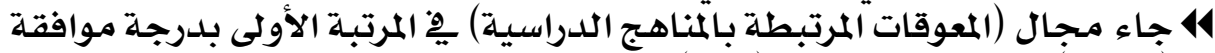

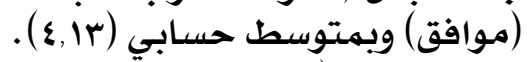

414

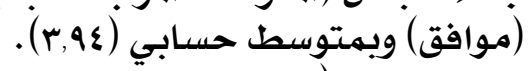

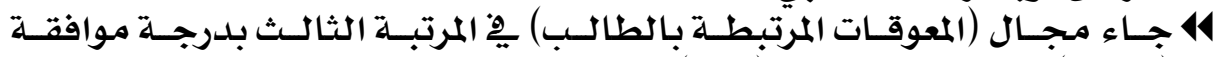

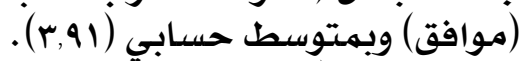

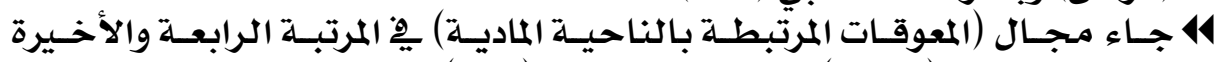

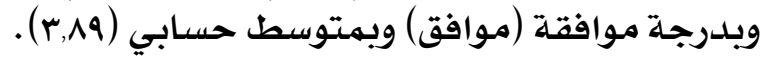

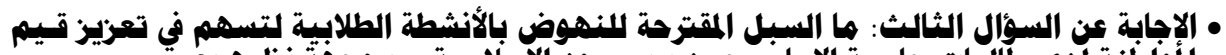

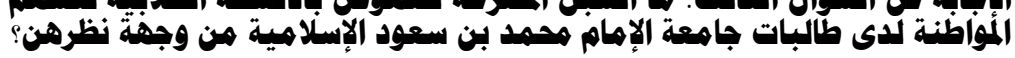

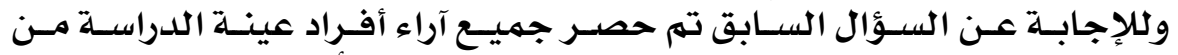

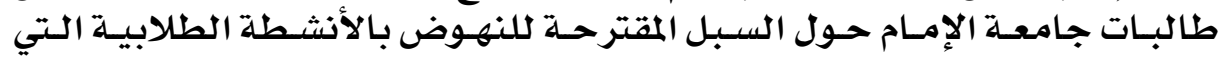

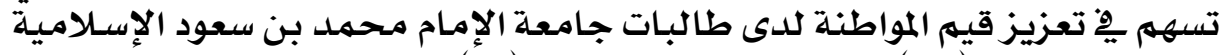

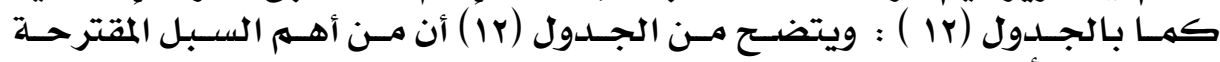

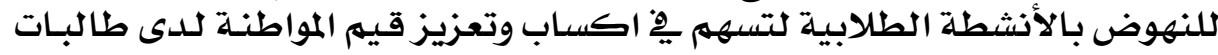

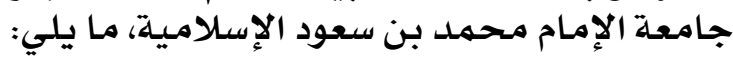

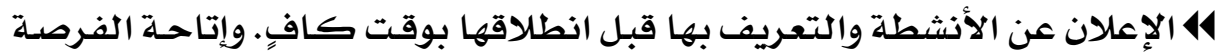

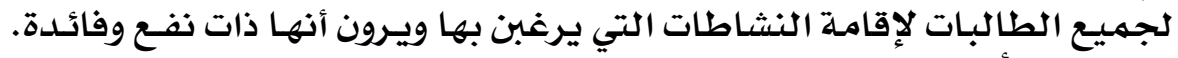

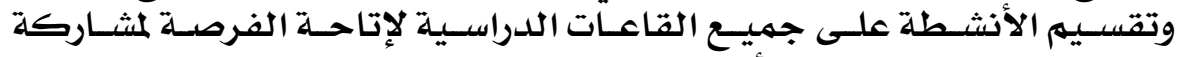

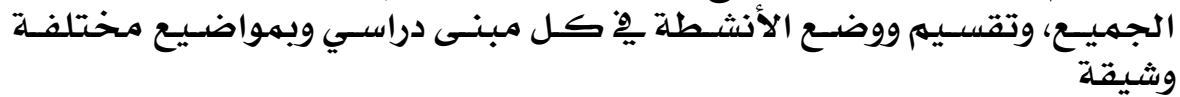

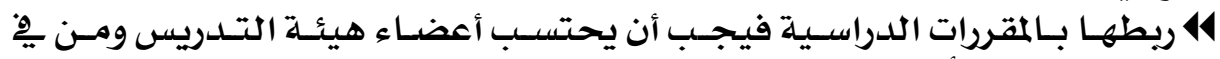

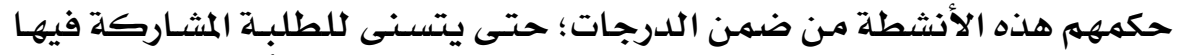

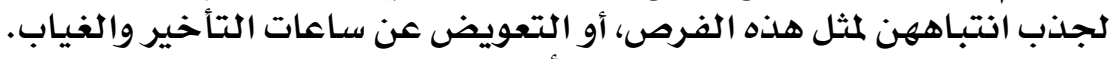

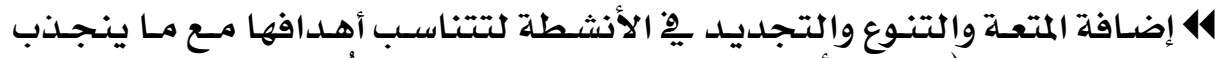

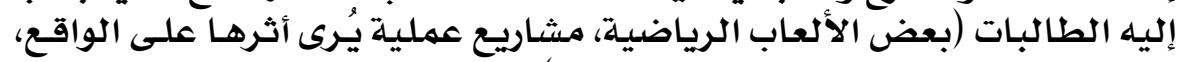

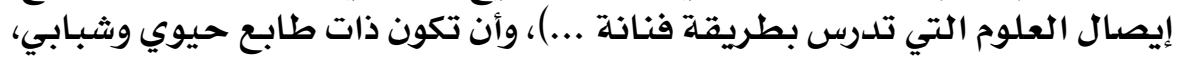

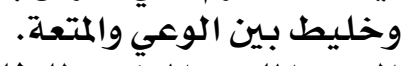

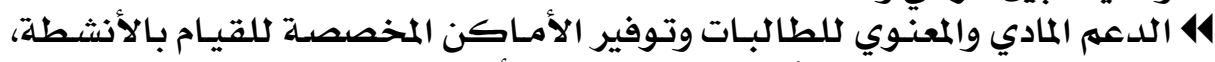

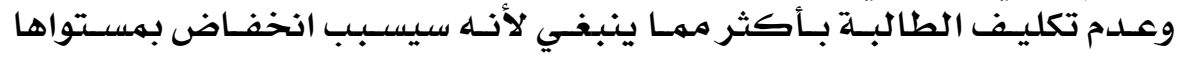
الدراسي. 


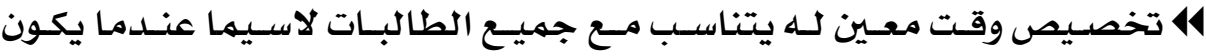

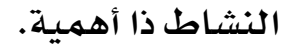

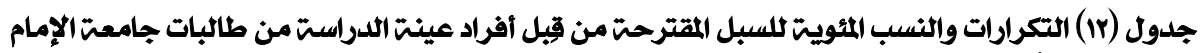

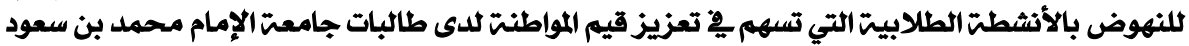
الإسلاميت

\begin{tabular}{|c|c|c|c|}
\hline النسبتة & التكرار & سبل اخرى يقترحها أفراد عينت الدراست من طالبات جامعتَّة الإمام محمد بن سعود الإسلاميتّ للنهوض & $p$ \\
\hline$\%$ & rr & 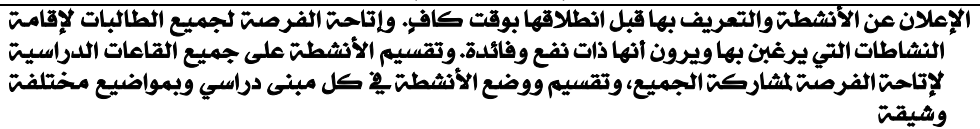 & 1 \\
\hline$\%$ & M & 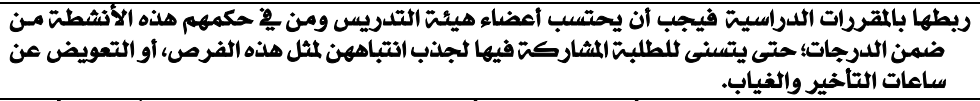 & $r$ \\
\hline$\%$ & 9 & 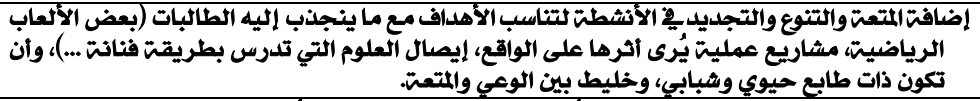 & $r$ \\
\hline$\%$ \%,rq & 0 & 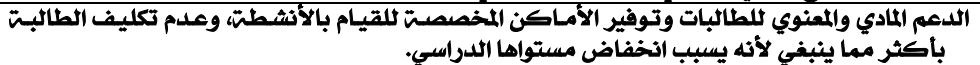 & $\varepsilon$ \\
\hline$\%$ \%,Yq & 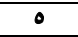 & تخصيص وقت معين للنشاط يتناسب مي جدول الطالبات ضمن اليوم الدراسي. & 0 \\
\hline$\%$ & $\varepsilon$ & تكثيف الأنشطت وأن تكون مخطط لها بشكل محكم وأن تكون متنوعت وفق احتياجات الطالبات. & 7 \\
\hline$\%$ & $\varepsilon$ & 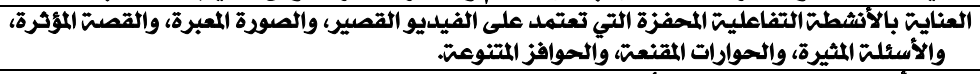 & $v$ \\
\hline 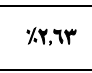 & $\varepsilon$ & 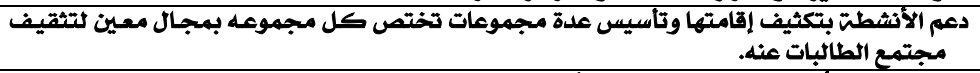 & $\wedge$ \\
\hline$\%$ \%,Tr & $\varepsilon$ & العنايت ببناء الأثطت الإبداعيت الملهمت بأفكار بناءة وجلديلة. & 9 \\
\hline$\%, 9 \vee$ & $r$ & عدم تكرار المواضيع، فالتنويع مهم فيجب الا تصب ِ2ْ مجال وتجحف باقي المجالات. & 1. \\
\hline$\%, 9 \vee$ & $r$ & الوعي الفكري للطالبات وتشجعيهن لعمل نشاطات أكثر فعاليت والمثاركت فيها. & 11 \\
\hline$\%, 9 \vee$ & $r$ & إتاحت أماكن للطالبات لممارست النشاط والجمع بين النشاط والترويح عن النفس. & ir \\
\hline$\%, 9 \vee$ & $r$ & 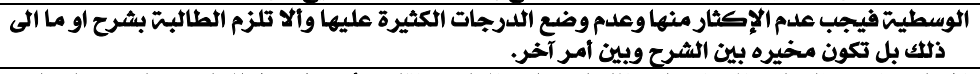 & Ir \\
\hline$\%, r Y$ & r & 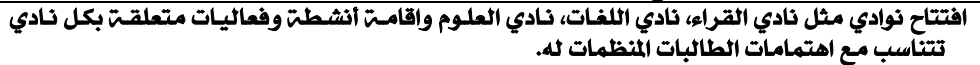 & $1 \varepsilon$ \\
\hline$\%, r Y$ & $r$ & تشر استبيان يحصي احتياج الطالبات من الأتشطت حتى يكون موافق لرغباتهم. & 10 \\
\hline$\%, r Y$ & r & 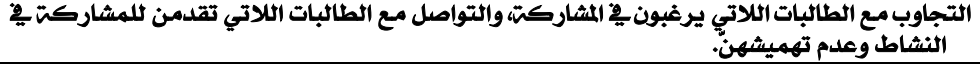 & 17 \\
\hline$\%, r Y$ & $r$ & انتقاء الطالبات المتميزات وعقد جلسات تخطيط ودراست جلدوى ونحو ذلك؛ لتطوير النشاط & IV \\
\hline$\%, r Y$ & r & 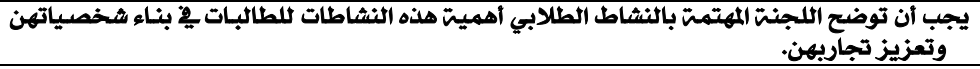 & $M$ \\
\hline$\%, 74$ & 1 & التتبه إلى أي سوء تعامل من موظفات النشاط الطلابي. & 19 \\
\hline$\%, \pi$ & 1 & منح ثهادات حضور لمثل هذه الأثشطت. & $\gamma+$ \\
\hline
\end{tabular}

• الحهور الأول: هدي تأثير المشاركة في الأنشطة الطلابية في اكساب وتعزيز قيم المواطنة لدى طالبسات

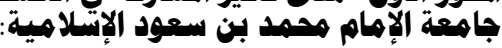

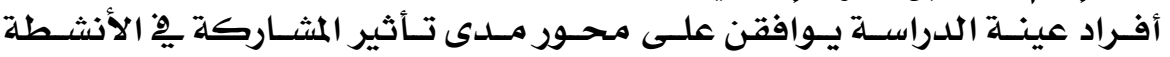

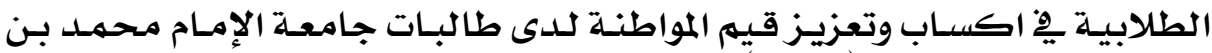

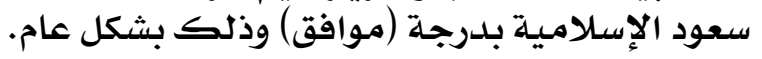

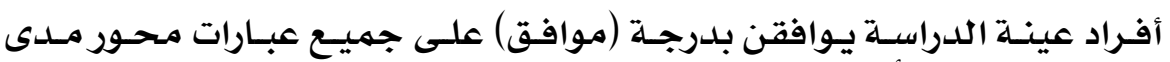

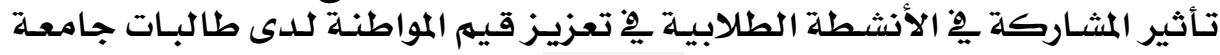




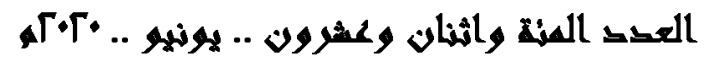

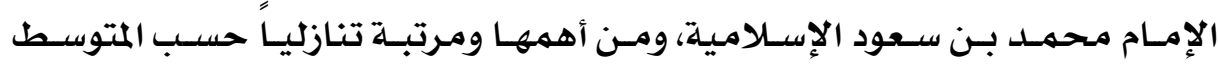

الحسابي ما يأتي:

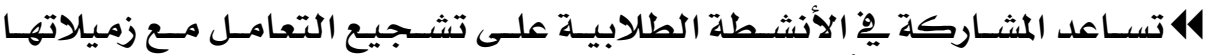

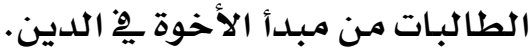

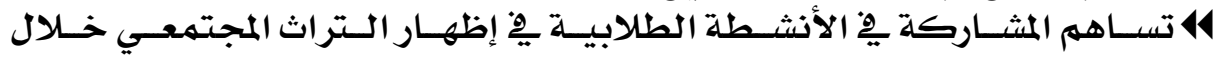
المناسبات المختلفة المثارة

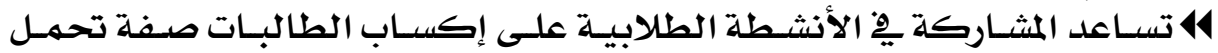

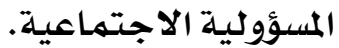

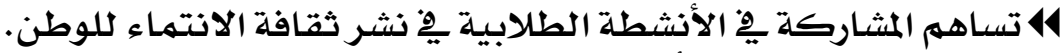

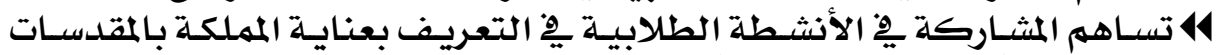

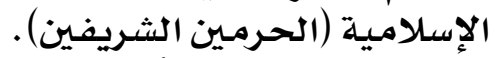

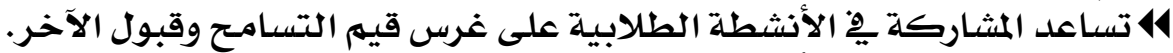

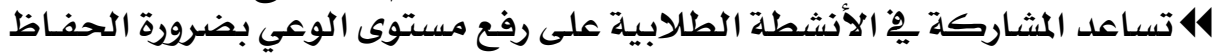

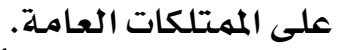

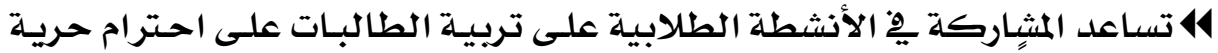

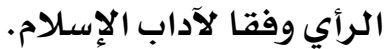

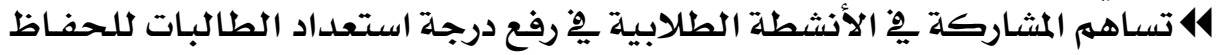

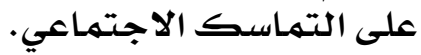

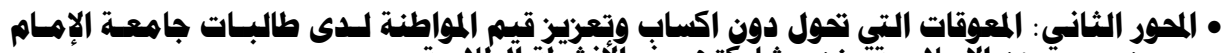

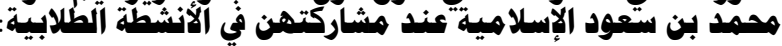

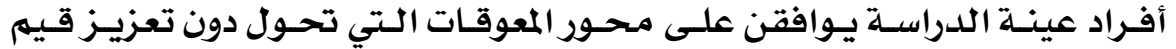

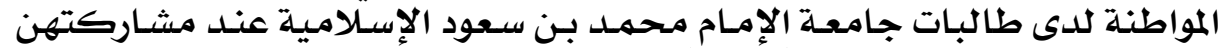

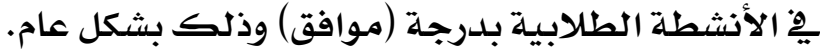

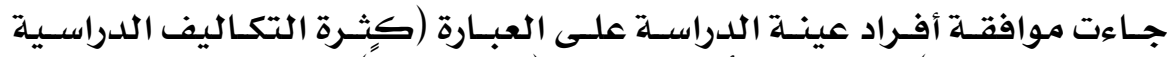

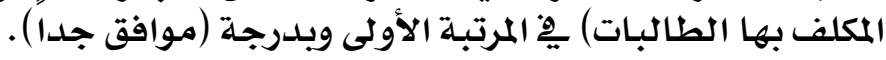

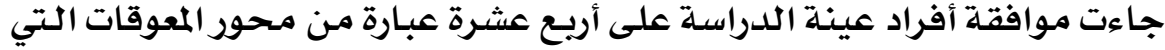

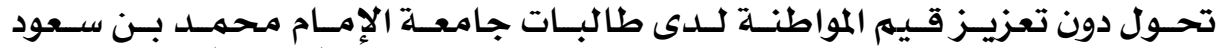

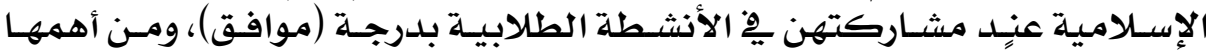

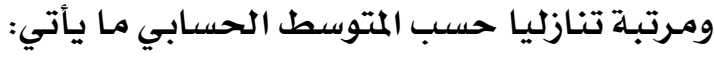

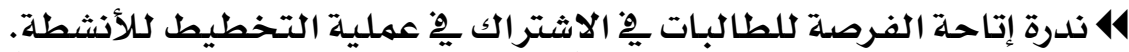

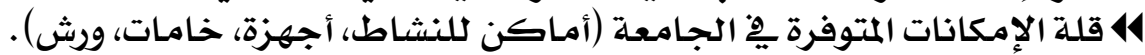

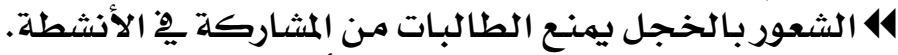

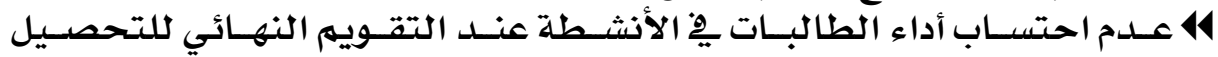
الدراسي.

41 قلة الحوافز المعنوية التي تعود على المثاركين يِّان الأنشطة.

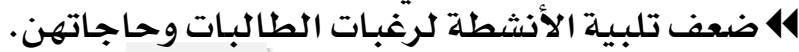

\section{Y}




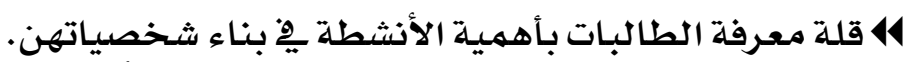

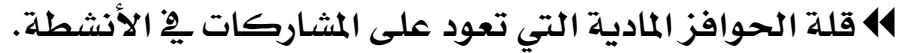

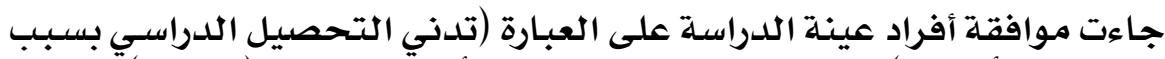

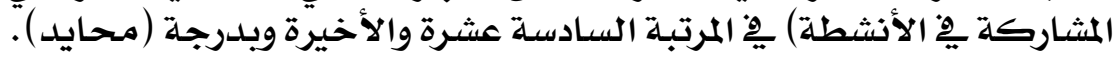

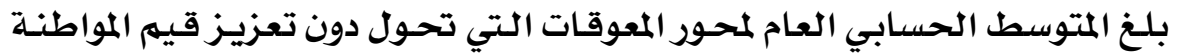

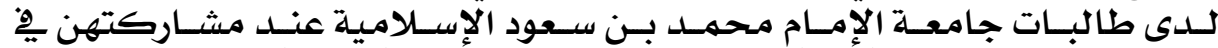

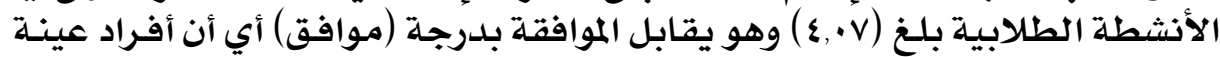

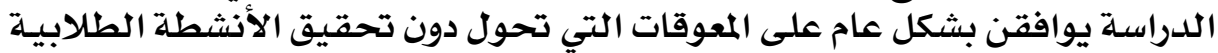

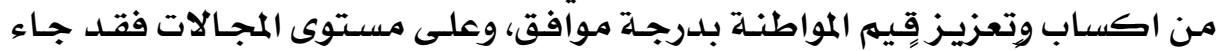

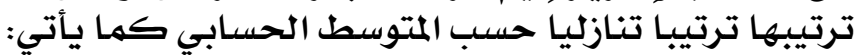

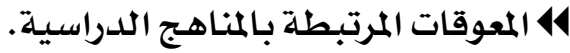

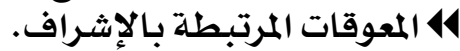

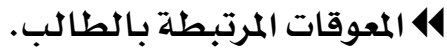

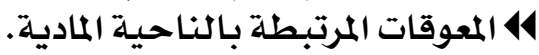

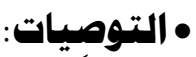

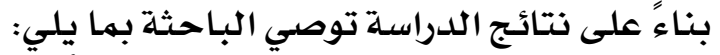

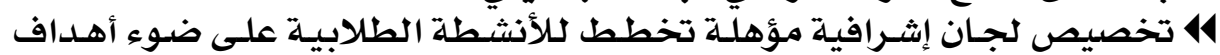

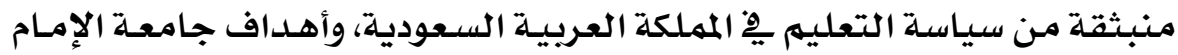

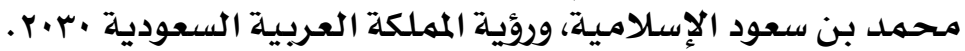

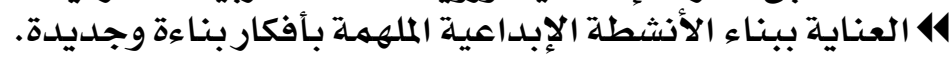

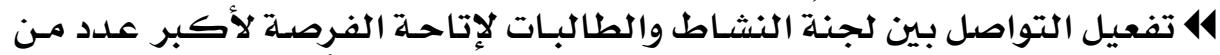

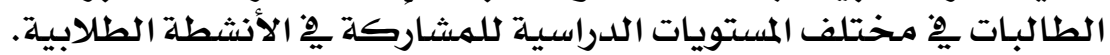

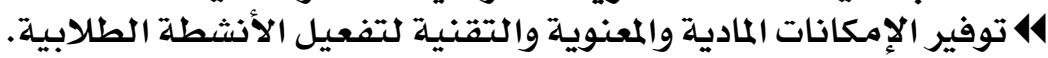

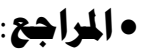

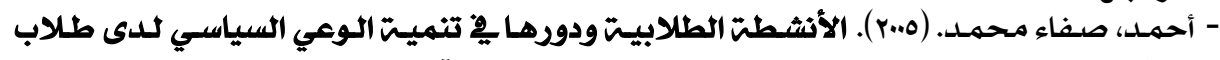

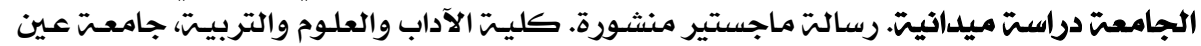

شمس، سوريا.

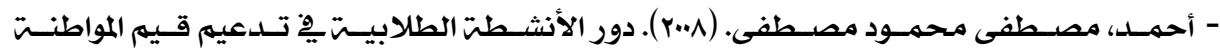

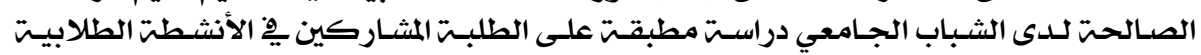

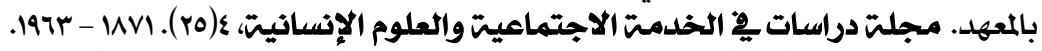

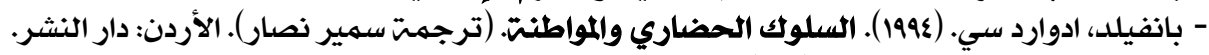

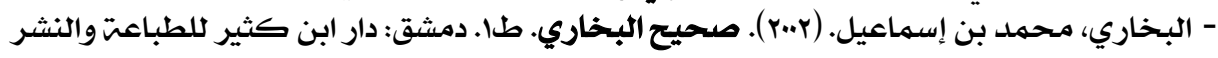

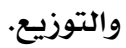

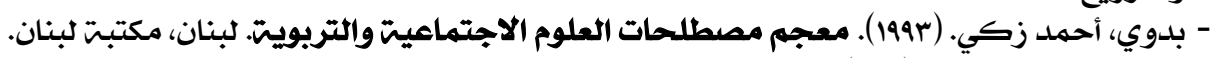

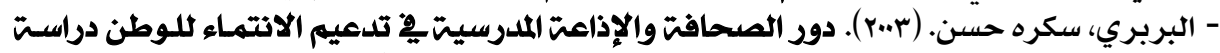

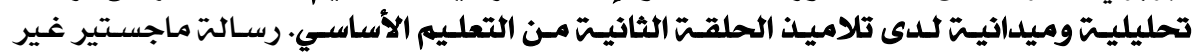

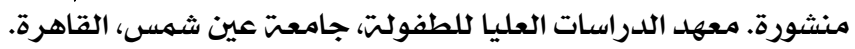

\section{$1 \cdot r$}




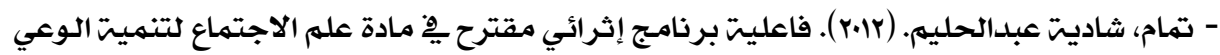

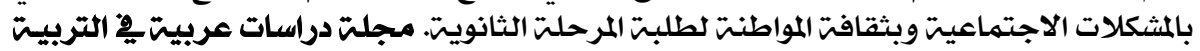

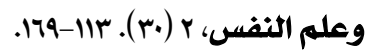

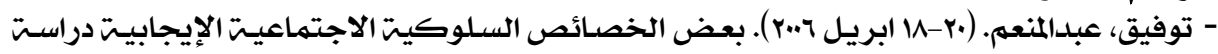

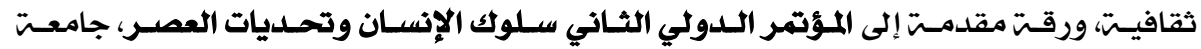

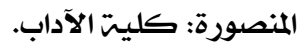

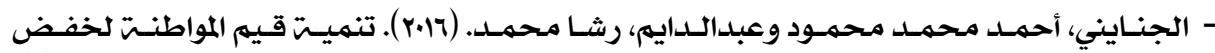

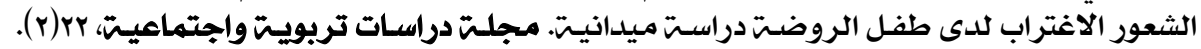
. r.Y-rrV

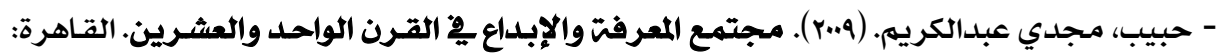
دار الفكر العربي.

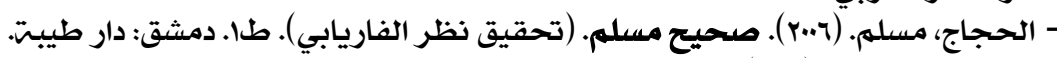

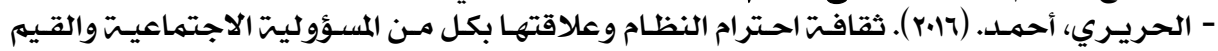

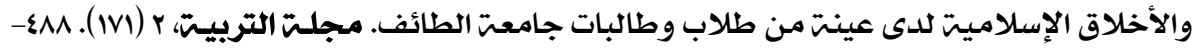
.07.

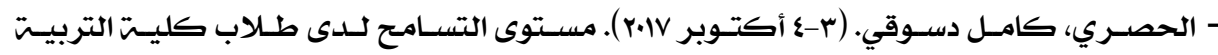

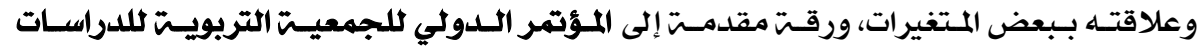

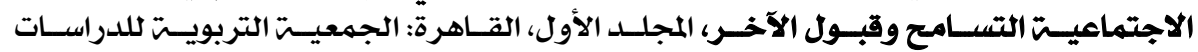
الاجتماعيت.

- الحقيل، سليمان بن عبدالرحمن. (11.r). نظام وسياست التعليم بِ المملكت العربيت السعوديت. طها.

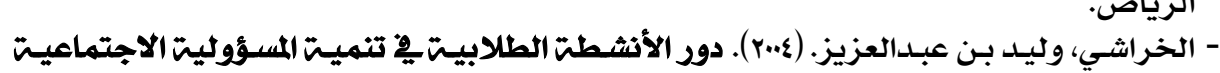

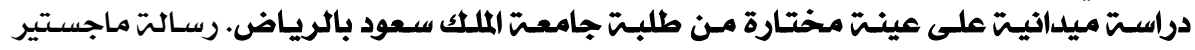

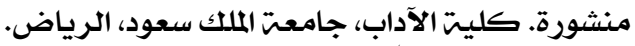

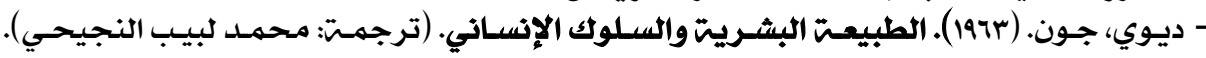

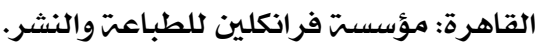

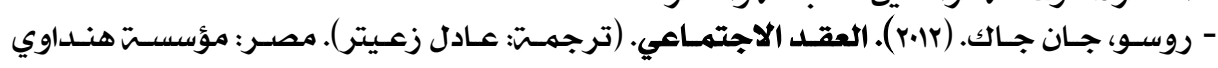
للتعليه والثقافتة.

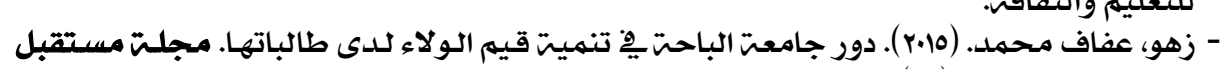

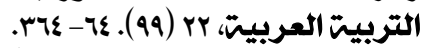

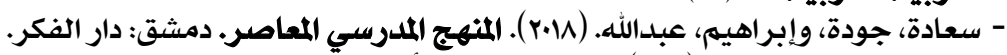

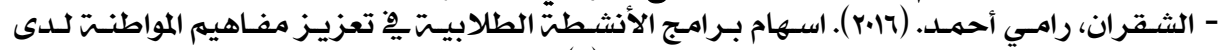

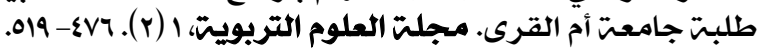

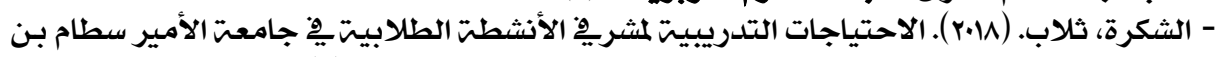

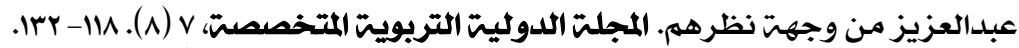

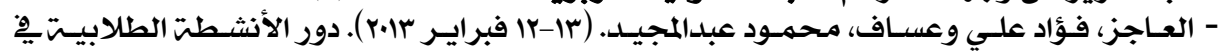

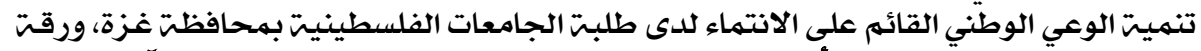

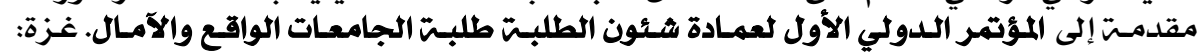
الجامعت الإسلاميتة.

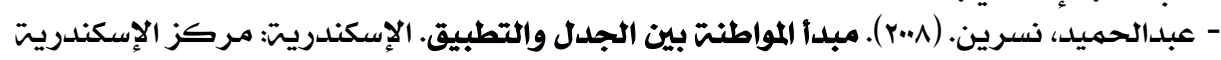
للكتاب. 


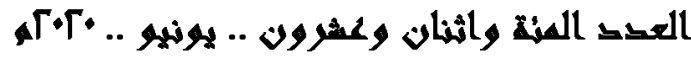

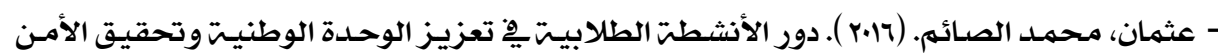

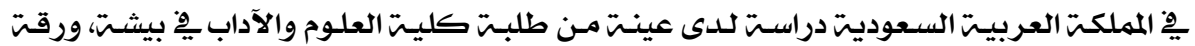

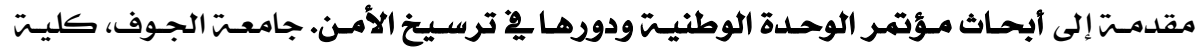
الشريعت والقانون.

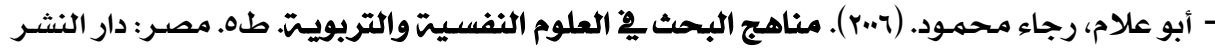

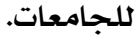

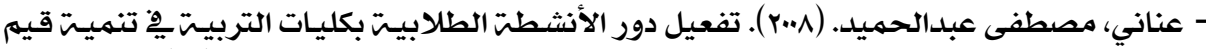

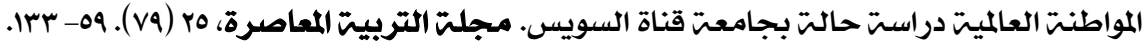

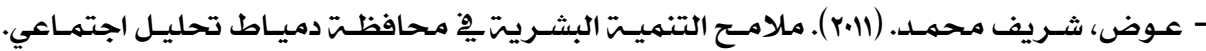

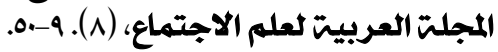

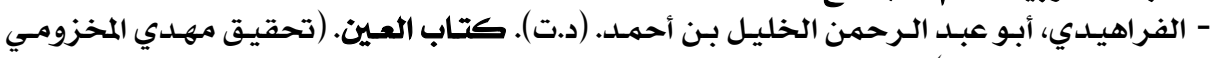

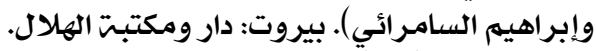

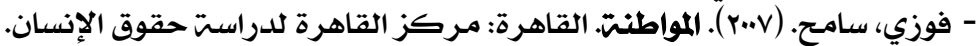

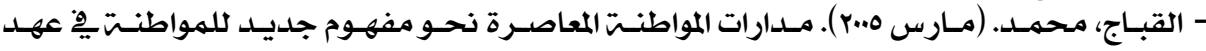

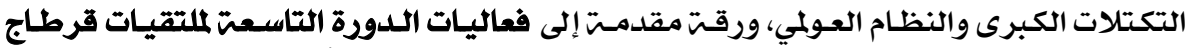

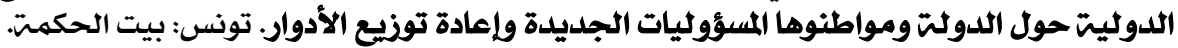

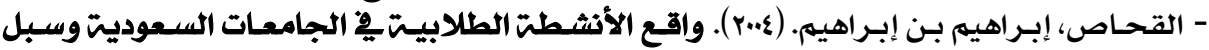

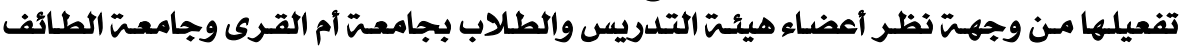

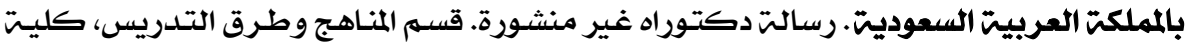

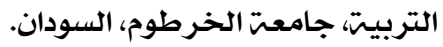

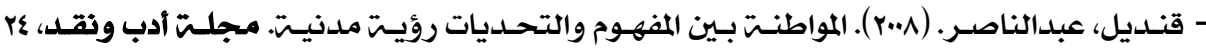
.

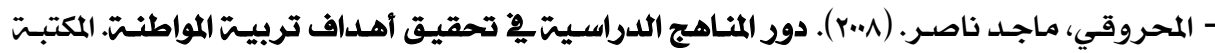

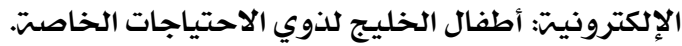

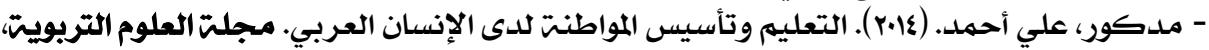
. $27-1 .(1) 1$

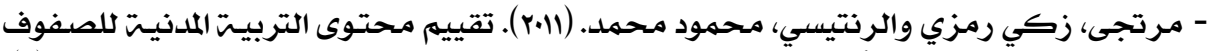

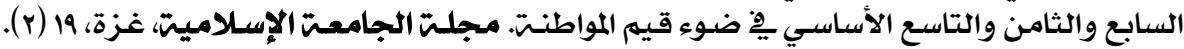
. 190-171

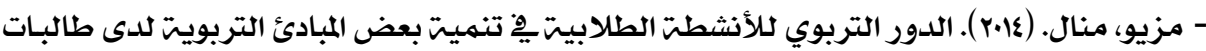

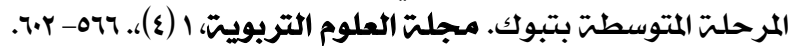

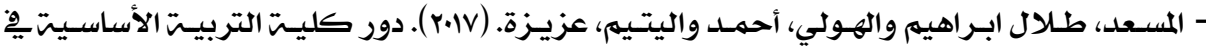

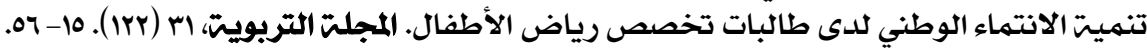

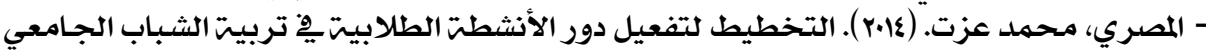

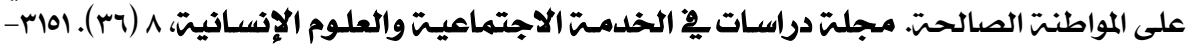

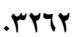

- مكروم، عبدالودود. (ع..r). القيه ومسؤوليات المواطنت رؤيتّ تربويت. القاهرة: دار الفكر العربي.

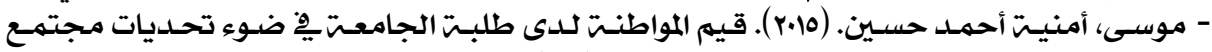

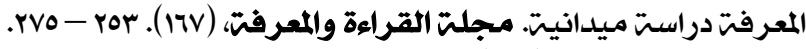

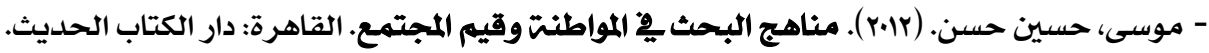

\section{$1 \cdot 0$}




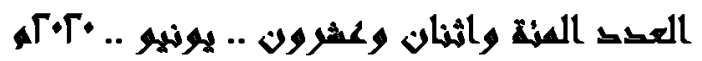

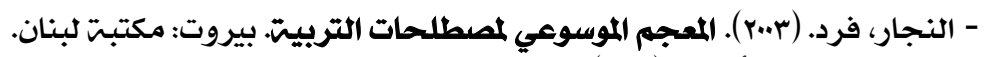

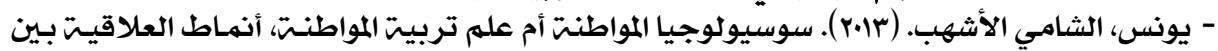

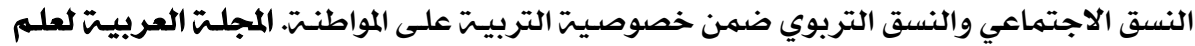

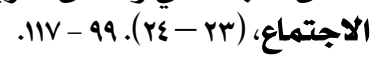

- Chanzanagh, H. and others (2011). Citizenship Values in school subjects A case - study on Iran's elementary and secondary education school subjects. procedia social and behavioral sciences. (15). PP 3018- 3023

- Joslin, B. and others (2007). Post-16 Citizenship in Work-based Learning: An Introduction to Effective Practice. The Learning and Skills Network. PP1-20. available at www.LSNeducation.org.uk

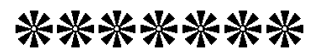

